Archives

Du cahier de la coutume ... au livre // Études urbaines

\title{
Les assemblées d'états et la mise en forme du droit
} Comparaisons et analyses formelles des coutumes rédigées et réformées d'Auxerre, de Sens et de Touraine

\section{Anette Smedley-Weill et Simone Geoffroy-Poisson}

\section{(2) OpenEdition}

\section{Journals}

Édition électronique

URL : http://journals.openedition.org/ccrh/1592

DOI : $10.4000 /$ ccrh. 1592

ISSN : $1760-7906$

Éditeur

Centre de recherches historiques - EHESS

Édition imprimée

Date de publication : 20 avril 2001

ISSN : 0990-9141

Référence électronique

Anette Smedley-Weill et Simone Geoffroy-Poisson, «Les assemblées d'états et la mise en forme du droit », Les Cahiers du Centre de Recherches Historiques [En ligne], 26 | 2001, mis en ligne le 16 janvier 2009, consulté le 01 mai 2019. URL : http://journals.openedition.org/ccrh/1592 ; DOI : 10.4000/ ccrh. 1592

Ce document a été généré automatiquement le 1 mai 2019.

Article L.111-1 du Code de la propriété intellectuelle. 


\section{Les assemblées d'états et la mise en forme du droit}

Comparaisons et analyses formelles des coutumes rédigées et réformées d'Auxerre, de Sens et de Touraine

Anette Smedley-Weill et Simone Geoffroy-Poisson

\section{Introduction}

1 Les coutumes officiellement rédigées ont, pour la plupart, été publiées à l'époque de leur rédaction et suivies de plusieurs éditions. Nous avons pris pour référence le Nouveau Coutumier Général ou Corps des Coutumes générales et particulières de France et des provinces connues sous le nom des Gaulles de Charles Bourdot de Richebourg, paru en 1724. L'auteur signale dans son avis au lecteur :

[...] s'être servi pour y parvenir des originaux déposés aux Greffes, soit du Parlement de Paris, soit des autres Cours et Juridictions du Royaume, et même de ceux qui sont conservés dans les Bibliothèques et Cabinets particuliers ${ }^{1}$.

2 La coutume est jusqu'au $\mathrm{XV}^{\mathrm{e}}$ siècle la source presque exclusive du droit privé. Elle joue un rôle essentiel dans les rapports juridiques, économiques, familiaux et sociaux et dans l'histoire des institutions de cette période.

3 L'ordre de rédiger les coutumes est donné par le roi Charles VII (1422-1461), en avril 1453 avant Pâques (1454), par l'ordonnance de Montils-lès-Tours; le roi reprend possession de son royaume après la fin de la guerre de Cent ans, et le premier de ses devoirs envers ses peuples étant de rendre la justice, il veut que désormais ses sujets soient jugés rapidement, avec des références en droit claires et précises.

4 Les coutumes sont, soient générales et concernent un bailliage, une sénéchaussée, un pays, soit locales ou particulières et régissent un territoire plus restreint, tel que seigneurie, prévôté ou communauté d'habitants. 


\section{Procédure de rédaction}

5 Dans le royaume de France, quand il s'agit de vérifier des articles de coutumes, bien souvent, des personnes dignes de foi et reconnues pour leur compétence sont convoquées au tribunal pour témoigner si tel point relève ou non de la coutume : ce sont les enquêtes par turbe.

En 1454, à Montils-lès-Tours, Charles VII promulgue une ordonnance sur la réformation de la justice. Le roi, à l'article 125,

[...] voulans abréger les procez et litiges d'entre nos subjects et les relever de mises

et despens et oster toutes matières de variations et contrariétez ${ }^{2}$,

ordonne que les coutumes, usages et styles de tous les pays du royaume soient mis par écrit. La procédure, déterminée par le roi, prévoit que les coutumes seront accordées par les praticiens et les gens de chaque ordre des différents pays du royaume, mises en livres pour les faire voir et visiter par les gens de son conseil ou de son parlement, pour les décréter et confermer de son autorité royale et pour que les juges s'y soumettent.

7 Les retards inhérents à l'engagement de ce genre de procédure et de son déroulement empêchent Charles VII de conduire à terme ce projet ambitieux. Mais ce roi fait école dans le Cercle de Bourgogne : le duc Philippe III le Bon promulgue à son tour des lettres patentes le 11 mars 1457 à Bruges et deux coutumes, dont il a ordonné la rédaction, sont publiées en $1459^{3}$.

8 Charles VIII (1483-1498) par lettres patentes données à Lyon le 19 janvier 1495, énonce à nouveau les raisons de la rédaction et fixe une nouvelle procédure. Il constate les fautes et les abus, qui ont été faits dans le passé. En conséquence, il ordonne aux baillis, sénéchaux et autres juges du royaume d'appeler les officiers, les gens d'Église, les nobles, les praticiens et autres gens, de faire rédiger et mettre par écrit les coutumes, avec des avis de ce qui doit être corrigé, ajouté, diminué, interprété. Le roi fixe le rôle des commissaires et les nomme.

9 Ces personnages examinent les coutumes et donnent leur avis par écrit sur les difficultés constatées. Les trois états sont convoqués, les coutumes sont lues et les difficultés ouvertes par les mêmes commissaires, qui ont la charge de la publication, afin que tous les articles soient accordés par les états. Les difficultés et discords sont inscrits au procès-verbal, élément constitutif de la coutume, avec les différends survenus, pour que le roi y mette ordre et fin. La coutume est ainsi clere et evidente preuve.

Des lors pour maintenant les coutumes contenues dans les articles accordés de notre certaine science et propre mouvement, pleine puissante autorité royale seront gardées inviolablement et observées comme loy perpetuelle.

Le dispositif est simplifié par de nouvelles lettres patentes de Charles VIII données à Amboise le 15 mars 1497. Les commissaires se rendent dans les bailliages et publient les articles qui sont accordés comme coutumes et les différends inscrits dans la coutume sont renvoyés au parlement pour y être à faire par raison ${ }^{4}$. À l'instar de Charles VIII, Louis XII (1498-1515), par lettres patentes données à Blois le 4 mars 1505, se référant à celles de ses prédécesseurs, améliore la procédure en réduisant le délai de rédaction à deux mois, après réception des lettres de commission, et en donnant un cadre formel à la publication et à l'enregistrement des coutumes ${ }^{5}$. La rédaction de celles-ci connaît un rythme croissant au cours du XVI $I^{e}$ siècle, avec l'abandon progressif des styles de procédure insérés en fin de coutumes, considérés comme relevant de l'autorité du roi. La participation constructive 
de Thibault Baillet, président au parlement de Paris, dans une quinzaine de coutumes a été remarquable ${ }^{6}$. À partir de 1555, l'évolution jurisprudentielle, liée à des dispositions coutumières abusives ou tombées en désuétude, entraîne une nouvelle rédaction ou réformation de plusieurs coutumes du royaume, et le nom du premier président Christofle de Thou en est indissociable ${ }^{7}$.

Les lettres patentes données par Louis XII à Paris, le 21 janvier 1510, ordonnant la révision et l'approbation des coutumes du royaume, prévoient que les articles seront discutés contradictoirement. Les cahiers déjà préparés sont alors soumis à l'examen des commissaires en assemblée pour qu'ils entendent les objections présentées très librement. Les articles accordés par l'ensemble de l'assemblée ou par la plus grande et saine partie de celle-ci $i^{8}$, sont publiés pour coutumes et les articles discordés renvoyés devant la cour de justice pour être ordonnés comme de raison. En fait entre la rédaction et la réformation, les articles ne sont pas toujours examinés, plusieurs d'entre eux se retrouvent dans la coutume, ce qui justifie amplement la nouvelle rédaction. Un exemplaire du cahier est déposé par les commissaires au greffe du parlement pour enregistrement et ainsi donner force de loi au texte rédigé. Le délai peut aller jusqu'à un an. Un autre exemplaire portant leur signature, celle du lieutenant général ou du lieutenant particulier et celle du greffier du bailliage concerné, est conservé au greffe de ce siège.

\section{Les participants à la rédaction des coutumes}

11 Les demandes de rédaction sont prises à l'initiative du Roi, mais parfois elles émanent de gens du bailliage concerné. Ainsi, la demande réitérée de la duchesse de Berry, jusqu'à l'aboutissement de la rédaction de cette coutume de Berry de 1539. Le roi y répond en délivrant des lettres de commission.

\section{L'assemblée des trois états}

Dans chaque bailliage ou sénéchaussée, le bailli convoque une assemblée composée de gens du clergé, de la noblesse et du tiers état ; les officiers royaux et gens de justice, bien que faisant partie du tiers état, sont souvent mentionnés en groupe distinct, constituant une sorte de "quatrième état ». Les habitants du bailliage comparaissent en personne, mais le plus souvent représentés par un mandataire, praticien du droit, désigné sous le terme de procureur.

13 Les officiers du roi (bailli, lieutenant général ou lieutenant particulier du bailli, procureurs du roi et avocats du roi aux sièges royaux) interviennent fréquemment, soit pour s'opposer aux prétentions de certains comparants, soit pour apporter une interprétation d'un article donné, soit pour proposer une nouvelle rédaction pouvant entraîner l'accord des trois états. Le procureur du roi du bailliage est aussi chargé de défendre les droits du roi face aux prétentions des gens d'Église ou des nobles. Lorsque des articles de coutumes ne remportent pas l'adhésion de la totalité de l'assemblée, que l'opposition est fondée ou qu'aucune nouvelle rédaction ne rencontre l'approbation de tous, ces articles sont renvoyés à la cour du parlement. Tous les comparants sont cités par leur nom et titre ou fonction dans le procès-verbal ainsi que leurs représentants. Ils doivent faire serment de bien et royaument conseiller et dire vérité sur le fait des coutumes dudit bailliage?.

Les commissaires nommés pour les rédactions sont soit des parlementaires, soit des officiers locaux du bailli, qui connaissent donc très bien leurs coutumes et sont les plus 
aptes à les faire rédiger. Lors de la réformation, tous les commissaires sont issus du parlement de Paris, ce qui ne signifie pas qu'ils sont parisiens ${ }^{10}$. Ils sont désignés par lettres de commission royale. Ils président l'assemblée et s'assurent de la bonne régularité de la procédure suivie. Leur mission ne dure que quelques jours (cinq jours pour la coutume de Touraine de 1507, de même que pour la coutume réformée de 1559). Ils sont pris en charge pour leur logement et leur couvert par le bailliage et leur frais de mission sont taxés. Selon les procès-verbaux, ils prennent les décisions de renvoi.

La volonté de l'initiateur des rédactions, Charles VII, est ainsi reprise et précisée au niveau de la procédure par Charles VIII et Louis XII, avec les mêmes arguments, la fin des abus et le souci de bonne justice. Les juges doivent appeler les trois états, les coutumes doivent être rédigées en leur assemblée, les désaccords doivent être signalés et résolus, sinon renvoyés au roi et à sa cour de parlement. La coutume est officialisée au bailliage par l'accord de tous les membres des trois ordres. Lors des réformations, les rois Valois, Henri II (1547-1559), François II (1559-1560), Charles IX (1560-1574) et Henri III (1574-1589) font appliquer la même procédure : l'assemblée des trois ordres représente le peuple du bailliage, qui souhaite se donner un "droit coutumier commun", selon l'expression de Charles Dumoulin. Elle participe avec les officiers royaux et les praticiens à la publication et à l'enregistrement de ce qui constituera la preuve de la coutume, puisqu'il n'y avait plus lieu de recourir à l'enquête par turbe,

[...] attendu aussi qu'il n'est plus clere et évidente preuve de coustume, que celle qui est faite par commun accord et consentement desdits Estats ${ }^{11}$. L'assemblée ainsi constituée produit un droit consensuel, puisque lesdites coustumes seront tant pour les deffaillans que comparans, entretenues, gardées et observées pour loy ${ }^{12}$.

Nous présentons ces analyses comparatives en deux parties, Les assemblées : la procédure suivie pour leur réunion et les contestations qui sont émises lors des rédactions d'une part, lors des réformations d'autre part, pour les trois coutumes d'Auxerre (1507 et 1561) de Sens (1507 et 1555) et de Touraine (1507 et 1559). En seconde partie «Mise par écrit-Mise en ordre »: nous exposons les transformations intervenues entre les rédactions et les réformations selon les demandes ou les refus des états des bailliages, faisant ressortir les changements de titres et leur reclassement, les nouvelles écritures d'articles, qui reflètent l'évolution du droit entre le début et le milieu du XVI ${ }^{\mathrm{e}}$ siècle. Nous vérifions également par ces analyses dans quelle mesure les assemblées d'états suivent les règles fixées par les ordonnances royales, sous la présidence et le contrôle des commissaires royaux.

\section{Les assemblées}

\section{Les rédactions}

\section{Les Coutumes d'Auxerre ${ }^{13}$.}

\section{La procédure}

17 Selon le procès-verbal de rédaction, daté du 8 septembre 1507, Blanchet Dany, licencié ès lois, lieutenant général du bailli d'Auxerre, a reçu les lettres patentes du roi Louis XII, datées du 2 avril 1506,

[...] afin qu'en ensuyvant la teneur d'icelles eussions à diligemment vacquer au fait des Coustumes du bailliage d'Auxerre et Coustumes locales et particulières des seigneuries et châtellenies du dit bailliage desquels la teneur s'ensuyt. 
Le bailli ou son lieutenant doit assembler le bailliage par contrainte, tous doivent être présents ou représentés ; les nobles même pairs ${ }^{14}$ de France voient leurs fiefs relevés de la coutume quoiqu'ils en disent. Le commissaire décerne à son tour commission pour convoquer les habitants du bailliage, officiers, clergé, nobles pour voir corriger, augmenter, interpréter, arrêter, faire écrire et signer les coutumes, ainsi qu'il est dit dans les ordonnances royales. Les sergents du bailliage publient les lettres patentes et assignent les habitants à se présenter, en personne ou par procureur, au jour dit. Les habitants du bailliage, qui ont répondu à la convocation-assignation du roi, sont nommés précisément, avec leur qualité, leur fonction, leurs possessions. Les deux premiers nommés sont les officiers royaux du bailliage, Jean Feroul, licencié ès lois, est avocat du roi et Pierre Gontier, licencié ès lois, est procureur du roi, ces deux personnages font valoir les droits du roi, auxquels nul ne peut porter préjudice.

Les membres du clergé sont ensuite mentionnés, Jean Baillet, évêque d'Auxerre, est notamment seigneur châtelain de la ville de Varzy, dont les articles de coutumes sont repris dans le texte de celles d'Auxerre, sous les chapitres correspondant, et non à la fin avec les autres usages locaux, bien que les discussions sur les articles soient notées à la fin du procès-verbal; l'évêque est représenté par son official Crespin Prévost. Les autres membres de l'Église sont représentés par des procureurs, ainsi que les habitants des lieux concernés par ces détenteurs de terres du clergé. Certains sont dits défaillants. Sont ensuite indiqués les religieux, les religieuses et leurs représentants. Suivent les manants et leurs procureurs de la ville d'Auxerre; neuf avocats, onze procureurs et les praticiens du bailliage. Enfin les seigneurs, avec indications des noms et qualités, et les habitants des seigneuries citées avec leurs représentants.

Donc, l'ordre de comparution ne suit pas la hiérarchie des ordres, clergé, noblesse, tiers état; en premier sont cités les deux officiers royaux, puis le clergé, les habitants d'Auxerre, enfin la noblesse avec les roturiers en un seul ensemble. Les seigneurs, châtelains, barons, hauts-justiciers sont assignés pour apporter leurs coutumes locales et particulières. Ils doivent comparaitre le 14 octobre avec intimation (donc cinq semaines plus tard) sinon ils ressortiront de la coutume générale; le commissaire décerne commission

[...] pour mettre en la main du roi les seigneuries des défaillants jusqu'à ce qu'ils accordent les coutumes.

Les habitants d'Auxerre revendiquent des privilèges, et les coutumes locales ne peuvent $\mathrm{y}$ porter préjudice. Les gens d'Église et les nobles protestent également que les coutumes locales ne peuvent leur préjudicier. Toutes ces remontrances sont consignées au procèsverbal. Après la comparution de tous et la lecture des lettres patentes, le commissaire Dany prend le volume et le cahier des dites coutumes, qui avaient déjà été en partie accordées. La réunion de l'assemblée des trois ordres du bailliage est ainsi faite conformément aux procédures fixées par les rois dans leurs ordonnances de janvier 1495 et de mai 1506.

En 1507, les coutumes rédigées d'Auxerre comprennent 24 chapitres et 271 articles numérotés en continu.

Chapitre premier: de haute justice, moyenne et basse et des exploits d'icelles, articles 1 à 14 (14 articles)

II de moyenne justice et des exploits d'icelle, 15 à 16 (2)

III de basse justice et des exploits d'icelle, 17 à 18 (2)

IV de justice censière et des exploits d'icelle, 19 à 27 (9) 
$V$ de forfaiture et confiscation, 28 à 31 (4)

s'ensuit la coutume locale de Varzy 32 à 33 (2)

VI des bâtards, 34 à 38 (5)

VII de retrait, ${ }^{*} 39$ à 61 (23)

VIII des successions, partages et divisions, 62 à 79 (18)

s'ensuit la coutume de la châtellenie de Varzy, 80 à 83 (4)

IX de servitudes, 84 à 89 ( 7 dont 2 portent le numéro 85$)$

s'ensuit la coutume de la châtellenie de Varzy, 90 (1)

$X$ de testaments, institution d'héritiers, legs et donations faites par iceux, et des exécuteurs de testaments, 91 à 107 (17)

XI de donation entre-vifs et mutuelle, 108 à 115 (8)

XII d'acquérir, garder et retenir possession d'héritage et des causes propriétaires et possessoires, 116 à 119 (4)

XIII des censives et droits seigneuriaux, 120 à 147 (28)

s'ensuivent les coutumes locales de Varzy, 148 à 154 (7)

XIV de compagnie et communauté de biens entre homme et femme mariés et de toutes autres personnes, 155 à 168 (14)

s'ensuit la coutume de Varzy, 169 à 170 (2)

$\mathrm{XV}$ de convenances, marchés, ventes, achats, louages, prêts et autres deniers contrats, 171 à 180 (10)

XVI de prescription et laps de temps, 181 à 182 (2)

XVII de rentes foncières, volages et hypothèques, 183 à 195 (13)

XVIII des bourgeoisies et des aveux, 196 à 202 (7)

XIX des eaux, bois et forêts, usages et pâtures, 203 à 214 (12)

XX de tutelle et curatelle d'enfants mineurs nobles et non nobles, 215 à 219 (5)

XXI de douaire préfix ou coutumier, 220 à 222 (3)

XXII d'assurements et sauvegardes, 223 à 231 (9)

XXIII des fiefs, droits et profits féodaux, 232 à 264 (33)

s'ensuit la coutume de Varzy, 265 (1)

Les coutumes, tant générales que locales, sont accordées sur avis des procureurs et avocats, donc des spécialistes en droit, et des autres présents des trois états, les articles non accordés sont renvoyés devant la cour $\mathrm{du}$

[...] parlement et autres ayant puissance d'icelles coutumes accorder, arrêter et déterminer.

\section{Les contestations}

Les premières contestations présentées concernent le ressort. Dans sa lettre de commission, le roi est ferme sur ce sujet, nul ne peut faire valoir des privilèges, même les pairs de France, qui exempteraient de présence à l'assemblée. Le commissaire doit les contraindre tous. Les terres des seigneurs situées dans ce territoire dépendent des coutumes du bailliage. C'est ce territoire qui est pris en compte et non la personne, le bailliage est donc l'espace juridique imposé à tous les habitants. Lorsque les seigneurs veulent faire valoir d'autres privilèges, le commissaire rappelle la volonté du roi ${ }^{15}$.

Dès avant l'assemblée, une partie des chapitres et articles ont été déjà accordés, selon les termes du procès-verbal. Ensuite sont mentionnés les articles, qui prêtent à controverses et, particularité auxerroise, les motifs de renvois sont insérés dans le texte de la coutume et numérotés comme articles, ce qui entraîne un accroissement du nombre de ceux-ci, 
sans pour autant augmenter le nombre d'articles de la coutume elle-même. De plus, les articles de renvois ne sont pas repris in extenso dans le procès-verbal, qui mentionne les difficultés sans spécifier le numéro de l'article. Le compte-rendu, qui suit, reprend ce procès-verbal et les articles qui figurent dans la coutume expliquant les motifs de renvois. Pour la compréhension du texte, les articles, qui sont des notifications de renvois, sont soulignés.

\section{Reprenons les termes utilisés justifiant les discords et les renvois}

Chapitres I de haute justice, moyenne et basse et des exploits d'icelles, 14 articles; II de moyenne justice et des exploits d'icelle, 2 art. ; III de basse justice et des exploits d'icelle, 2 art. ; IV de justice censière et des exploits d'icelle, 9 art. ; $V$ de forfaiture et confiscation, 4 art. et 2 art. de Varzy; VI des bâtards, 5 art., ces 38 articles ont été accordés sans discussion à l'assemblée.

VII de retrait, 23 art. L'article 42, cinquième article du chapitre, est demeuré en difficulté et non accordé, pour cause d'opposition des aucuns de la dite assemblée... et les autres d'icelle assemblée. L'article 43 donne la décision : à cette cause n'a pu être accordé iceluy article et est demeuré croisé. 21 articles sont accordés et le chapitre comprend 22 articles de coutumes et un article de renvoi.

VIII de successions, partages et divisions, 18 art. et 4 art. de coutume locale de Varzy. L'article 66, cinquième article rédigé, lequel est demeuré non accordé. Article 67 : constat de l'opposition entre les aucuns et les autres de l'assemblée et renvoi. Article 78 et dernier : les seigneurs châtelains, barons hauts-justiciers ont discordé le dit article; les avocats et procureurs disant le contraire. Article 79 : par tant est demeuré non accordé. 14 articles sont accordés sans discussion, ce chapitre comprend 16 articles de coutumes et 2 de renvois. Les articles de Varzy sont accordés.

IX de servitudes, 7 art. et un article de la coutume de Varzy. 8 articles sont accordés.

$X$ de testaments, institution d'héritiers, legs et donations faites par iceux et des exécuteurs de testaments, 17 art. Le 8 septembre, la totalité du chapitre est accordée. L'opposition à l'article 106 n'est posée que le 14 octobre (cf. infra, p. 69). 15 articles sont accordés, ce chapitre comprend 16 articles et un de renvoi.

XI de donation entre vifs et mutuelle, 8 art. ; XII d'acquérir, garder et retenir possession d'héritages et des causes propriétaires et possessoires, 4 art. Ces 12 articles sont accordés. XIII des censives et droits seigneuriaux, 28 art. L'article 121 est demeuré discordé. Article 122, les prélats et les seigneurs châtelains maintiennent que l'article tel qu'il est posé n'est pas de raison, les avocats, les procureurs et autres ayant charge des communautés disent que l'article a déjà été accordé et pratiqué. À cette cause avons renvoyé la difficulté $d u$ dit article pour icelle être accordée. Article 125, discordé par les gens d'Église et les nobles contre les avocats et praticiens. Article 126, les religieux de Vézelay refusent l'article, non accordé par eux, mais accordé entre les seigneurs. Ce désaccord est noté dans le texte de la coutume mais n'est pas repris au procès-verbal. Article 129, discordé. Article 130, les avocats, praticiens et autres ayant charge des communautés s'opposent aux prélats et aux nobles, pour lesquels cet article ne peut être accordé. Article 135, demeuré discordé. Article 136, les prélats et les nobles veulent insérer un rectificatif, les avocats, praticiens et communautés le contestent, l'article doit être gardé, car il contient vérité, est vraye coutume et accordé en ces termes. Vu le désaccord avons croisé et renvoyé. Articles 141 et 142 ont été discordés. Article 143 justifie le renvoi des deux articles, les avocats, procureurs, praticiens et autres ayant charge des villes opposent les jugements aux prélats et aux nobles, qui disent que ces sentences rendues contre eux ne peuvent 
leur préjudicier, qu'ils ont joui et usé de l'article et obtenu aussi des sentences favorables. À cette cause les avons croisé et renvoyé. Article 144 demeuré en difficulté. Article 145, les avocats, procureurs, praticiens, et autres des villes et châtellenies soutiennent la forme de l'article, les prélats et les seigneurs s'y opposent, tous disent que leur version contient vérité. À cette cause avons croisé et renvoyé ledit article. Article 146, énoncé suivi de l'article 147, délaissé au droit commun sur avis du Conseil, donc supprimé dans la coutume. Cette mention figure dans le texte et non au procès-verbal. 14 articles sont accordés, la coutume générale contient 20 articles et 7 articles de renvois pour 7 discordés et un supprimé de la coutume, car réglé par le droit royal selon avis du conseil, droit commun à tous les Français.

Des coutumes locales de Varzy sont imprimées sous le même chapitre censives, 7 articles. Article 149 discordé. Article 150 note l'opposition entre les habitants du lieu et l'évêque d'Auxerre. Article 151 discordé. Article 152 demeure en difficulté, pour cause d'opposition entre les mêmes. Article 153 discordé. Article 154, demeure en difficulté, vu l'opposition entre les mêmes. Dans les trois cas, l'opposition porte sur les lods et ventes lors de la vente d'un héritage franc, droits revendiqués par l'évêque, qui s'appuie sur des sentences, et refusés par les habitants. Un article de la coutume de Varzy est accordé, 4 articles énoncent la coutume et 3 sont des articles de renvois.

$X I V$ de compagnie et communauté de biens entre homme et femme mariés et de toutes autres personnes, 14 art. et 2 de Varzy ont été vérifiés et accordés ensemble. XV de convenances, marchés, ventes, achats, louages, prêts et autres deniers contrats 10 art. XVI de prescription et laps de temps, 2 art. XVII de rentes foncières, volages et hypothèques, 13 art. XVIII des bourgeoisies et des aveux, 7 art. ont été accordés.

XIX des eaux, bois et forêts, usages et pâtures, 12 art. Article 204 second du chapitre discordé. Article 205, les habitants des communautés, des villes et châtellenies, les avocats, procureurs et praticiens, disent que l'article contient vérité et déjà accordé en dernières coutumes. Par les officiers du roi, les prélats et les nobles disent le contraire faisant valoir également leur usage. Article 213 discordé. Article 214, vu la difficulté de l'article, il est renvoyé à la prochaine assignation, qui sera faite pour apporter les coutumes locales des villes et châtellenies du bailliage le 14 octobre, pour accorder si faire ce peut ou bailler tel appointement que de raison. Il s'agit du temps de greiner (cf. infra, p. 71 ). 8 articles sont accordés, le chapitre contient 10 articles et 2 de renvois.

$X X$ de tutelle et curatelle d'enfants mineurs nobles et non nobles, 5 art.

$X X I$ de douaire préfix et coutumier, 3 art.

XXII d'assurements et sauvegardes, 9 art. ont été accordés.

XXIII des fiefs, droits et profits féodaux, 33 art. Article 251 discordé. Article 252 les nobles et les prélats disent que l'article ne contient pas vérité et proposent une autre rédaction; par les officiers $d u$ roi, les habitants des villes, châtellenies et seigneuries disent que l'article doit être accordé. À cette cause avons croisé et renvoyé le dit article. Soit 31 articles sont accordés, le chapitre contient 32 articles et un de renvoi.

XXIV de rapports qui se doivent faire en succession, 6 art. ont été accordés.

Ainsi qu'il est prévu le 8 septembre, la discussion reprend le 14 octobre sur l'article 213 discordé du chapitre XIX eaux, bois et forêts: le temps de greiner en bois et forêts commence à la Saint Remy (1er octobre) et dure jusqu'à la Saint André (30 novembre); les gens d'Église et les nobles s'opposent aux avocats, procureurs, praticiens et autres des communautés. Article 214, les premiers maintiennent que le temps de greiner commence à la Saint-Remy et finit à la purification de Notre-Dame (Bénie Vierge Marie [B. V. M.], 2 février). Les seconds disent que le temps de greiner commence à la Saint André et que 
les nobles et gens d'église en ont joui ainsi. L'article est croisé et renvoyé car aucun accord n'est obtenu. Greiner ou faire paisson : en effet les propriétaires de bois et forêts revendiquent un temps plus long d'usage et diminuent celui qui serait accordé au tiers état. Ce même 14 octobre, les prélats et gens d'Église s'opposent aux nobles, avocats, procureurs et autres sur l'article 106. Article 107, les procureurs, les nobles, les avocats et les communautés font valoir l'accord de l'article le 8 septembre, les gens d'Église doivent justifier leur opposition récente, les parties sont entendues. Il s'agit de femme conjointe par mariage ne pourra tester sans l'autorité de son mari. Les gens d'Église prétendent pouvoir toucher les legs pieux avec ou sans l'autorité du mari. Avons réservé aux prélats et gens d'Église de déduire leurs causes d'opposition par messieurs les gens de la Cour et autres ayant puissance de terminer d'icelles coutumes. Le commissaire a assigné les seigneurs et les habitants, dûment nommés, à présenter leurs coutumes locales le 14 octobre. Les contestations portent surtout sur le montant des lods, les seigneurs et les manants proposant des sommes différentes, 2 sols par les premiers, 12 deniers par les seconds. Les avocats et procureurs du roi confirment 2 sols pour lods selon la coutume d'Auxerre.

L'article 144 du chapitre censives, tous héritages sont tenus et réputés francs s'il n'appert du contraire, est repris de nouveau, soutenu par les procureurs, avocats et autres ayant charge des communautés, les habitants de Vézelay et de Varzy auraient tenu des héritages sans payer redevance, les seigneurs contestent et proposent une autre version, l'article est renvoyé à la cour.

Le texte des coutumes, et le procès-verbal moins complètement, reprennent les discussions du 8 septembre et du 14 octobre, donc la rédaction des deux documents est postérieure à cette seconde date.

Sur les 24 chapitres et 271 articles de coutumes, 17 sont les coutumes locales de Varzy insérées à la fin de chaque chapitre concerné : 14 articles énoncent les coutumes, dont 3 articles sont renvoyés -3 articles notifient les renvois. Pour les coutumes générales, 14 articles sont renvoyés et 1 article est renvoyé au droit commun, 14 articles sont des notifications de renvois, mais le $\mathrm{n}^{\circ} 85$ est porté sur deux articles. Les coutumes générales sont donc rédigées en 240 articles en 1507 (en retirant 17 de décisions et 1 supprimé, ainsi que les coutumes de Varzy). Les articles discordés subsistent dans les coutumes, ils seront repris lors de la réformation et certains seront accordés.

Les coutumes locales de 14 articles figurent sous 6 chapitres ( $V$ forfaiture, VIII successions, IX servitudes, XIII censives, XIV communauté, XXIII fiefs) Les 3 articles discordés et renvoyés sont dans le chapitre XIII censives, pour cause d'opposition sur les lods et ventes entre les habitants et l'évêque d'Auxerre. 


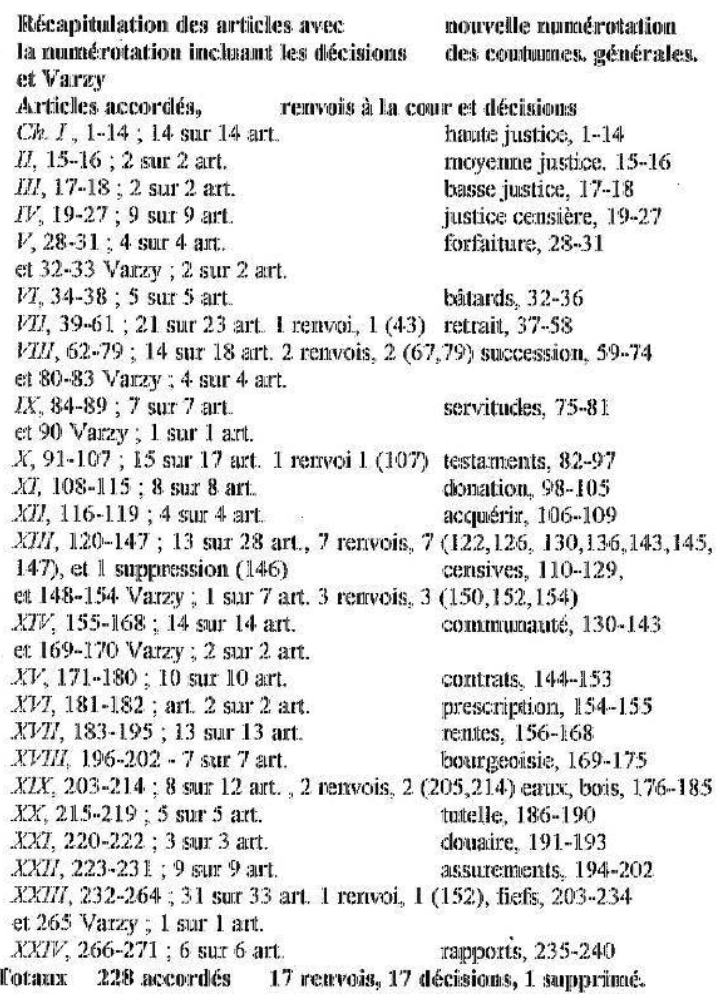

Dix-huit chapitres sont accordés en entier y compris les coutumes locales, comptant 129 articles ; 99 articles des 6 autres chapitres sont également accordés. Le procès-verbal indique que des chapitres ont été accordés ce qui suggère un temps avant la tenue de l'assemblée, les membres des états auraient-ils eu connaissance des chapitres des coutumes, grâce au travail préparatoire des juristes? Des articles dans ces 6 chapitres sont examinés, 17 articles demeurés en difficulté ou discordés puis les avons croisés et renvoyés. Donc tous les articles discutés sont renvoyés, aucune nouvelle rédaction commune n'emporte l'adhésion de l'assemblée, même l'article sur le temps de greiner, dont la discussion est pourtant reportée au 14 octobre pour tenter de trouver un accord. Les uns et les autres proposent des versions différentes, voire opposées, ainsi la charge d'apporter les titres prouvant que la terre est franche par le détenteur ou prouvant que le seigneur a droit au cens par le dit seigneur (art. 144 du chapitre XIII censives).

Le vocabulaire utilisé dans le texte de la coutume lors des discussions d'articles est peu varié, les mêmes termes sont repris à tous les articles concernés, ils sont tirés de l'ordonnance de Charles VIII, ainsi :

- pour justifier les renvois : discordés ou demeurés en difficulté ou demeurés non accordés, 17 articles.

- pour signifier les renvois : avons croisé et renvoyé, 17 articles.

L'emploi de ce avons première personne du pluriel, signifie l'intervention directe du commissaire, qui selon la volonté du roi, fait le constat du désaccord et prend la décision de renvoi à la cour de parlement. Nous trouvons déjà ce verbe mentionné après la liste des présents, les comparutions et la lecture des lettres patentes avons prins le volume et cayer des dites coutumes. Le commissaire Blanchet Dany, nommé par le roi, fait acte de présence et d'autorité. Lieutenant général du bailli d'Auxerre et non membre du Parlement, il impose le respect de la procédure fixée par les ordonnances. 


\section{Relevé des oppositions manifestées à l'assemblée :}

Aucuns... les autres, sans spécification des personnes ou de l'ordre concernés : aux titres retrait, 1 art. (les rentes volages gisent ou non en retrait); successions, 1 art. (les oncles sont plus proches ou non que les neveux pour succéder).

Les seigneurs châtelains et barons hauts-justiciers contre les avocats et les procureurs: au titre successions 1 art. (la succession d'un étranger va aux hauts justiciers ou au roi, en cas de non parenté dans le royaume).

Les prélats et gens d'Église contre les nobles, les avocats et les procureurs des communautés : au titre testaments, 1 art. (femme conjointe par mariage ne peut tester sans l'autorisation de son mari, contesté par les premiers).

Les prélats et seigneurs châtelains contre les avocats et les procureurs des communautés : aux titres censives, 7 art. (tous concernent le paiement des lods et ventes réclamés en toutes occasions par les seigneurs); bois et forêts, 1 art. (sur le temps de greiner)

Les praticiens, les avocats et procureurs contre les prélats et les nobles s'exprimant « par les officiers du roi »: au titre bois et forêts, 1 (les habitants ne peuvent prétendre avoir usages outre la vaine pâture, sans payer redevance ou avoir titre ou en ont joui de longtemps qu'il n'est mémoire du contraire, contesté par les premiers).

33 Les nobles et les prélats opposés aux habitants des communautés, des villes, châtellenies et seigneuries s'exprimant « par les officiers du roi » : au titre fiefs, 1 art. (quand le vassal fait un faux aveu, il y a commise du fief, sauf tenu du roi, contesté par les premiers).

Le chapitre le plus contesté est celui sur les censives (XIII, 7 articles et 1 supprimé sur 28 renvoyés) et l'opposition est claire, l'Église et la noblesse contre le tiers état, de même l'article du chapitre bois, mais les officiers du roi interviennent pour les premiers. L'article du chapitre fiefs montre les mêmes opposants, mais les officiers du roi appuient les praticiens et les communautés, pour soutenir les droits du roi. L'article du chapitre successions oppose les nobles au tiers état, sans les prélats. Les contestations portent principalement sur les droits féodaux que les seigneurs ecclésiastiques et laïcs défendent avec énergie.

\section{Les Coutumes de Sens ${ }^{16}$}

\section{La procédure}

Les coutumes de Sens sont rédigées en 1495 et publiées en 1507.

Selon la procédure habituelle de rédaction, elles sont accordées par les gens et les officiers du roi au bailliage de Sens, en la présence de plusieurs gens d'Église, de nobles, d'avocats, de praticiens, de notables bourgeois et marchands de la ville de Sens. Tous ces membres des états du bailliage ont été appelés et convoqués ensemble par François Boucher, licencié ès lois et décret, lieutenant général du bailli de Sens, suivant en cela les ordres du roi Charles VIII de mars 1495. Les coutumes doivent être signées du seing manuel de nous et des presens assistans et scellées du contrescel du dit bailliage le mercredi 16 mars 1495. La rédaction est donc faite selon les ordonnances. Le même roi donne de nouvelles lettres pour la publication de ce coutumier le 2 septembre 1497, qui ne sont pas exécutées.

Louis XII intervient le 23 mai 1506, en adressant ses propres lettres à Thibaut Baillet, second président au parlement de Paris, et à Guillaume de Besançon, conseiller au parlement. Le roi reprend les lettres de Charles VIII également adressées à Thibaut Baillet 
et à Guillaume Dauvet maître des requêtes en 1497. Sont également nommés Nicoles de Hacqueville et Étienne Poncher, présidents ès requêtes, Philippe Simon, Guy Arbaleste et Guillaume de Besançon, conseillers au parlement, Jean Le Maistre et Guillaume Vollant, avocats du roi. Le nombre important de commissaires peut signifier que le roi entend que au moins deux de ses parlementaires trouvent le temps de se déplacer à Sens, les lettres de son prédécesseur étant restées sans effet.

Lors de la rédaction de 1495, un officier du bailliage est commis par le roi, comme à Auxerre, il connaît les coutumes, et par les lettres ordonnant la publication en 1497 et 1506, des officiers du parlement de Paris sont nommés commissaires.

Lors de cette tardive publication, les coutumes sont lues en l'auditoire du bailliage, en présence et par ordonnance des commissaires royaux Baillet et Besançon. Sont cités ensuite les participants à l'assemblée, dont l'archevêque de Sens représenté par procureur, le même François Boucher commissaire lors de la rédaction et ayant le même office, lieutenant général du bailli de Sens. L'assemblée se tient pendant 4 jours du mercredi 7 au samedi 10 mars 1507. À la requête du procureur du roi du bailliage, après lecture faite, les coutumes arrêtées par les trois états seront entretenues, gardées et observées pour Loi. Il est interdit d'observer d'autres coutumes. Le procès-verbal est signé des deux commissaires. Deux assemblées sont ainsi tenues à Sens, pour la rédaction et 11 ans plus tard pour la publication, respectant la procédure édictée par les rois, les peuples doivent être présents pour accorder et publier les coutumes.

La disparition du procès-verbal de rédaction ne nous permet pas de connaître les accords ou désaccords intervenus entre les membres de l'assemblée. En effet, selon une note de Bourdot de Richebourg, cette ancienne coutume de 1495 est intitulée Cahier des articles prétendus estre l'ancienne coustume du bailliage de Sens. Il fut mis au greffe du Parlement par les commissaires ordonnés pour la réformation de la même coutume en 1555 et

[...] ce à la requête des trois Estats pour servir et valoir à ceux qui pourraient prétendre avoir un droit acquis auparavant la réformation.

En 1507, les coutumes rédigées de Sens comprennent 24 chapitres non numérotés et 283 articles numérotés en continu.

Chapitre premier de haute justice et des exploits d'icelle, articles 1-11 (11 art.)

II de moyenne justice et des exploits d'icelle, 12-15 (4)

III de basse justice et des exploits d'icelle, 16-17 (2)

$I V$ de justice foncière et des exploits d'icelle, 18-22 (5)

$V$ de forfaitures et confiscations, 23-26 (4)

VI des bâtards, 27-30 (4)

VII de retrait lignager, 31-56 (26)

VIII de successions, partages et divisions, 57-73 (17)

IX des servitudes, 74-80 (7)

$X$ des testaments, institutions d'héritiers, legs, donation faite en testament et des exécuteurs de testaments, 81-94 (14)

XI de donation entre vifs, mutuelle et pour cause de mariage, 95-102 (8)

XII comme on peut acquérir, garder et retenir possession, 103-106 (4)

XIII de rentes foncières, volages et hypothèques, 107-121 (15)

XIV des bourgeoisie et aveux, 122-131 (10)

$X V$ des bois, forêts, usages et pâturages, 132-140 (9)

XVI de bail et garde des enfants mineurs nobles et tutelle des non-nobles, 141-149 (9)

XVII de douaire coutumier et préfixe, 150-158 (9) 
XVIII des assurements, 159-168 (10)

XIX des fiefs et profits féodaux, 169-220 (52)

$X X$ des censives et droits seigneuriaux, 221-244 (24)

XXI des convenances, marchés, ventes, achats, louages, prêts, dépôts, et autres contrats, 245-258 (14)

XXII de prescription et laps de temps, 259-260 (2)

XXIII des rapports qui se doivent faire en partage, 261-268 (8)

XXIV de compagnie et communauté de biens entre homme et femme mariés et autres personnes, 269-283 (15)

Les lettres patentes de Henri II du 17 août 1555 données pour la réformation de la coutume nous apprennent que le procès-verbal ne se trouvait plus des lors qu'il était perdu et adhiré et que c'était même un des principaux motifs qui rendait nécessaire la réformation de la coutume de Sens.

\section{Les Coutumes de Touraine ${ }^{17}$}

\section{La procédure}

Coutumes et usages du pays et Duché de Touraine, des ressorts et exemptions d'iceluy interprétées, corrigées, augmentées, arrestées, rédigées et mises par escrit, par nous Guillaume Sireau, Licencié en Loix, Conseiller du Roy, notre Sire, Juge et Lieutenant général de Monseigneur le Bailly de Touraine, en l'assemblée générale faite en la ville et cité de Tours en l'hostel d'icelle : par l'oppinion, advis, accord, conseil et délibération d'honorables hommes et sages.

Des lettres patentes de Louis XII datées de Grenoble, le 2 avril 1506 avant Pâques, enjoignent au bailli de Touraine de convoquer les officiers du roi des sièges du bailliage, l'assemblée des trois ordres relevant de son ressort pour

[...] voir, corriger, augmenter, interpréter, arrêter et pour faire écrire et signer et renvoyer signés les articles rédigés

de la coutume et de contraindre par des saisies ceux qui refuseraient de comparaître. Le 12 septembre 1507, ces lettres patentes sont remises à Thibault Baillet, président en la cour du parlement et à Jean Burdelot, procureur général en la même cour, qui arrivent en la ville de Tours le 25 octobre 1507. Ils sont accueillis à l'hôtel de ville par Étienne Binet, lieutenant particulier du bailli de Touraine, informé par lettres royales données à PontLevry le 5 octobre précédent, de tenir l'assemblée à la date susdite.

La comparution des membres de l'assemblée, composée du clergé, de la noblesse et du tiers état, complétée d'officiers, avocats, procureurs et praticiens du bailliage, se tient le 26 octobre. Le nom des comparants ou de leurs mandataires, avec l'indication de leur titre ou fonction et du lieu de leur domiciliation ou de leurs terres, est inscrit au procès-verbal par maître Jehan Moreau, greffier du bailliage. Les premiers désignés sont les officiers royaux, Adam Fumée, conseiller et maître des requêtes ordinaires de l'hôtel du roi, Jacques de Baulne, conseiller du roi et général des finances, Guillaume Sireau, lieutenant général du bailliage, Étienne Binet lieutenant particulier, Jehan Ragueneau, procureur du roi, Julian Chalopin, avocat du roi au bailliage de Tours, Jehan Perrigault, receveur du bailliage et Mathurin Richart, prévôt de Tours. Plusieurs d'entre eux avaient déjà participé à la commission préparatoire qui s'était réunie à Tours le 2 avril 1494, chargée de réviser la coutume de 1460, restée manuscrite. Charles VII n'eut pas le temps de confirmer cette coutume. Elle le fut cependant par Louis XI en 1462, mais elle n'obéissait 
pas aux formes requises par l'ordonnance de Montils-lès-Tours, n'ayant été, ni promulguée en assemblée générale par des commissaires royaux, ni soumise pour homologation au Parlement ${ }^{18}$.

[Elle] fut faite sur simples usages observés par tradition, et dont il ne reste aujourd'hui aucuns vestiges ${ }^{19}$.

Les comparants ou leurs représentants, après avoir remis leur pouvoir au greffe, font serment de bien et royalement conseiller et dire la vérité sur le fait des coutumes du bailliage. Pour l'ordre du clergé, l'archevêque de Tours est représenté par son trésorier, ses chanoines et vicaires, puis viennent les autres doyens, chanoines, chapitres, abbés et couvents, en général représentés. Suivent les gens de la noblesse, avec indication de leur nom et titre. Ainsi est citée à comparaître toute la noblesse, et notamment Dame Françoise de Laval ${ }^{20}$ pour ses enfants mineurs, le comte de Dunois ${ }^{21}$, seigneur châtelain de Château-Regnault, la duchesse d'Alençon comme ayant le bail de son fils mineur ${ }^{22}$. Enfin, pour le tiers état, sont mentionnés, en particulier, le maire de Tours Henri Bohier, conseiller du roi et receveur général de ses finances, les échevins, les manants et habitants de la ville de Tours, mais aussi des gens de justice et les officiers. Ces gens de robe sont mentionnés séparément comme s'ils constituaient un ordre distinct.

Suit alors la discussion du projet de la coutume, à partir d'un cahier qui a été rédigé dans une précédente assemblée, composée d'officiers royaux et de gens de justice des divers sièges du bailliage, des échevins de Tours, de membres du clergé et de barons et châtelains, sous la présidence de Guillaume Sireau, licencié ès loi, lieutenant général du bailli de Touraine. Ce cahier a été auparavant adressé et examiné par les commissaires royaux. Les articles de la coutume sont débattus contradictoirement et les membres de l'assemblée des trois ordres ont pu s'exprimer très librement, chacun pouvant présenter ses objections. La discussion est close le 5 novembre 1507.

La coutume est alors lue et publiée officiellement à l'hôtel de ville de Tours en présence des commissaires, des officiers royaux et des membres de l'assemblée pour prendre effet immédiat

[...] en faisant deffense ausdits lieutenant, officiers du roi et autres advocats, practiciens et coustumiers du dit bailliage, que doresnavant, pour la preuve des dites coustumes publiées comme dessus, ils ne facent aucunes preuve par turbes, ne tesmoings particuliers, mais par l'extrait d'icelles signées et deuement expédiées: et aussi de non alleguer, ne poser autres coustumes contraires, ne derogantes aux coustumes publiées et arrestées, ains les observer et garder comme loy ${ }^{23}$.

Un exemplaire est remis aux commissaires royaux pour dépôt au greffe du Parlement. Un autre exemplaire portant leur signature, celles du lieutenant général et du greffier, est laissé au greffe du bailliage. L'enregistrement à la cour du Parlement a lieu le 17 mars 1508 d'après la note transcrite en latin à la fin du procès-verbal.

La coutume rédigée de Touraine de 1507 comprend 36 chapitres et 334 articles. La numérotation des articles n'est pas continue, mais propre à chaque chapitre, aussi pour faciliter la comparaison ultérieure avec la coutume de 1559, nous donnons en parallèle une numérotation d'articles en continu en italique.

Chapitre premier des droits de la basse justice qui est appelée basse voirie et autrement semi-droit, 33 art., $1-33$

II des droits de la moyenne justice qui est autrement appelée grande voirie, 13 art., 34-46

III d'épaves mobilières, 3 art., 47-49

IV des droits de haute justice, non ayant-droit de châtellenie ou baronnie, 3 art., 50-52 
$V$ des droits de seigneur châtelain, 11 art., 53-63

VI des droits de baronnie, 4 art., 64-67

VII des droits de péages et coutumes, 7 art., 68-74

VIII des loyaux-aides et roucins de service, des gardes dues aux châteaux des seigneurs, et la manière et comment ils doivent être faits et levés, 7 art., 75-81

IX des droits de fautrage et péage, 2 art., 82-83

$X$ banc à vin, 1 art., 84

$X I$ d'indemnité et d'injonction, 5 art., 85-89

XII comment hommage se doit offrir à son seigneur, 5 art., 90-94

XIII de depié de fief et de parages, 17 art., 95-111

XIV des rachats et ventes, 19 art., 112-130

$X V$ des retraits, 40 art., 131-170

XVI quittances et exponces d'héritages, 2 art., 171-172

XVII des héritages défensables, 6 art., 173-178

XVIII prescription en coutume, 4 art., 179-182

XIX des vues et égouts de maisons, gouttières et latrines, 2 art., 183-184

$X X$ des hypothèques et comment elles se divisent et comment l'on se peut faire payer de ses rentes et dettes par assiette ou autrement, d'interruption contre acquéreurs lesquels sont à préférer et lesquels viennent à contribution, 3 art., 185-187

XXI des choses qui sont réputées meubles ou héritages, 5 art., 188-192

XXII de communauté de biens, 2 art., 193-194

XXIII de donations faites entre gens roturiers, 10 art., 195-204

XXIV des donations entre nobles, 20 art., 205-214

XXV des successions de fiefs et autres héritages entre nobles fors de baronnie, 23 art.,

215-237

XXVI comme baronnie doit être départie, 3 art., 238-240

XXVII des successions de gens roturiers et coutumiers, 27 art., 241-267

XXVIII de succession de bâtard, 1 art., 268

XXIX de douaire de femme noble et

XXX douaire entre roturiers, 11 art., 269-279

XXXI de bail, 8 art., 280-287

XXXII de tuteurs et curateurs, 3 art., 288-290

XXXIII d'émancipation, 1 art., 291

XXXIV comment l'on doit bailler rentes par assiette, 12 art., 292-303

$X X X V$ amendes, 23 art., 304-326

XXXVI crimes, 8 art., 327-334

50 À la fin de la coutume, mais sans être intégrées à celle-ci, sont arrêtées et publiées les coutumes locales de Châtillon-sur-Indre, Fromenteau appartenant au chapitre de l'église de Loches, Amboise, Montrichard, Meremontier, Prully, Azay-le-Ferron, La Roche-Posay, la vicomté de la Guerche, Ligne, La Motte-sur-Indre, la baronnie de Buzançais, la châtellenie de Banche, la baronnie de Saint-Genou, Coudray, la baronnie de Mazières, les châtellenies de Saint-Cyran, de l'Ile-Savary, de Château-Regnault et d'Herbault où le seigneur prétend avoir droit de châtellenie et des excluses. Des avocats et praticiens confirment qu'il s'agit de véritables coutumes pratiquées en ces lieux. Il est décidé que les autres coutumes locales, écrites sur un cahier de parchemin, considérées comme des droits seigneuriaux, seront réservées aux seigneurs pour en user sur leurs sujets, s'il est prouvé que ces droits leur appartiennent et que leurs sujets ne puissent alléguer du contraire. 


\section{Les contestations}

51 Avant de commencer la lecture des articles de la coutume, deux protestations sont présentées, l'une au nom de l'archevêque de Tours et de son clergé s'exprimant par son vicaire, qui déclare

[...] qu'il comparaît... pour le bien et l'utilité du pays et duché de Touraine et non pour assujettir ou imposer ses sujétions à sa dignité archiépiscopal, son clergé, sans déroger aux privilèges, immunités, libertés et prééminences du seigneur, de son clergé et de l'Église. Il proteste aussi qu'il n'entend qu'aucune chose soit statuée et arrêtée portant préjudice et atteignant les libertés et privilèges de l'Église et du clergé24.

Il demande que cette protestation soit insérée dans le procès-verbal. Ce à quoi le procureur du roi de Tours lui répond qu'il est question d'arrêter les coutumes du pays et duché de Touraine qui concernent les biens immeubles et temporels de l'Église dont la connaissance appartient au roi.

L'autre remontrance émane des habitants de la ville d'Amboise qui, se considérant comme sujets relevant directement du roi et de son parlement, ne veulent pas dépendre du bailliage de Touraine et considère que cette comparution est préjudiciable à leurs droits et prérogatives. Le procureur du roi leur répond que d'ancienneté le siège d'Amboise est l'un des sièges du bailliage. Le ressort ou détroit de la coutume de Touraine s'étend sur la Touraine et une partie du Berry, jusqu'à Buzançais.

Les articles accordés par les trois états assemblés ou par la plus grande et saine partie d'iceux sont aussitôt publiés pour preuve de coutume. Les articles discordés présentant des différends qui ne peuvent être résolus, sont renvoyés devant le parlement pour qu'ils soient ordonnés comme de raison. Dans la pratique, lorsque l'article est contesté par une partie notable de l'assemblée ou par le procureur du roi qui défend les droits du roi ou de la chose publique, un accord transactionnel est recherché. Dans le cas contraire, les commissaires ne peuvent trancher et l'article est renvoyé à la cour. Ce renvoi est mentionné dans le procès-verbal joint à la coutume. Cependant, les commissaires peuvent autoriser la publication de l'article par provision, en attente d'une décision de la cour. De fait, l'article maintenu provisoirement, sauf procès, devient souvent définitif jusqu'à la réformation ${ }^{25}$. Le procès-verbal fait état d'un certain nombre de contestations à l'origine des articles discordés ou remis à la cour ou des rapports à la cour rédigés par les commissaires royaux.

Reprenons les termes utilisés dans le procès-verbal de l'assemblée.

Chapitre premier des droits de la basse justice qui est appelée basse voirie et autrement semi-droit, (33 art.). Sur l'article 4, le procureur du roi s'oppose à la ville d'Amboise. Il est donné raison sur l'application de la coutume locale d'Amboise et pour les autres fiefs du bailliage, et il y sera pourvu comme de raison, car en sa qualité de baron d'Amboise, le roi a un droit exclusif de moulin banal et celui d'interdire au meunier demeurant en sa ville ou ailleurs d'aller chauffer ou quérir le blé de ses sujets pour le moudre à leurs moulins s'ils ne sont affermés au fermier du roi, à l'exception de ceux qui bénéficient de privilèges. Par contre, l'article 19 est maintenu malgré l'opposition du procureur du roi. Les assistants des différents sièges plaident que, en l'absence d'hommage, les seigneurs font plusieurs grands excès en commettant violences et forces publiques et en prenant les fruits, alors que le roi entend soulager ses vassaux et sujets, et obvier aux voies de fait et ravages. Les lettres patentes de Louis XII ordonnent expressément, dans la continuité des 
ordonnances royales de ses prédécesseurs, la rédaction de la coutume pour le soulagement de ses sujets.

II des droits de la moyenne justice qui est autrement appelée grande voirie, 13 art. À l'article 2, une contestation oppose le prévôt de Tours d'une part, et les chapitres de l'Église de Saint Martin de Tours, l'abbé et le couvent de Meremontier d'autre part, sur le droit qui appartient aux seigneurs, qui ont moyenne justice, de bailler à leurs sujets mesures à blé, vin ou huile. Le premier revendique ce droit pour la ville et la banlieue de Tours, ayant droit de police, donc de garde. Les seconds y prétendent également. Comme un procès est en cours, l'article est maintenu et une restriction est ajoutée sinon qu'il y ait usance au contraire.

$V$ des droits de seigneur châtelain, 11 art. L'article 2 accorde aux vassaux fondateurs d'églises le droit d'avoir littre funèbre avec armoiries timbrées au dedans des églises, si l'église est paroissiale, au dedans et au dehors pour les autres églises, malgré l'opposition de trois ou quatre seigneurs châtelains parmi lesquels Guillaume de Varie, seigneur de l'Ile Savary, qui entendent conserver leurs prééminences. Sur l'opinion des assistants, l'article accordé dans la précédente assemblée doit demeurer ainsi qu'il a été écrit.

$X$ banc à vin, 1 art. Ou ban à vin, permet par proclamation au seigneur de vendre son vin avant celui de ses sujets. Le seigneur de l'Ile Bouchard conteste la teneur de l'article unique, indiquant qu'il a coutume d'affermer son ban à vin. Malgré cette opposition, l'article est arrêté par l'opinion de l'assistance.

XXIII de donations faites entre gens roturiers ${ }^{26}, 10$ art. Ce chapitre, comme celui des donations entre nobles, donne lieu à de fortes controverses : le maire et les échevins de Beaune au nom des habitants de la ville, refusent les modifications induites par les articles 1 , 4, 5, 6, 7. Après en avoir longuement débattu, les contestataires persistent formellement dans leur opposition, malgré l'avis de la majorité des assistants. Le procureur du roi décide la publication immédiate de ces articles. Les commissaires ordonnent au maire et aux échevins de déposer au greffe leurs motifs de contestation, qui seront communiqués au procureur du roi pour y répondre. Il appartiendra au greffier du bailliage de transmettre l'ensemble de ces éléments aux commissaires, le lendemain de la Saint-André (30 novembre) pour qu'ils puissent faire leur rapport à la cour pour y être pourvu comme de raison. Le représentant de l'archevêque de Tours demande qu'il soit ajouté un article qui distingue leur patrimoine de celui des roturiers. Après débat et devant les avis contradictoires et le refus du procureur du roi, les commissaires décident que les gens d'Église leur communiqueront par écrit leurs raisons, le lendemain de la Saint André, afin qu'ils puissent faire leur rapport à la cour, pour que par elle il en soit ordonné comme de raison.

XXIV des donations entre les nobles, 8 art. L'article 1 rencontre l'opposition des religieux de l'ordre de Saint-Benoît, des abbayes de Meremontier et de Saint-Julien de Tours qui contestent l'exclusion de toute succession d'un homme ou d'une femme noble ou roturier entré en religion. Le procureur du roi et l'assistance y sont hostiles. Sur l'opinion de l'assemblée, l'article est arrêté et publié pour coutume. Il leur est proposé de communiquer leurs causes d'opposition au procureur du roi qui les transmettra aux commissaires pour qu'ils puissent faire leur rapport à la cour. Les articles 2, 5, 7, 10, sur les donations entre époux nobles n'ont pu être accordés et ils sont remis à la cour avec les articles contestés au chapitre des donations entre roturiers, en raison des contradictions portées par le maire et les échevins de Tours.

XXVI comme baronnie doit être départie, 3 art. L'article 3 (et non l'article 2 comme l'indique le procès-verbal) dispose que le préciput appartient à l'aîné en cas de partage de 
la baronnie. Le procureur du roi s'oppose et requiert que les mots droit de guet soient ôtés. L'article est cependant maintenu en l'état par l'assistance, avec ajout de mots en fin d'article.

XXXI de bail, 8 art. Les articles 5 et 6 sont lus et mis pour coutumes par l'assistance. Ces dispositions extraites du style de procédure relative au bail à attente d'héritiers en actions réelles, constituent une innovation très importante tant pour le bailliage que pour les autres lieux où il y a une coutume semblable. Aussi, les commissaires royaux décident que ces articles ne seront pas arrêtés parce qu'ils sont de conséquence non seulement pour le bailliage mais pour les autres lieux où il $\mathrm{y}$ a une coutume semblable et qu'ils en feront rapport à la cour pour qu'elle y pourvoit comme de raison.

XXXVI ancien de perte de fief à vie ou à héritage, 7 art. Les 7 articles sont délaissés et remis à la disposition des droits (ils sont retranchés).

XXXVI crimes, 8 art. Ce chapitre est une survivance de dispositions disparates, empruntées au droit canonique et au droit romain, qui relevant du droit pénal, auraient dû être régies par ordonnances royales plutôt que par coutume. L'assemblée propose que l'article 8 ne soit plus mis au livre coutumier, ni couché par coutume, et qu'il soit remis à la disposition des droits ou droits royaux. Le crime de faux commis par un notaire ou autre devient soumis aux dispositions du droit commun (ou royal).

La coutume de 1507 présente 36 chapitres et 334 articles :

223 articles sont accordés. Selon la terminologie utilisée dans le procès-verbal, des mots ou des articles ont été ajoutés, mis, corrigés, diminués, rayés, ôtés, interposés, interprétés ou passés pour coutume sans modification.

11 articles sont remis à la décision de la cour, parmi lesquels l'article 8 du chapitre XXXVI des crimes, qui n'est que partiellement remis à la décision du droit pour ce qui concerne les faux commis par un notaire ou autre. Pour les 10 autres, bien que les articles soient remis à la cour, ils sont publiés dans le corps de la coutume. Les articles 1, 4, 5, 6 et $7 \mathrm{du}$ chapitre XXIII de donations faites entre gens roturiers font également l'objet d'un rapport à la cour des commissaires royaux, en raison de l'opposition qui s'est élevée contre leur rédaction. À ce même chapitre, l'article proposé en ajout ne figure pas dans le texte publié de la coutume. Les articles 2, 5, 7 et 10 du chapitre Des donations entre les nobles sont aussi remis à la cour, mais publiés, l'article 1 du même chapitre, arrêté et publié, en raison d'une contestation, fait l'objet d'un rapport à la cour.

Les articles 5 et 6 du chapitre XXXI de bail sont inscrits dans la coutume, parce que arrêtés et passés pour coutume par l'assemblée des trois ordres. Mais leur portée juridique et territoriale n'échappe pas aux commissaires qui les renvoient au parlement.

Les 7 articles de l'ancien chapitre XXXVI du cahier préparatoire relatif au depié de fief sont également remis à la décision du droit, mais ils seront, de fait, retranchés de la coutume rédigée.

Ces premiers éléments appellent les remarques suivantes: les rubriques sont rangées dans un ordre raisonnable. Le mot "rédaction» est dérivé de redactum, qui vient de redigere, dont le sens premier était de condenser, avant de prendre le sens de mettre par écrit. L'imprimerie est, non seulement, le support qui va favoriser la diffusion des coutumes, mais elle contraint ses rédacteurs à opter pour une concision et une précision dans le choix du vocabulaire, et même de la ponctuation. Les travaux préparatoires sont minutieusement réalisés par des praticiens attachés aux différents sièges du bailliage et qui font autorité. En effet, ce sont eux qui sont appelés pour constater et faire la preuve d'un usage ou d'une coutume générale ou locale. La procédure formelle, sous l'autorité 
royale, de la rédaction officielle de la coutume lui donne un caractère certain, mais qui ne modifie pas la nature de ce droit qui reste coutumier.

Tous les articles sont accordés ou passés pour coutume par le consentement des états. Le roi conserve sa prérogative et le texte des ordonnances ou des lettres patentes de commission le rappelle par l'utilisation de la première personne du pluriel, ou par l'apposition des sceaux royaux ou l'enregistrement en son parlement, pour donner à la coutume valeur de loi perpétuelle. Il est évident que le droit coutumier traite presque essentiellement du droit privé et cette coutume n'y déroge pas. Les droits des biens et des personnes, le régime matrimonial, les successions, le retrait lignager, pour citer les principaux. Sans doute cela explique-t-il les vives oppositions en matière de donations ou de bail rencontrées dans cette coutume. Seule singularité dans cette coutume rédigée de Touraine, le maintien de quelques dispositions de droit pénal.

\section{Les réformations}

\section{Les Coutumes d'Auxerre ${ }^{27}$}

\section{La procédure}

Lors de la réformation, comme lors de la rédaction, les coutumes du bailliage sont mises par écrit et discutées en assemblée des trois états. Les commissaires chargés de la réformation sont Christofle de Thou, président en Parlement, Barthélemy Faye et Jacques Viole, conseillers du roi en Parlement. La procédure suivie par les trois commissaires est la même que celle adoptée en 1507; les volontés des rois Charles VII, Charles VIII et Louis XII, exprimées dans leurs ordonnances, sont respectées et imposées par les monarques de la seconde moitié $\mathrm{du} \mathrm{xVI}^{\mathrm{e}}$ siècle. Aucun autre texte législatif n'est promulgué pour confirmer ou modifier la procédure.

Comme les rois précédents, Henri II adresse des lettres le 12 février 1558,

[...] les peuples de ce bailliage ayant remontré au roi que leurs coutumes devaient être revues de nouveau.

Ces premières lettres ne sont pas exécutées. Après la mort du roi le 5 juillet 1559, son fils François II envoie de nouvelles lettres du 24 juillet 1559, mais celles-ci demeurent également sans effet, ce roi meurt le 5 décembre 1560 . Les lettres de son frère et successeur Charles IX sont du 5 janvier 1560 avant Pâques (donc janvier 1561) seulement un mois après celles de François II. Elles nomment les commissaires désignés par les premières missives. Ces parlementaires procèdent à la réformation dans l'assemblée des états tenue en juin 1561, les coutumes réformées sont portées au Parlement et registrées le 2 avril 1562, le délai est donc relativement court. Ajoutons que ces trois commissaires président à une dizaine d'assemblées de bailliage de 1555 à 1561, ils sont donc particulièrement compétents, connaissant très bien le droit français et les procédures de rédaction des coutumes.

Dans le texte de la coutume, les décisions de renvois ne sont plus incluses, c'est-à-dire que chaque numéro d'article correspond à un texte de coutume. Rappelons que le document de 1507 contient 240 articles de coutumes générales; les 14 articles des coutumes locales de Varzy sont également retirés.

Le dimanche 15 juin 1561, les commissaires arrivent à Auxerre pour la réformation avec les lettres des deux rois défunts et celles de Charles IX. Le président de Thou adresse sa lettre au bailli d'Auxerre, en vertu de sa propre commission du 27 mars 1561, assignant 
les membres des trois états à s'assembler le 30 mars. Les commissaires étant encore une fois retenus à Paris, l'assemblée se tient donc le 15 juin 1561, trois ans après les lettres de Henri II.

L'état de l'Église est cité en premier, respectant la hiérarchie des ordres, contrairement à 1507. Il comprend l'évêque d'Auxerre Philippe de Lénoncourt pour plusieurs seigneuries et châtellenies, représenté par son vicaire général et official assisté d'un avocat. Suivent les religieux notamment les chanoines du chapitre de Saint-Étienne d'Auxerre, qui sont présents avec un procureur, pour plusieurs fiefs. Les détenteurs de seigneuries sont membres du haut clergé, très proches du roi : le cardinal de Guise ${ }^{28}$ représenté par le grand vicaire de Saint-Germain d'Auxerre, le cardinal de Ferrare ${ }^{29}$ représenté par un procureur général et un receveur assisté de son procureur; le cardinal de Châtillon ${ }^{30}$, abbé de Vézelay représenté par son juge de Vézelay. Sont ensuite cités les ordres religieux tant masculins que féminins, les chapitres et les curés. L'état de l'Église est très détaillé, les personnages représentés sont puissants, les Guise sont alliés à la famille royale par le mariage de Marie, nièce du cardinal, avec le roi défunt François II.

Suit l'ordre de la noblesse, aussi détaillé et groupé. Le duc de Nevers, pair de France ${ }^{31}$ représenté. Nicolas d'Anjou chevalier de l'Ordre suivi des seigneurs, dits barons et chevaliers, tous représentés, des hommes et des femmes détenteurs de seigneuries. Ces nobles sont donc disjoints de leurs manants contrairement à la liste établie en 1507.

Ces ecclésiastiques et nobles, membres du conseil du roi, se font représenter à l'assemblée du bailliage d'Auxerre pour défendre leurs droits, comme n'importe quel habitant de ce territoire, obligés de comparaitre s'ils veulent les conserver. L'importance, que ces grands nobles apportent à la réformation, montre également la prégnance des coutumes dans le droit dit français, qui régit le quotidien des hommes.

Ensuite vient la liste des officiers du roi et des praticiens du bailliage, notamment Pierre le Briois lieutenant général et président du présidial d'Auxerre ; les membres du présidial, du bailliage et de la prévôté; les receveurs des deniers royaux; les avocats et les procureurs du bailliage. Les officiers royaux sont donc, comme en Touraine, rassemblés en un groupe distinct des trois ordres.

Enfin le tiers état, les habitants d'Auxerre et les échevins, les habitants des communautés avec leur procureur. La liste des présents remplit cinq pages, dont trois à part égale pour l'Église et la noblesse. Les commissaires notent les non comparants contre lesquels ils donnent défaut. Les participants prêtent serment

[...] ayant seulement égard au bien public et non à leur intérêt particulier.

En 1561, les coutumes comprennent 15 titres au lieu de 24 chapitres et 272 articles au lieu de $\mathbf{2 4 0}$ articles de $\mathbf{1 5 0 7}$ dont 14 ont été discordés et renvoyés, mais sont restés dans le corps du texte, au contraire des articles notifiant les décisions de renvois qui ont été enlevés.

Titre premier de justice haute, moyenne et basse, 1 à 41 (41 art.)

II de fiefs, 42 à 82 (41)

II des censives et droits seigneuriaux, 83 à 99 (17)

IV de servitudes, 100 à 117 (18)

$V$ de rentes et criées, 118 à 133 (16)

VI de contrats et conventions, 134 à 153 (20)

VII de retrait lignager, 154 à 185 (32)

VIII de prescription, 186 à 189 (4) 
IX de communauté de biens, 190 à 207 (18)

$X$ de douaires, 208 à 216 (9)

XI des donations, 217 à 224 (8)

XII, de testaments et exécutions d'iceux, 225 à 238 (14)

XIII de successions et rapports, 239 à 253 (15)

$X I V$ de tutelle et curatelle, 254 à 259 (6)

$X V$ des usages et pâturages, 260 à 272 (13)

\section{Les contestations}

Au niveau du ressort, plusieurs nobles présentent des remontrances. Le duc de Nevers est dit convoqué à tort pour la rédaction et l'homologation, ainsi que les habitants de son duché ; le pays de Dozy (Douzioys) est en fait régi par la coutume du Nivernais de toute ancienneté. Ces coutumes ont été enregistrées et imprimées en 1505, rédigées selon la même procédure. Donc il demande de licencier le représentant du dit pays. La réponse du procureur du roi et des avocats du bailliage est ferme, le pays de Dozy a de tout temps relevé de la coutume d'Auxerre, selon également les lettres du roi et les commissions. Sur l'avis de l'assistance, les commissaires décident que les gens du Dozy garderont les coutumes d'Auxerre. La volonté royale est imposée ici par la voix du procureur du roi.

Plusieurs châtellenies prétendent faire partie du bailliage de Sens. En cas de désaccord, elles demandent le renvoi en la cour du Parlement, la réponse du procureur du roi et des avocats $d u$ bailliage est identique, ces terres relèvent de la coutume d'Auxerre. Les commissaires ordonnent que les concernés auront actes de leurs

[...] remontrances pour leur servir et se pourvoir sur icelles ainsi qu'il appartiendra par raison.

Ainsi, comme lors de la rédaction, le territoire prime sur la qualité de la personne, un duc et pair relève certes du parlement personnellement, mais ses seigneuries situées dans un territoire donné, dépendent juridiquement de ce territoire.

Le texte, la place des articles et des chapitres sont profondément bouleversés.

Modifications apportées aux titres lors de l'assemblée de réformation :

Titre premier de justice haute, moyenne et basse, 41 articles. : 6 mis au lieu de ; 9 nouvel introduits ou ajoutés ; 2 rédigés nouveaux; 2 renvoyés à la Cour ; 1 demeuré ; 7 dans lesquels des mots ont été changés ou ajoutés ou rayés ; 3 articles anciens sont remplacés venant des ch. I et IV; 17 articles anciens sont rayés, signalés dans le titre I mais repris des chapitres: II, IV, XXII, XIII, V, VI. Soit 30 articles sont discutés, 73,17\% du titre, dont 25 accordés ; 11 ne sont pas mentionnés.

II de fiefs, 41 articles : 8 mis au lieu de; 9 nouvel introduits; 5 avec mots ajoutés, remplacés ou rayés ; 1 article ancien abrogé du ch. XXIII. Soit 22 articles sont discutés et accordés, 53,66 \% ; 19 non mentionnés.

III de censives et droits seigneuriaux, 17 articles : 3 mis au lieu de ; 1 demeuré ; 1 accordé bien que discordé en $1507 ; 4$ avec des mots ajoutés, remplacés ou rayés. Soit 9 articles sont discutés et accordés, 52,94 \% ; 8 non mentionnés.

IV de servitudes, 18 articles : 1 mis au lieu de ; 10 nouvel introduits ; 3 avec des mots ajoutés, remplacés ou rayés. 14 articles discutés et accordés, 77,77 \%; 4 non mentionnés. $V$ de rentes et criées, 16 articles : 3 mis au lieu de ; 2 nouvel introduits ; 6 avec mots ajoutés, remplacés ou rayés. Soit 11 articles discutés et accordés $68,75 \%$; 5 non mentionnés. 
VI de contrats et conventions, 20 articles : 2 mis au lieu de ; 10 nouvel introduits ; 3 avec mots ajoutés, remplacés ou rayés. Soit 15 articles discutés et accordés $75 \%$; 5 non mentionnés.

VII de retrait lignager, 32 articles : 3 mis au lieu de ; 5 nouvel introduits ; 5 avec mots ajoutés, remplacés ou rayés. Soit 13 articles discutés et accordés 40,62\%; 19 non mentionnés.

VIII de prescription, 4 articles : 2 nouvel introduits ; 1 avec mots ajoutés, remplacés ou rayés. Soit 3 articles discutés et accordés ; 1 non mentionné.

IX de communauté de biens, 18 articles: 6 nouvel introduits; 1 avec mots ajoutés, remplacés ou rayés ; 1 article ancien est rayé. Soit 7 articles discutés et accordés $38,88 \%$; 11 non mentionnés.

$X$ de douaires, 9 articles : 7 nouvel introduits ; 1 accordé, dit discordé en 1507 mais rayé par le conseil du roi. Soit 8 articles discutés et accordés $88,88 \%$; 1 non mentionné.

XI des donations, 8 articles : 1 mis au lieu de ; 1 nouvel introduit ; 4 avec mots ajoutés, remplacés ou rayés. Soit 6 articles discutés et accordés $75 \% ; 2$ non mentionnés.

XII de testaments et exécutions d'iceux, 14 articles : 2 mis au lieu de ; 1 accordé bien que discordé en $1507 ; 3$ avec des mots ajoutés, remplacés ou rayés ; 2 articles anciens rayés. Soit 6 articles discutés et accordés $42,86 \% ; 8$ non mentionnés.

XIII de successions et rapports, 15 articles : 2 mis au lieu de; 4 nouvel introduits; 1 accordé bien que discordé en $1507 ; 2$ avec mots ajoutés, remplacés ou rayés ; 1 article ancien abrogé. Soit 9 articles discutés ; accordés $60 \%$ et 6 non mentionnés.

XIV de tutelle et curatelle, 6 articles : 1 nouvel introduit ; 1 avec mots ajoutés, remplacés ou rayés. Soit 2 articles discutés et accordés ; 4 non mentionnés.

$X V$ des usages et pâturages, 13 articles : 1 mis au lieu de ; 3 nouvel introduits ; 2 avec mots ajoutés remplacés ou rayés. Soit 6 articles discutés et accordés $46,15 \%$; non mentionnés.

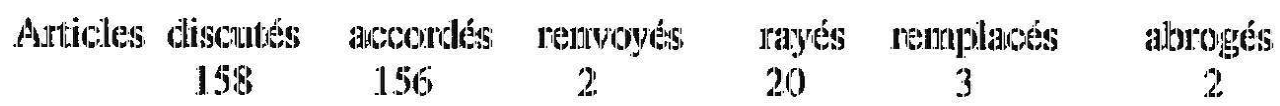

soit 161 articles discutés sur 272. Les modifications portent donc sur $59 \%$ des articles des coutumes.

\section{Les Coutumes de Sens ${ }^{32}$}

\section{La procédure}

Comme à Auxerre, le procès-verbal mentionne les lettres du roi Henri II du 17 août 1555 adressées aux trois commissaires, aux bailli et lieutenant général du bailli, à l'avocat et au procureur de Sens. Ces lettres nomment Christofle de Thou, président en parlement, Barthélemy Faye, conseiller, et Gilles Bourdin, avocat en parlement, à la place de Christophe de Harlay, qui sera présent lors de l'assemblée, au contraire de Bourdin absent. Deux des trois commissaires, de Thou et Faye, réaliseront la réformation des coutumes d'Auxerre. L'assemblée se tient le lundi 4 novembre 1555 dans la grande salle du couvent des Jacobins.

Suit la liste des comparants : premier ordre selon la hiérarchie, les gens d'Église, ces personnages sont particulièrement influents et proches de la cour du roi (comme à Auxerre), notamment le cardinal de Bourbon archevêque de Sens ${ }^{33}$ et le personnel de l'archevêché ; un procureur pour le cardinal de Givry, le personnel de l'église de Langres, le cardinal de Châtillon (supra, note 30, présent à Auxerre), le cardinal Du Bellay ${ }^{34}$, le cardinal de Guise (supra, note 28, présent à Auxerre), tous représentés. Suivent de très 
nombreux membres de l'Église, les noms et qualités des personnes occupent deux pages in folio.

Les membres de la noblesse sont aussi importants, le duc de Lorraine et de $\mathrm{Bar}^{35}$, la duchesse douairière de Guise ${ }^{36}$, le duc de Nevers pair de France (supra, note 31, présent à Auxerre), le duc de Guise pair de France ${ }^{37}$, le duc de Montmorency, pair de France ${ }^{38}$ et connétable, tous représentés par procureurs. L'état de la noblesse occupe également deux pages.

Enfin le tiers état, de nombreux officiers du roi et les habitants des villes sur quatre pages et demi.

70 Comme à Auxerre, la hiérarchie des ordres est respectée, lors de la réformation, Église, noblesse, tiers état comprenant les officiers. Les grands personnages se font représentés, montrant l'importance qu'ils attachent à ces coutumes contenant leurs droits.

En 1555, comme lors de la rédaction, les coutumes sont rédigées par écrit et accordées en l'assemblée des gens des trois états du bailliage en présence des commissaires du roi Henri II. Ce roi ordonne entre 1555 et sa mort de nombreuses rédactions et réformations dans le ressort du parlement de Paris (au moins huit), comme Louis XII pendant son règne avait ordonné une quinzaine de rédactions. Deux rois plus persévérants que les autres pour mettre par écrit le droit français de façon clere et evidente, de mettre fin aux abus et de tenir compte de l'évolution du droit.

En 1555, les coutumes réformées de Sens comprennent 24 titres et 286 articles numérotés.

Titre premier, de haute justice et des exploits d'icelle, 1-13 (13 art.)

II de moyenne justice et des exploits d'icelle, 14-17 (4)

III de basse justice et des exploits d'icelle, 18-19 (2)

IV de justice foncière et des exploits d'icelle, 20-23 (4)

$V$ de forfaitures et confiscations, 24-27 (4)

VI de bâtard, 28-31 (4)

VII de retrait lignager, 32-67 (36)

VIII des testaments, institution d'héritier, legs, donation faite en testament et des exécuteurs de testaments, 68-81 (14)

IX des successions, partages et divisions, 82-97 (16)

$X$ des servitudes, 98-107 (10)

XI de donation d'entre-vifs, mutuelle et pour cause de mariage, 108-115 (8)

XII comme on peut acquérir, garder et retenir possession, 116-119 (4)

XIII des rentes foncières, volages et hypothèques, 120-135 (16)

XIV des bourgeoisies et aveux, 136-145 (10)

$X V$ des bois, forêts, usages et pâturages, 146-155 (10)

XVI de bail et garde des enfants mineurs nobles et tutelle des non nobles, 156-161 (6)

XVII de douaire coutumier et préfix, 162-169 (8)

XVIII des assurements, 170-179 (10)

XIX des fiefs et profits féodaux, 180-224 (45)

$X X$ des censives et droits seigneuriaux, 225-244 (20)

XXI des convenances, marchés, ventes, achats, louages, prêts, dépôts et autres contrats, 245-262 (18)

XXII de prescription et laps de temps, 263 (1)

XXIII des rapports qui se doivent faire en partages, 264-271 (8) 
XXIV de compagnie et communauté de biens entre homme et femme mariés et autres personnes, 272-286 (15)

\section{Les contestations}

73 Au niveau du ressort, le cardinal de Givry, évêque, duc de Langres, pair de France, prétend, par la voix de son procureur, que ses duché, comté, baronnies et seigneuries ne sont aucunement du bailliage de Sens, il dépend seulement du ressort du parlement de Paris à cause de sa pairie. Les magistrats des présidiaux ne peuvent pas prétendre que lui et ses officiers dépendent de leur ressort, le procureur du roi rejette la demande, les terres et fiefs de Langres sont du bailliage de Sens depuis plus de mille ans.

Les mêmes oppositions sont présentées par le duc de Nemours ${ }^{39}$ et Anne de Pisseleu, duchesse d'Étampes ${ }^{40}$, qui se dit sous la coutume de Loris, comme le seigneur de Courtenay. Ces difficultés sont réglées par rejets des demandes, tous sont du ressort du bailliage de Sens, la politique royale exprimée par le procureur est constante, la personne peut avoir un privilège, pour ses terres, elle dépend de la coutume.

Sont ensuite mentionnées, les coutumes locales de la ville de Sens, trois articles, celles de Langres et comté de Mont-Saulion, cinq articles. Sont pris en compte également, un article qui concerne les Successions à la requête du cardinal de Givry, évêque duc de Langres et un second du même titre à la requête du chapitre de Langres, les deux requérants arguent qu'il s'agit d'articles de coutumes locales de ce lieu.

Après la fixation du ressort, le roi confirme les commissaires Christofle de Thou, Christophe de Harlay et Barthélemy Faye. Le lendemain a lieu la lecture et la publication des articles de la coutume, sur le cayer du Coustumier imprimé de 1552, il s'agit d'un document préparé pour la réformation et non de la publication de 1506.

Ensuite, les titres et articles sont examinés par l'assemblée.

Modifications apportées aux:

Titre premier de haute justice et des exploits d'icelle 13 art. (1555) au lieu de 11 (1506) : 2 art. maintenus (art. 1 pour préservation des droits du roi ; art. 9 malgré objections). 4 renvoyés à la cour (art. 2 contestation entre les seigneurs et le procureur du roi ; art. 3 opposition, pour préservation des droits du roi; art. 5 mais appliqué par provision; art. 10 opposition des seigneurs sur les droits du roi). 1 art. avec des ajouts de mots pour précision. 1 art. modifié avec l'accord de tous. 1 art. corrigé pour précision. 2 art. nouveaux. Soit 11 articles sont discutés dont 4 sont renvoyés soit $84,61 \% ; 2$ non mentionnés.

II de moyenne justice et des exploits d'icelle 4 art. et 4 art.: 1 renvoyé (art. 14 contestation entre les seigneurs, gardé dans la coutume). 1 avec ajout de mots. 1 accordé (art. 17 après protestation du procureur du roi et du prévôt) 3 articles discutés dont 1 renvoyé ; 1 non mentionné.

III de basse justice et des exploits d'icelle 2 art. et 2 art. : 1 avec ajout de mots. 1 avec un mot rayé. 2 articles discutés.

$I V$ de justice foncière et des exploits d'icelle 4 art. au lieu de 5 art.: 1 maintenu. 2 renvoyés (art. 20 et 21 nouveaux pour opposition sur les attributions) 1 rayé (art. 21 ancien compté rayé malgré le renvoi) 3 discutés, dont 2 renvoyés ; 1 non mentionné. $V$ des forfaitures et confiscations 4 art. et 4 art. : 1 renvoyé, 1 réformé. 2 articles discutés dont 1 renvoyé, soit $50 \% ; 2$ non mentionnés. 
VI des bâtards 4 art. et 4 art.: 1 maintenu malgré opposition de l'évêque de Langres, 1 renvoyé, 1 ajout dans l'article non contesté. 3 articles discutés dont 1 renvoyé ; 1 non mentionné.

VII de retrait lignager 36 art. au lieu de 26 art. : 26 anciens rayés, 36 articles nouveaux rédigés sur avis des états soit $100 \%$.

VIII nouveau / $\mathbf{X}$ ancien des testaments, institutions d'héritiers, legs, donations faites en testament et des exécuteurs de testaments 14 art. et 14 art.: 1 renvoyé avec mots remplacés (art. 79 le tiers état et la noblesse s'opposent à l'Église) 3 réformés avec avis des états. 4 art. avec ajout dans l'article (art. 71 pour précision afin d'éviter les fraudes; art. 72 ajout et retrait de mots pour précision; 75 pour précision; 80) 8 articles discutés dont 1 renvoyé soit $57,14 \%$; 6 non mentionnés.

L'ancien article 61 est dit rayé, cet article est repris du chapitre VIII successions devenu IX, qui compte un article de moins en 1555. Ainsi le titre testaments comprend le même nombre d'articles et le titre suivant ne mentionne aucun article rayé, puisque reprenant 16 articles au lieu de 17.

IX nouveau / VIII ancien des successions, partages et divisions 16 art. au lieu de 17 : 1 renvoyé (art. 87 malgré ajout de mots sur une contestation de chanoines) 6 réformés. 6 avec ajout de mots (art. 82 et mots rayés ; 84 pour précision ; 85 pour précision ; 86 pour précision ; 89 pour précision ; 94 pour précision). 13 discutés dont 1 renvoyé soit $81,25 \%$; 3 non mentionnés.

$\boldsymbol{X}$ nouveau / IX ancien des servitudes 10 art. au lieu de 7 art. : 2 avec ajout de mots pour précision, 2 nouveaux, 1 avec mots remplacés. 5 discutés; 5 non mentionnés. (8 art. anciens sont repris et non 7)

$X I$ de donation entre vifs, mutuelle et pour cause de mariage 8 art. et 8 art. : 2 réformés. 1 rédigé (art. 112 nouvelle rédaction sur intervention du procureur du roi, pour accorder l'avis de tous) 2 avec ajout de mots pour précision, 1 art. ancien rayé (car pourvu par ordonnance) 1 nouveau. 6 art. discutés soit $75 \% ; 2$ non mentionnés

XII comme on peut acquérir, garder et retenir possession 4 art. et 4 art : 1 avec ajout de mots. 3 non mentionnés.

XIII des rentes foncières, volages et hypothèques 16 art. au lieu de 15 art. : 1 maintenu (art. 133 malgré les protestations des archevêques et des chapitres de Sens et Langres) 1 nouveau (art. 134 sur demande des précédents) 3 réformés. 4 avec ajout de mots pour précision. 9 discutés soit $56,25 \%$; 7 non mentionnés

XIV des bourgeoisies et aveux 10 art. et 10 art. : les 10 art. nouveaux sont renvoyés à la cour (sur opposition des 3 états au droit dû au roi). $100 \%$.

$X V$ des bois, forêts, usages et pâturages 10 art. au lieu de 9 art. : 1 réformé, 2 avec ajout de mots (art. 147 et 152 pour précision. 1 maintenu avec ajout de mots (art. 146 : malgré l'opposition des villes qui sont déboutées). 1 nouveau. 5 discutés ; 5 non mentionnés XVI de bail et garde d'enfants mineurs nobles et tutelle des non nobles 6 art. au lieu de 9 art. : 1 réformé (art. 156 et maintenu malgré protestation) 2 avec ajout de mots (art. 158 et changement pour précision, 160) 2 anciens rayés. 3 discutés ; 3 non mentionnés

149 ancien est repris au titre suivant donc il n'est pas signalé rayé, expliquant qu'il y ait trois articles en moins dans ce titre et seulement deux rayés.

XVII de douaire coutumier et préfix 8 art. au lieu de 9 art. : 1 réformé (art. 167 reprenant les art. 154 et 155 anciens) 2 avec ajout de mots pour précision. 3 discutés soit 37,5\%, 5 non mentionnés.

Un seul article reprend deux anciens, donc aucun n'est signalé rayé, bien que le titre ait perdu un article. 
XVIII des assurements 10 art. et 10 art. : 1 réformé. 9 non mentionnés.

XIX des fiefs et profits féodaux 45 art. au lieu de 52 art. : 1 maintenu (art. 202 sur avis des états, malgré des remarques) 7 réformés, 3 avec ajout de mots pour précision dont 1 avec ajout et retrait, 2 avec mots remplacés, 3 avec des mots rayés dans les articles, 5 anciens rayés sur avis des états, 1 nouveau. 17 discutés soit 37,77 \% ; 28 non mentionnés.

Seulement 5 articles sont signalés rayés au lieu de 7, car les articles 219 et 220 sont repris au titre suivant.

$X X$ des censives et droits seigneuriaux 20 art. au lieu de 24 art. : 1 renvoyé à la cour (art. 225 ajout et retrait de mots, opposition du procureur sur des remarques de plusieurs lieux) 1 réformé, 4 avec ajout dans les articles dont 2 avec également remplacement de mots ou de chiffres, 1 avec mots rayés, 3 anciens rayés, 1 nouveau. 8 discutés soit $40 \% ; 12$ non mentionnés. Seulement 3 art. sont signalés rayés au lieu de quatre et 1 nouveau, le nombre d'articles du titre 20 s'explique par la non reprise de quatre articles anciens mentionnés sous le titre Contrats.

XXI des convenances, marchés, ventes, achats, louages, prêts, dépôts et autres contrats 18 art. au lieu de 14 art. : 1 réformé, 2 avec ajout de mots (art. 246 puis radiation du reste, 259 pour précision et mots changés) 3 avec mots remplacés, 1 ancien rayé, 5 nouveaux. 11 articles discutés soit $61,11 \% ; 7$ non mentionnés. Le décalage des numéros d'articles persiste, mais le nombre d'articles repris est correct à savoir 14 .

XXII de prescription et laps de temps 1 art. au lieu de 2 art. : 1 maintenu, 1 ancien rayé.

XXIII des rapports qui se doivent faire en partages 8 art. et 8 art. : 1 réformé. 2 avec ajout de mots (art. 270 à la fin, 271 pour précision) 1 avec mots remplacés. 4 discutés ; 4 non mentionnés.

XXIV de compagnie et communauté de biens entre homme et femme mariés et autres personnes 15 art. et 15 art. : 1 réformé, 5 avec ajout de mots pour précision, 1 avec mots remplacés. 7 discutés soit $46,66 \% ; 8$ non mentionnés.

$\begin{array}{cccc}\text { Articles : discutés } & \text { accordés } & \text { renvoyés } & \text { rayés } \\ 172 & 150 & 22 & 4.4\end{array}$

Soit 172 articles sur 286. Les modifications portent sur $64,33 \%$ des articles de la coutume.

Exemple d'article réformé, signifiant réécrit entièrement.

VIII testament, article 81 de 1506 :

Toute personne franche aagée suffisamment peut faire testament et par iceluy disposer à son plaisir de tous ses meubles, conquests, immeubles et de la quinte partie de ses propres héritages.

devient l'article 68 de 1555 :

Toute franche personne aagée, à sçavoir le masle de 20 ans, la femelle de 18 peut faire testament et par iceluy disposer à son plaisir de tous ses biens meubles, conquests et acquests, immeubles et de la quinte partie de ses propres, et où ils n'auront que meubles, n'en pourront disposer que de la quarte partie.

\section{Les coutumes de Touraine ${ }^{41}$}

\section{La procédure}

Les nouvelles coutumes sont accordées et mises par écrit en une assemblée des gens des trois états du bailliage en présence de maître Christofle de Thou, président au Parlement, Barthélemy Faye et Jacques Viole, conseillers du roi au Parlement. Ils sont nommés 
commissaires pour procéder à la réformation de la coutume rédigée en 1507, en exécution de lettres patentes données à Paris par Henri II le 12 février 1558 et, celui-ci étant décédé, par son fils François II le 24 juillet 1559.

Le dimanche 8 octobre 1559, Christofle de Thou ${ }^{42}$, Barthélemy Faye et Jacques Viole arrivent à Tours pour procéder à la réformation des coutumes du duché et bailliage de Touraine, suivant les lettres patentes du roi, ces mêmes commissaires se retrouveront à la réformation de la coutume d'Auxerre. Le lendemain, ils se transportent au Palais-Royal de la ville et non plus à l'hôtel de ville, comme en 1507. En fait, il s'agissait du même bâtiment dont les deux salles étaient séparées par une grande porte de communication. Deux différences notables apparaissent par rapport à la convocation de 1507, l'assemblée est beaucoup plus importante, le bas clergé, la petite noblesse, la bourgeoisie et les communautés sont mieux représentés: la hiérarchie sociale est respectée dans la comparution des trois ordres. L'état ecclésiastique conserve sa primauté devant celui de la noblesse, suivi des officiers royaux, puis du tiers état. Parmi les membres de l'assemblée venus prêter serment, en personne ou représentés, Simon de Maillé, archevêque, seigneur baron du palais épiscopal de Tours, le cardinal de Lorraine ${ }^{43}$, abbé de Meremontier, le cardinal de Givry, baron de Châteauneuf, ou encore Antoine de Créquy, archevêque de Nantes, abbé de Saint-Julien de Tours. Pour l'état de la noblesse, comparaissent représentés par procureurs, notamment Louise de Bourbon ${ }^{44}$, duchesse de Montpensier et son fils Louis de Bourbon duc de Montpensier, pair de France pour leurs terres et seigneuries de Champigny sur Voulde, Suzanne de Bourbon pour les terres de Rieux et d'Ancenis, Leonor d'Orléans, duc de Longueville (descendant de Dunois, bâtard d'Orléans), seigneur de Château-Regnault et Diane de Poitiers ${ }^{45}$, duchesse de Valentinois et dame de Chenonceau, Antoine Bohier gouverneur de Touraine ${ }^{46}$ Les officiers du roi et les praticiens du bailliage occupent deux pages du procès-verbal, parmi lesquels, Jean Bourgeau, président au siège présidial de Tours, Adrien Quinart, lieutenant général du bailli de Touraine, Jean Challopin et Jean Falaiseau, avocats du roi et Jean Heudry, procureur du roi. Pour le tiers état, les manants et habitants de Tours sont représentés par leur maire, Laurent Le Blanc, écuyer seigneur de La Vallière et les échevins de la ville, ainsi que les villes d'Amboise, de Chinon, de Loches et autres, tous représentés par des mandataires, souvent des procureurs de fabrique dit fabrice ou fabriciers du dit lieu.

81 Les gens des trois états prêtent serment de rapporter, en conscience, ce qu'ils ont vu et observé des anciennes coutumes du bailliage en ayant seulement égard au bien public. Ils auront à donner leur avis sur ce qu'ils auront trouvé de rigoureux ou de déraisonnable dans celles-ci pour être tempéré, corrigé et abrogé. Enfin le procureur du roi requiert que soit donné défaut contre les gens d'Église, nobles et gens du tiers état défaillants.

Le coutumier est arrêté, lu et publié le vendredi 13 octobre 1559 en présence des commissaires royaux et des officiers du roi au Palais-Royal du bailliage de Touraine. Les séances durent quatre jours et demi. L'enregistrement à la cour du Parlement a lieu le jeudi 19 décembre 1560 .

83 Ces coutumes sont, tant pour les défaillants que pour les comparants, entretenues, gardées et observées pour loi, avec défense de recourir à d'autres coutumes ou aux témoignages par turbe. Lors de la rédaction de la coutume de 1507, les seigneurs qui prétendaient pouvoir bénéficier de certains droits qu'ils détenaient de toute ancienneté présentent à l'assemblée leurs coutumes locales écrites sur un cahier de parchemin pour y être mises et rédigées par écrit et ensuite ajoutées à la coutume générale, mais séparément. De toutes ces coutumes, un seul article commun est extrait et conservé dans 
la réformation de 1559 et la clôt (art. 359), qui concerne les coutumes locales des seigneuries de Mazières, Buzançais, Azay-le-Ferron, La Motte-sur-Indre, Banche, SaintGenou, Saint-Cyran, et de l'Ile Savary.

La coutume de Touraine de 1559 comprend 36 titres et 379 articles numérotés en continu.

Titre premier de basse justice, autrement dit de basse voirie, 38 art., 1-38

II de moyenne justice appelée grande voirie, 13 art., 39-51

III d'épaves mobilières, 3 art., 52-54

IV de haute justice où il n'y a droit de comté, vicomté ou baronnie ou châtellenie, 4 art., 55-58

$V$ des droits de seigneur châtelain, non ayant droit de comté, vicomté ou baronnie, 11 art., 59-69

VI des droits baronnie, 4 art., 70-73

VII des droits de comtes et de leurs droits et prééminences, 7 art., 74-80

VIII des droits de péage et coutume, 7 art., 81-87

IX des loyaux-aides et roucins de service et des gardes dues aux châteaux des seigneurs, 12 art., 88-99

$X$ des droits fautrage et préage, 2 art., 100-101

XI du droit de ban à vin, 1 art., 102

XII du droit d'indemnité, 6 art., 103-108

XIII des hommages et offres qui se doivent par le vassal à son seigneur, 9 art., 109-117

XIV de depié de fief et de parages, 14 art., 118-131

$X V$ des rachats et ventes, 20 art., 132-151

XVI de retraits, 46 art., 152-197

XVII de délaissement et exponces d'héritages, 4 art., 198-201

XVIII des héritages défensables, 6 art., 202-207

XIX des prescriptions, 4 art., 208-211

$X X$ des vues et égouts de maisons et autres servitudes, 2 art., 212-213

XXI de rentes et hypothèques, 7 art., 214-220

XXII des choses réputées meubles ou immeubles, 9 art., 221-229

XXIII de communauté de biens, 3 art., 230-232

XXIV des donations, 25 art., 233-257

$X X V$ des successions entre nobles, fors en baronnie, 36 art., 258-293

XXVI de partage de comté, vicomté et baronnie, 2 art., 294-295

XXVII des successions des gens roturiers coutumiers, 24 art., 296-319

XXVIII de succession de bâtard, 2 art., 320-321

XXIX de testament, 4 art., 322-325

XXX de douaires, 13 art., 326-338

XXXI de bail, 7 art., 339-345

XXXII de tuteurs et curateurs, 5 art., 246-350

XXXIII d'émancipation, 1 art., 351

XXXIV d'assiette de rentes, 12 art., 352-363

$X X X V$ d'amendes, 14 art., 364-377

XXXVI de crimes, 1 art., 378

Coutumes locales, 1 art., 379 


\section{Les contestations}

À l'appel des comparants, quatre protestations sont élevées, au titre du ressort du bailliage. La première émane de l'avocat du roi au bailliage de Blois, qui rappelle que les châtellenies de Château-Regnault et d'Herbault, et la seigneurie de Fougères sont du bailliage de Blois. La seconde vient du bailli d'Amboise, du maire et des échevins de la ville qui déclarent ne pas relever, en tant que sujets et justiciables, du bailli de Touraine et de ses lieutenants. La troisième est produite pour Antoine de Bourbon, roi de Navarre, duc de Vendomois, pour huit de ses terres et seigneuries, qui seraient régies par les coutumes d'Anjou, en raison de son château et de sa baronnie de Laverdin, relevant de son duché de Vendomois. La dernière, présentée par le mandataire d'Anne de Bastarnay, comtesse du Lude, soutient également que ses terres et seigneuries de Rillé et de la Ferriere dépendent de la coutume d'Anjou. Le procureur du roi rappelle qu'un arrêt a été rendu en février 1508, sur un partage de terres selon la coutume de Touraine et, de plus, que les contestataires avaient comparu lors de la rédaction de la coutume de 1507, sans qu'il y ait eu débat ou contradiction sur leur appartenance comme sujets relevant de cette coutume. En conséquence, tous relèvent du ressort du bailliage de Touraine. Cependant, les commissaires royaux ayant des difficultés à trancher ces questions de délimitations de frontières en donnent aux

[...] parties acte pour leur servir ainsi qu'ils verront être à faire pour raison. cahier (la coutume de 1507) les mandataires de l'archevêque de Tours reproduisent les remontrances présentées en 1507 concernant leurs biens. Il leur est répondu à nouveau que leurs biens possédés en Touraine sont de la connaissance des juges royaux et non des ecclésiastiques.

es modifications intervenues dans le texte:

Titre II de moyenne justice, appelée grande voirie, 13 art., 39-51. Le substitut du procureur général du roi proteste sur l'article 41 (ch. II, art. 3 de 1507) concernant les poids et mesures des seigneurs, rendu inutile par l'édit du roi du 13 novembre 1540 déjà promulgué pour réduire le nombre des poids et mesures. L'article est maintenu, mais acte lui est donné.

$V$ des droits du seigneur châtelain non ayant droit de comté, vicomté ou baronnie, 11 art., 59-69. L'article 62 (ch. 5, art. 4 de 1507) maintient au seigneur châtelain le droit de police, ban, cri, proclamation en sa ville, de mettre aune, poids, balance, crochets et innovation, mesures sous réserve d'apporter le cep ou étalon de mesures à l'hôtel de la ville la plus proche, ayant droit de mairie ou de communauté, ou à défaut au juge royal voisin. Cet article provoque de vives remontrances, d'une part, du maire et des échevins de Tours, d'autre part, du portier et garde de la première porte et des prisons du château d'Amboise, et dont il leur est donné acte.

VII des droits des comtes, et de leurs prééminences, 7 art., 74-81. Ce titre nouveau est, sur l'avis des trois ordres, ajouté pour avoir lieu à l'avenir et sans égard pour l'opposition formée par le représentant du seigneur de la Roche-Posay et en partie de la baronnie de Prully, car l'article 79 lui ôte un degré de juridiction.

XV des rachats et ventes, 20 art., 132-151. L'article 147 stipule que le rachat est dû pour vente d'héritage à l'amiable ou chose adjugée par décret, tant du prix principal que du vin de marché pour éviter les fraudes commises. Acte est donné à trois protestations des procureurs du seigneur de Guémené, de Gilles de Commacre, maître d'hôtel ordinaire du 
roi, et de Claude de Laubespine secrétaire d'État et finances du roi, pour leurs terres et seigneuries. Elles sont, cependant, contredites par le sieur Gardette, conseiller au présidial et échevin de la ville de Tours, qui considère que quel que soit l'usage allégué par les seigneurs contestataires, il ne peut être porté préjudice au tiers état, comme étant plutôt usurpation que possession.

XXIV de donations, 25 art., 233-257. Les nouveaux articles 233 à 239 (ch. XXIII art. 1 de 1507) entièrement remaniés rencontrent de fortes oppositions, en particulier du clergé et du conseiller et échevin Gardette, qui considèrent que l'article 233 restreint la possibilité de donner pour des causes pieuses, alors que l'ancien cahier offre la faculté aux roturiers sans enfant de donner à perpétuité tous leurs meubles et acquêts et la tierce partie de leur patrimoine pour ce type de legs.

XXVII de succession de gens roturiers ou coutumiers, 24 art., 296-319. Comme dans la précédente coutume, le principe selon lequel le religieux est mort est confirmé. Il ne peut, noble ou roturier, prétendre à une succession. Acte est donné au frère Antoine de SaintGelais, chevalier de l'ordre de Saint-Jean de Jérusalem. Un arrêt de la cour a jugé que les chevaliers de cet ordre sont admis à succéder à leurs parents pour jouir de leur portion héréditaire à vie. Ce qui contredit, selon le sieur Gardette, l'usage de l'ancienne Coutume. Coutumes locales (art. 379).

Après lecture de la coutume générale, les représentants des seigneurs présentent le cahier des coutumes locales. Le substitut du procureur général du roi et le syndic Gardette pour le tiers état rappellent qu'en 1507, sur avis des états, ces coutumes, considérées comme droits seigneuriaux n'avaient été ni arrêtées, ni publiées comme coutumes. Elles étaient réservées aux seigneurs pour user de tels droits sur leurs sujets qui pouvaient leur appartenir. Il propose même de rayer lesdits articles. Il est ordonné, après avis des états, d'ajouter l'article 379. Mais les autres articles ne sont ni reçus, ni arrêtés, les seigneurs n'ayant pu faire la preuve de leurs droits. Réservant aux seigneurs respectifs de pouvoir user des droits dans lesquels ils se trouvent fondés par aveux dûment vérifiés et autres titres particuliers, ou par jouissance de temps immémorial. Actes sont également donnés au seigneur d'Argis et au seigneur de la Rohaudière.

\section{Mise par écrit - mise en ordre de la rédaction à la réformation}

\section{Le bailliage d'Auxerre}

Se pose le problème du texte de référence repris par les juristes auxerrois, la coutume de 1507 a une numérotation particulière, les spécialistes du droit sont donc amenés à reconstituer les coutumes en enlevant les décisions de renvois. En effet, il est fait lecture d'un certain cayer que les officiers, praticiens et gens des trois états avoient entre eux dressé sur un ancien livre de papier escrit à la main intitulé par ces mots :

Ce sont les coustumes qui ont été rédigées et mises par escrit par les gens des trois états du bailliage d'Auxerre en ensuyvant les lettres patentes du roi, datées du 2 avril avant Pâques 1506 ainsi qu'il est plus amplement contenu au procès-verbal sur ce fait en l'assemblée dernièrement tenue en l'hostel des bourgeois, manans, habitants de la ville d'Auxerre. commissaire) Jean Feroul (avocat du roi) Pierre Gontier (procureur du roi) Crespin 
Prevost (official de l'évêque d'Auxerre) Le Muet et Bourdeau. Le cahier est accepté comme coutumier. de 1507 renumérotés et augmentés.

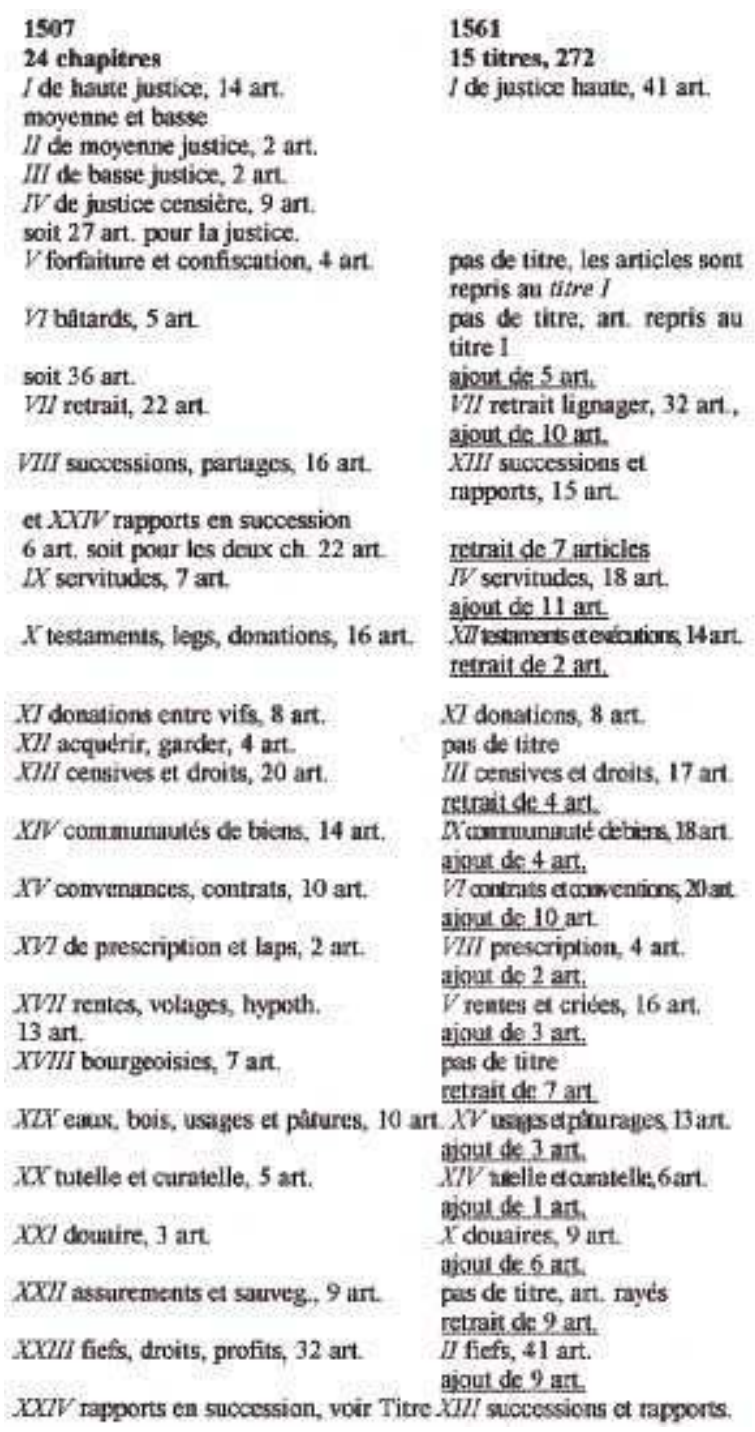

Selon ce tableau, 64 articles auraient été ajoutés et 28 retirés, la coutume de Varzy n'est pas reprise. Soit 276 art., et non les 272 notés dans le texte de 1561.

Donc avant la réformation des coutumes d'Auxerre, il y a une "reformation ", un remaniement formel important, par le retrait d'articles non coutumiers écrits en 1507 dans le corps du texte, par un rassemblement de plusieurs chapitres en un seul titre (ainsi les six premiers chapitres) par un changement de places de chapitres, impliquant un reclassement $\mathrm{du}$ droit (le titre testaments est placé logiquement avant le titre successions, au contraire de 1507) par la suppression de titre et la radiation d'articles (ainsi assurements et sauvegardes). Ce travail est donc accompli avant toute discussion en assemblée, par les juristes qui en effet retirent les articles donnant des explications de renvois et de coutumes locales, dès avant tout reclassement des titres.

Bilan de la réformation reprenant les termes utilisés dans le procès-verbal.

Pour tous les articles modifiés ou ajoutés, il est spécifié : sur avis des états. 
Articles mis au lieu de : 32 articles soit $11,76 \%$.

Nouvel introduits ou ajoutés de nouvel : 39 articles soit 14,39\%.

Rédigés nouveaux : 2 articles.

Articles anciens rayés : 20 articles soit 7,35\%.

Anciens remplacés : 3 articles.

Abrogés : 2 articles.

Renvoyés à la cour : 2 articles.

Articles demeurés (maintenus) malgré opposition : 2 articles.

Discordés en 1507, accordés en 1561 : 4 articles.

Mots ajoutés ou interposés ou remplacés et/ou rayés dans ou à la fin d'un article, pour plus grande explication ou interprétation : 47 articles soit 17,28 \%.

Les transformations intervenues dans la coutume d'Auxerre entre la rédaction de 1507 et la réformation de 1561, se fait, comme à Sens, à partir d'un nouveau document rédigé dans ce but, mais qui se réfère au coutumier de 1507.

1 - La rédaction de 1507 est confiée à un officier du bailliage, aucun commissaire du parlement de Paris n'est envoyé sur place. Rédaction et publication sont réalisées la même année, les lettres de Louis XII sont immédiatement exécutées.

Compte tenu du mode de numérotation des articles en 1507, incluant les explications de renvois, un nouveau cahier est nécessaire qui ne contient que le texte de la coutume générale proprement dit, lors de la réformation.

Les oppositions manifestées lors de la rédaction sont importantes et surtout apparemment non résolues puisqu'il y a renvoi à la cour, mais les articles subsistent.

2 - La réformation bouleverse non seulement la numérotation ancienne, mais aussi l'ordre des chapitres, des titres rassemblent plusieurs chapitres de 1507, ainsi le titre I, qui reprend non seulement tout ce qui concerne les justices, mais aussi les chapitres bâtards, forfaiture, les articles sur assurements y sont mentionnés renvoyés. Seuls deux chapitres disparaissent, d'acquérir et bourgeoisies, celui-ci portant atteinte aux droits du roi.

Des commissaires royaux sont nommés, deux sont les mêmes qu'à Sens, Christofle de Thou et Barthélemy Faye, le troisième est Jean Viole et non plus Christophe de Harlay comme à Sens.

3 - Le vocabulaire indiquant les changements est différent de celui utilisé à Sens, le terme discordé n'est plus utilisé.

Dans les deux cas, les oppositions des uns et des autres, pour obtenir de dépendre d'autres coutumes que celles du bailliage, sont fermement rejetées. Quelle que soit la qualité du demandeur, les procureurs imposent les coutumes générales du bailliage à tous, elle doit être gardée comme loi pour les terres et les personnes du bailliage.

\section{Le bailliage de Sens} titre par titre, selon les décisions prises par les états sur les articles mentionnées au procès-verbal.

La coutume comprend 24 titres comme en 1507 et 286 articles au lieu de 283 articles 


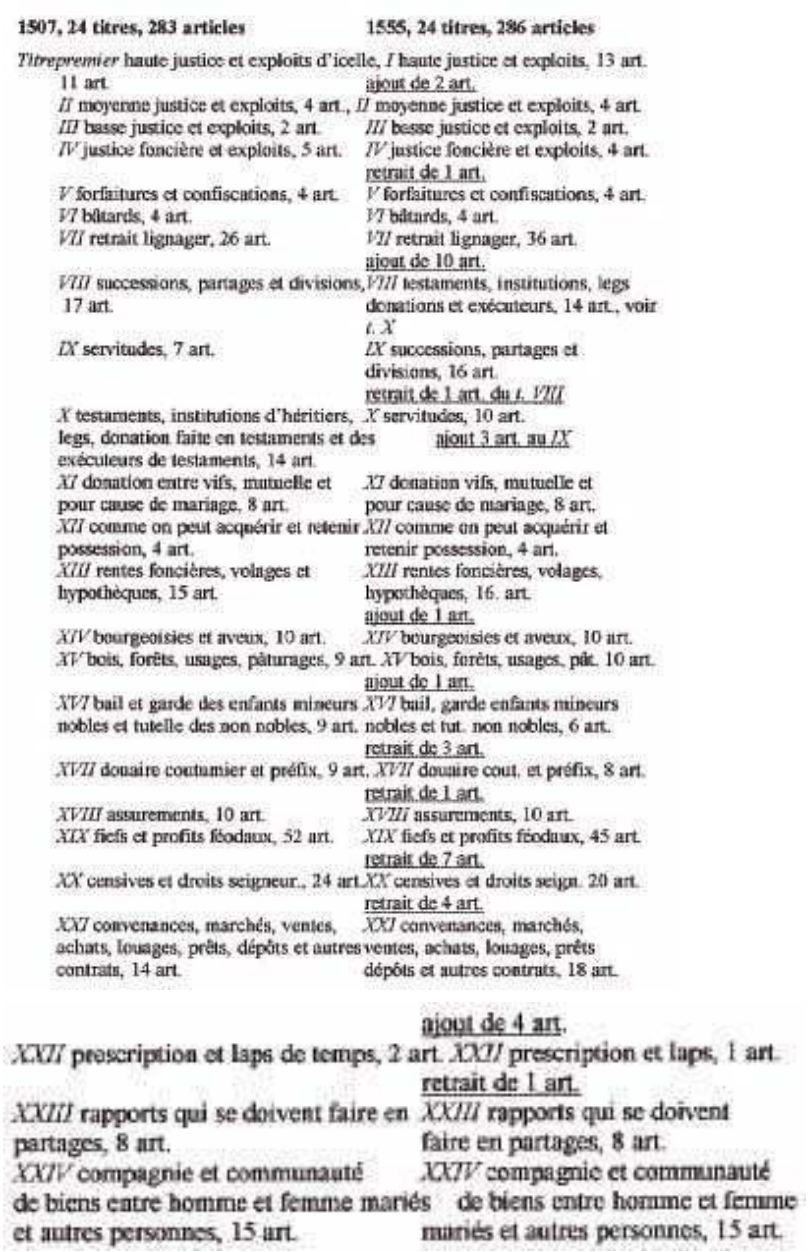

Selon ce tableau, 21 articles ont été ajoutés et 18 retirés, il y a bien 286 articles dans la coutume réformée et non plus 283 comme en 1507.

Bilan de la réformation de 1555 sur 24 titres et 286 articles.

Maintenus : 7 articles, 2,44\%.

Renvoyés à la cour : 22 articles, 7,77 \%.

Réformés (réécrits entièrement) : 31 articles, 10,84\%.

Ajouts de mots dans ou à la fin des articles, pour précision : 46 articles, $16,08 \%$.

Modifié : 1 article.

Corrigé $: 1$ article.

Accordé : 1 article.

Mots rayés dans des articles : 5 articles, $1,74 \%$.

Mots remplacés dans des articles : 8 articles, $2,8 \%$.

Anciens rayés : 44 articles, $15,28 \%$.

Nouveaux : 50 articles, $17,48 \%$.

Non mentionnés : 108 articles, $37,76 \%$.

Relevé des oppositions manifestées dans l'assemblée :

Le procès-verbal de Sens est beaucoup moins explicite que celui d'Auxerre sur les interventions de l'assemblée, le plus souvent les décisions, telles que ajouts de mots, rayés ou maintenus sont indiquées sans spécifier les qualités des intervenants demandeurs ou opposants. 
Décisions en faveur de la préservation des droits du roi malgré des objections de l'assemblée : 14 art.

Contestation entre les seigneurs et le procureur du roi : 1 art.

Contestation entre les seigneurs : 1 art.

Accordés après protestation du procureur du roi : 2 art.

Oppositions sur les attributions et renvois : 2 art.

Maintenus malgré l'opposition du clergé : 3 art.

Renvoi pour contestation de chanoines : 1 art.

Renvoi pour opposition tiers état et noblesse contre l'Église : 1 art.

Maintenu malgré l'opposition des villes : 1 art.

Tous les articles examinés sont changés ou accordés avec l'avis des trois états, en clair, cela signifie que les membres présents sur assignation, intimation royale, sont mis en obligation de respecter les coutumes, puisqu'ils ont donné avis unanime, spécifié dans le procès-verbal, c'est une procédure obligatoire et contraignante inscrite dans les ordonnances royales. Nul ne peut désormais ignorer la loi, réclamer un droit non inclus, mettre en question ce qui a été résolu à l'assemblée.

Dans le procès-verbal, les coutumes de Langres sont ensuite examinées, elles contiennent 7 articles qui sont tous discutés et donnent lieu à des décisions différentes. Concernant les trois premiers, le représentant du cardinal de Givry nie que ces articles soient dans la coutume, mais il accepte qu'ils soient observés comme coutume nouvelle; les habitants disent que c'est la coutume locale et ancienne. Quant aux articles 4 et 5, le même représentant les refuse, car sur ces points, la coutume générale a toujours été observée. Les articles 6 et 7 sont renvoyés au Parlement avec jouissance par provision, pour le reste la coutume générale sera observée.

Les états contestent l'existence d'une coutume locale de Tonnerre, la coutume générale y a toujours été observée, donc les articles apportés par le représentant de Jacques Du Bellay, soi-disant comte de Tonnerre, ne sont pas enregistrés, la coutume générale sera observée.

Le cardinal Charles de Bourbon s'oppose aux états et au procureur du roi sur la coutume locale de la ville de Sens. Trois articles sont rédigés pour le maintien des privilèges accordés et confirmés à la ville de Sens par les rois et l'intégration dans la coutume est demandée pour que nul ne les ruyne, à savoir : droit des habitants de tenir fief noble sans verser de redevance - juridiction sur les biens des débiteurs forains situés dans la ville. Le procureur du roi reconnaît l'existence de ces privilèges de la ville de Sens pour l'article 1 er tenir fief, les deux autres articles sont contestés par le représentant du cardinal de Bourbon et les autres présents de la noblesse. Les habitants pourront jouir de l'article $1^{\text {er }}$ non contredit, les articles 2 et 3 (juridiction sur les biens forains) sont renvoyés au Parlement, les parties en jouiront cependant comme auparavant. Les trois commissaires signent le procès-verbal.

102 Les transformations intervenues au bailliage de Sens entre la publication de 1507 et la réformation de 1555, se font à partir d'un cahier imprimé en 1552. Les coutumes rédigées en 1495 sont intitulées :

Cahier des articles prétendus estre de l'ancienne coustume du bailliage de Sens mis au greffe du Parlement par les commissaires en 1555, pour préserver les droits acquis avant la réformation. 

1497 avant Pâques). demander la réformation. sous le titre servitudes. trouve au titre XIII rentes. mentionné est le 276 et non le 283.

L'ordre de Charles VIII de mars 1495 pour la rédaction est donné à et transmis par le lieutenant général du bailli de Sens selon la procédure habituelle. La rédaction est faite en présence des trois états. Il n'y a donc pas de commissaire issu du parlement de Paris lors de cette rédaction, mais un officier royal du bailliage, François Boucher.

Dans les lettres de Charles VIII de septembre 1497 pour la publication, il y a des commissaires nommés, membres du parlement de Paris. Les trois commissaires ne peuvent se déplacer à ce moment. La mort de Charles VIII intervient le 7 avril 1498 (alors

Les commissaires reçoivent de nouvelles lettres de Louis XII, du 23 mai 1506, adressées à Thibaut Baillet, Guillaume de Besançon, en effet on n'exécute pas les lettres d'un roi défunt, qui donnerait ainsi des ordres au roi régnant. Les coutumes sont de nouveau lues mais pas discutées, publiées et enregistrées en octobre 1507. Sous la mention de publication, les commissaires Baillet et Besançon sont présents pour cette lecture, ainsi que le même lieutenant du bailliage Boucher et des membres des trois états, donc en assemblée comme lors de la rédaction. Les dates mentionnées sont 7, 8 et 9 mars 1507, les deux commissaires signent. La perte du procès-verbal de rédaction est invoquée pour

Selon les énoncés du procès-verbal titre par titre, les anciens numéros d'articles de 1507 renumérotés nouvellement pour la réformation de 1555, correspondent effectivement jusqu'au titre VII retrait lignager; dans l'ancienne coutume, il y a 26 articles, dans le procès-verbal de 1555,25 seulement sont repris, rayés et 36 nouveaux sont entièrement rédigés. Le dernier article 56 de retrait lignager est repris au titre IX de 1555 successions, partages et divisions. Le changement de place du titre testaments ne permet plus de faire correspondre exactement les numéros d'articles de la coutume de 1507 avec les numéros dits anciens dans le procès-verbal de 1555. Ainsi l'article 61 du titre successions en 1507 est repris au titre testaments de 1555 et rayé ; le numéro 73 de successions est dit ancien

Ainsi le document repris lors de la réformation dit cayer imprimé de 1552 n'est pas le même que celui de la coutume de 1507. Le titre XII comment acquérir, les articles de 103 à 106 ne sont pas repris, le seul mentionné ancien est le 115, qui dans l'ancienne coutume se

8 Quant au titre XIX fiefs et profits féodaux, qui selon le procès-verbal perd 7 articles lors de la réformation, les numéros anciens 169 à 220 sont repris avec un numéro de décalage à partir de 168, qui dans l'ancienne coutume appartient au titre XVIII assurements et en laissant au titre censives les deux derniers numéros de fiefs 219 et 220 . Donc la réformation reprend en fait 51 articles et non 52,5 sont rayés et un nouveau, donc seulement 4 articles sont enlevés du titre. Le même problème se trouve au titre censives, 3 rayés, 1 nouveau et le dernier article ancien repris est le 240 et non le $244 ; 241$ à 244 apparaissent sous le titre contrats. Au dernier titre communautés, le dernier article

Il est donc difficile de comprendre la réformation en tant que telle, en comparant le document pris en compte avec le texte des coutumes de 1495/1507. Peut-on inférer que le cahier imprimé de 1552 peut être une édition fabriquée par les officiers royaux pour la réformation, qui ne reprendrait pas la totalité des articles de la coutume publiée en 1507, ayant perdu des articles dû à un reclassement différent, plus rigoureux du droit. Il s'agit d'un cahier, il y aurait comme à Auxerre, une « reformation » avant la réformation, mais 
beaucoup moins importante, car la plupart des titres sont identiques et il y eut seulement permutations de titres et déplacements d'articles en conséquence.

Nous constatons que les énoncés et les places des titres sont semblables entre 1507 et 1555, jusqu'au titre VII.

Le titre VIII de 1507 de successions, partages et divisions devient le titre IX de 1555.

Le titre IX de 1507 servitudes devient le titre $X$ de 1555.

Le titre X de 1507 testaments, institutions d'héritiers... devient le titre VIII de 1555.

111 Ainsi les articles repris de l'ancienne coutume sont déplacés avec les titres : en 1555, le titre testaments passe avant le titre successions qui le suit immédiatement. Servitudes passe après successions en 1555 alors qu'il était placé en 1507 entre successions et testaments. Les énoncés des trois titres déplacés sont semblables. À partir du titre XI de donation jusqu'à XXIV de Compagnie et communautés, les places des titres et les énoncés sont semblables.

112 Cette permutation de titre et ce reclassement de testaments puis de successions signifient une plus grande logique chronologique, donc plus de rigueur dans le classement des catégories du droit, sur ce sujet au moins.

113 Les coutumes locales apparaissent en 1555 et non en 1507, les articles sont discutés, il y a pourtant un ancien texte pris en compte, non mentionné lors de la publication de 1507, mais peut-être discuté en 1495 .

114 Le bailliage de Touraine

La mise par écrit de la coutume de 1507, par le classement des rubriques, est l'occasion d'une première rationalisation des domaines relevant du droit privé, du droit public ou du droit pénal, sans omettre la délimitation de l'espace géographique. La réformation de 1559 propose une mise en ordre de ces mêmes matières dans un corpus juridique, qui tend à devenir un droit commun coutumier.

115 Il convient, à présent, par un travail d'analyse formelle, d'étudier l'écriture juridique du cahier de coutume à travers le classement des articles, chapitres, titres, les modifications intervenues dans leur ordre, la terminologie utilisée, les articles ou mots ôtés, rayés, abrogés, ajoutés, corrigés, mis au lieu de, interposés, interprétés, diminués, nouvel introduits pour reprendre le vocabulaire utilisé par les rédacteurs et les réformateurs.

116 Coutume de 1507 - 36 chapitres - 334 articles

Coutume de 1559 - 36 titres - 379 articles

Chapitre premier des droits de basse justice qui est appelée basse voirie, autrement semi droit, $1507: 33$ articles.

Titre premier de basse justice, autrement dite basse voirie, 1559: 38 articles (art. 1 à 38). 5 articles nouvel introduits ou ajoutés -4 art. mis au lieu de -15 art. avec mots ajoutés, rayés, interposés - 14 art. non mentionnés au procès-verbal.

Ch II des droits de la moyenne justice, qui est appelée autrement grande voirie, 1507 : 13 articles.

T II de moyenne justice appelée grande voirie, 1559: 13 articles (art. 39 à 51). 2 art. mis au lieu de -8 art. avec mots ajoutés ou rayés -3 art. non mentionnés.

Ch III d'épaves mobilières, $1507: 3$ articles.

T III d'épaves mobilières, $1559: 3$ articles (art. 52 à 54). 3 articles non mentionnés.

ChIV des droits de haute justice, non ayant-droit de châtellenie ou baronnie, 1507 : 3 articles.

T IV de haute justice, où il n'y a droit de comté, vicomté, baronnie ou châtellenie, 1559: 
4 articles (art. 55 à 58). 1 art. nouvel introduit - 1 art. avec mots ajoutés -2 art. non mentionnés.

Ch $V$ des droits de seigneur châtelain, $1507: 11$ articles.

$T V$ des droits de seigneur châtelain, non ayant droit de comté, vicomté ou baronnie, 1559: 11 articles (art. 59 à 69). 2 art. avec mots mis au lieu de-2 art. avec mots ajoutés -7 art. non mentionnés.

Ch VI des droits de baronnie, $1507: 4$ articles.

$T$ VI des droits de baronnie, 1559: 4 articles (art. 70 à 73). 1 art. mis au lieu de et corrigé - 2 art. avec mots ajoutés et rayés - 1 art. non mentionné.

$T$ VII des droits des comtes et de leurs droits et prééminences, 1559: 7 articles (art. 74 à 80). 1 titre nouveau et 7 articles nouvel introduits.

Ch VII des droits de péages et coutumes, $1507: 7$ articles.

$T$ VIII des droits de péage et coutume, 1559: 7 articles (art. 81 à 87). 4 art. avec mots ajoutés ou interposés - 3 art. non mentionnés.

Ch VIII des loyaux aides et roucins de services, des gardes dues aux châteaux des seigneurs et la manière et comment ils doivent être faits et levés, 1507 : 7 articles.

$T$ IX des loyaux-aides et roucins de service et des gardes dues aux châteaux des seigneurs, 1559 : 12 articles (art. 88 à 99). 5 art. avec mots ajoutés - 7 art. non mentionnés.

Ch IX des droits de fautrage et préage, $1507: 2$ articles.

$T X$ des droits de fautrage et préage, 1559: 2 articles (art. 100 et 101). 2 art. avec mots ajoutés.

Ch X banc à vin, $1507: 1$ article.

$T$ XI du droit de ban à vin, 1559: 1 article (art. 102). 1 art. avec mots interposés.

Ch XI d'indemnité et d'injonction, $1507: 5$ articles.

T XII du droit d'indemnité, 1559: 6 articles (art. 103 à 108). 1 nouvel article ajouté - 1 art. avec mots ajoutés -4 art. non mentionnés.

Ch XII comment hommage se doit offrir à son seigneur, $1507: 5$ articles.

$T$ XIII des hommages et offres qui se doivent faire par le vassal à son seigneur, 1559: 9 articles (art. 109 à 117). 1 art. avec mots mis au lieu de -5 art. avec mots ajoutés ou interposés -3 art. inscrits viennent du titre XIV suivant.

Ch XIII de depié de fief et de parages, $1507: 17$ articles.

$T$ XIV de depié de fief et de parages, 1559: 14 articles (art. 118 à 131). 3 art. rayés mais réintroduits -2 art. nouvel introduits -1 mis au lieu de -4 art. avec mots ajoutés -7 art. non mentionnés.

Ch XIV des rachats et ventes, 19 articles.

$T X V$ des rachats et ventes, 1559 : 20 articles (art. 132 à 151). 1 art. nouvel ajouté - 1 art. corrigé - 12 art. avec mots ajoutés et interposés - 5 non mentionnés.

Ch XV de retraits lignagers, $1507: 40$ articles.

$T$ XVI de retraits, 1559: 46 articles (art. 152 à 197). 1 art. rayé - 6 art. nouvel ajoutés ou introduits - 1 art. corrigé et réformé, 5 art. mis au lieu de - 22 art. avec des mots ajoutés ou interposés - 12 non mentionnés.

Ch XVI quittances et exponces d'héritages, $1507: 2$ articles.

$T$ XVII de délaissement et exponces d'héritages, 1559: 4 articles (art. 198 à 201). 2 art. nouvel introduits -1 art. mis au lieu de -1 art. non mentionné.

Ch XVII d'héritages défensables, $1507: 6$ articles.

$T$ XVIII des héritages défensables, 1559: 6 articles (art. 202 à 207). 1 art. rayé -2 art. mis au lieu d'1 - 1 art. avec mots ajoutés - 3 non mentionnés. 
Ch XVIII prescription en coutume, $1507: 4$ articles.

T XIX des prescriptions, 1559: 4 articles (art. 208 à 211). 1 art. corrigé - 2 art. avec mots ajoutés ou interposés - 1 art. non mentionné.

Ch XIX des vues et égouts de maisons, gouttières et latrines, $1507: 2$ articles.

$T X X$ des vues et égouts de maison et autres servitudes, 1559: 2 articles (art. 212 et 213). 2 art. avec mots ajoutés.

Ch XX des hypothèques, et comment elles se divisent, et comment on se peut faire payer de ses dettes et rentes par assiette ou autrement, d'interruption contre acquéreurs lesquels sont à préférer, et lesquels viennent à contribution, $1507: 3$ articles.

$T$ XXI des rentes et hypothèques, 1559: 7 articles (art. 214 à 220). 3 art. nouvel introduits -3 art. mis au lieu de -1 non mentionné.

Ch XXI des choses réputées meubles ou héritages, $1507: 5$ articles.

$T$ XXII des choses réputées meubles ou immeubles, 1559 : 9 articles (art. 221 à 229). 4 art. nouvel introduit -2 art. mis au lieu de -3 art. avec mots ajoutés.

Ch XXII de communauté de biens, $1507: 2$ articles.

TXXIII de communauté de biens, 1559: 3 articles (art.230 à 232). 1 art. nouvel ajouté -1 art. corrigé - 1 art. mis au lieu de.

Ch XXIII des donations faites entre gens roturiers.

Ch XXIV des donations entre nobles, $1507: 20$ articles.

TXXIV des donations, 1559: 25 articles (art. 233 à 257). 15 art. accordés et mis au lieu - 1 nouvel ajouté - 1 art. avec mots ajoutés -8 art. non mentionnés.

Ch XXV successions de fief et autres héritages entre nobles, fors de baronnie, 1507 : 23 articles.

$T$ XXV des successions entre nobles, fors de baronnie, 1559 : 36 articles (art. 258 à 293). 13 art. nouvel introduits dont 1 interprétatif -5 art. mis au lieu de et corrigés -11 art. avec mots ajoutés ou rayés, pour avoir lieu dans l'avenir, sans préjudice des droits acquis et des procès intentés -7 art. non mentionnés.

Ch XXVI comment baronnie doit être départie, $1507: 3$ articles.

T XXVI de partage de comté, vicomté et baronnie, 1559: 2 articles (art. 294 et 295). 2 art. mis au lieu de $3-1$ art. abrogé.

Ch XXVII des successions des gens roturiers ou coutumiers, $1507: 27$ articles.

$T$ XXVII des successions des gens roturiers ou coutumiers, 1559: 24 articles (art. 296 à 319). 3 art. rayés mais réintroduits -6 art. mis au lieu de, accordés pour l'avenir sans préjudice du passé - 10 art. avec mots ajoutés ou interposés - 8 non mentionnés.

Ch XXVIII de succession de bâtard, $1507: 1$ article.

TXXVIII de succession de bâtard, 1559: 2 articles (art. 320 et 321). 1 art. nouvel introduit -1 art. non mentionné.

T XXIX de testament, 1559: 4 articles (art. 322 à 325). 1 nouveau titre -4 nouvelles rubriques pour avoir lieu à l'avenir.

Ch XXIX de douaire de femme noble.

Ch XXX douaire entre roturiers, $1507: 11$ articles.

$T X X X$ de douaires, 1559: 13 articles (art. 326 à 338). 1 art. abrogé -1 art. nouvel introduit -2 art. mis au lieu de -4 art. avec mots ajoutés ou interposés -5 art. non mentionnés.

Ch XXXI de bail, $1507: 8$ articles.

T XXXI de bail, $1559: 7$ articles (art. 339 à 345). 2 art. rayés - 1 art. nouvel ajouté -1 art. mis au lieu de -1 art. avec mots ajoutés -5 art. non mentionnés. 
Ch XXXII de tuteurs et curateurs, $1507: 3$ articles.

$T$ XXXII de tuteurs et curateurs, 1559: 5 articles (art. 346 à 350). 2 art. nouvel ajoutés -3 art. avec mots ajoutés.

Ch XXXIII d'émancipation, $1507: 1$ article.

T XXXIII d'émancipation, 1559:1 article (art. 351). 1 art. mis au lieu de.

Ch XXXIV comme l'on doit bailler rentes par assiette, $1507: 12$ articles.

$T$ XXXIV d'assiette de rentes, 1559: 12 articles (art. 352 à 363) non mentionnés.

Ch XXXV amendes, $1507: 23$ articles.

TXXXV d'amendes, 1559: 14 articles (art. 364 à 377). 10 art. rayés -1 art. nouvel ajouté -1 art. avec mots mis au lieu de -2 art. avec mots ajoutés -10 art. non mentionnés.

Ch XXXVI crimes, $1507: 8$ articles.

T XXXVI de crimes, 1559: 1 article (art. 378). 7 art. rayés - 1 art. corrigé.

Coutumes locales art. 379 de la coutume de 1559. 1 art. nouvel introduit.

Il ressort de cette analyse que :

- 29 articles de l'ancien cahier sont rayés ou abrogés, parmi lesquels 7 articles du titre de crimes. Il faut cependant prendre en compte les articles remaniés qui se retrouvent dans un autre titre (titre 13, 24, 25, ou 27) et 10 articles au titre amendes.

- 58 articles sont nouvel introduits ou ajoutés, en particulier sous les rubriques de la justice seigneuriale, du retrait, des donations, des successions et testaments,

- 7 articles sont remis à la discrétion des juges pour en juger en leur conscience selon les ordonnances du Roi et la raison écrite ${ }^{47}$.

- 59 articles sont accordés et mis au lieu de (ce qui est déjà l'action de mettre dans une situation nouvelle, de mettre en ordre), corrigés ou réformés dont 6 au titre de retrait, 15 à donation et 11 à successions.

- 8 articles sont maintenus malgré des oppositions, que nous avons examinées au chapitre des contestations.

- 118 articles contiennent des mots rayés, ajoutés, interposés, dans le corps ou en fin d'article, pour donner une plus grande explication et intelligibilité.

- 129 articles ne sont pas mentionnés au procès-verbal de réformation, alors que, dans le texte de la coutume des modifications apparaissent, parfois substantielles. Les réformateurs ont réduit les droits du moyen justicier en matière criminelle, par substitution et corrections essentielles sans la moindre mention sur le procès-verbal.

Des substitutions de mots comme banier plus en usage que celui de banquier ou le remplacement du mot sujet par justiciable ou de seigneur suzerain, au lieu de juge supérieur marquent bien que la banalité est un droit de fief et celui de contrainte un droit de justice foncière, inséparable du fief. La substitution requiert l'avis de l'assemblée (titre I - 1559). Des synonymes, comme larron pour voleur sont supprimés et il est apporté plus de précision dans les définitions (titre III). Le mot délaissement est mis au lieu de celui de quittances, parce qu'il est plus précis (titre XVII). La coutume réformée répare l'erreur figurant dans la précédente qui inscrivit le banc à vin quand il s'agissait de l'exercice du droit de banvin (titre XI). Également, au titre XVI de retraits, nombreuses additions et corrections de forme sont apportées pour clarifier un sujet extrêmement complexe. Le mot possession, emprunté au droit romain, remplace le mot ensaisinement; celui d'ajournement en retrait se substitue à celui de clam ou clain (réclamation en justice). Aux articles 224, 225 (articles 4 et 5/1907), immeubles se substitue à héritages. 
118 Cette coutume réformée comporte 45 articles supplémentaires, un grand nombre d'additions aux articles issus de l'ancienne coutume, des radiations de certains mots, et des titres qui se substituent aux anciens chapitres. En 1507, la coutume comportait autant de séries de numéros qu'il y avait de chapitres. La grande innovation est la numérotation des articles en continu, toujours utilisée dans notre codification moderne. Mais la disposition générale du texte de la coutume est restée identique : les chapitres en 1507 sont devenus les titres en 1559. Leur nombre également est demeuré à trente-six. Mais cette ré-écriture est aussi un remaniement, un reclassement, une reformulation et des novations.

Deux titres entièrement nouveaux ont été introduits : le titre VII sur les droits des comtes et le titre XXIX sur les testaments. Ce dernier n'apparaît que dans la réformation de 1559 . Auparavant s'appliquait le droit commun pour la forme et la validité des testaments et la coutume relative aux donations pour ce qu'il était permis de disposer. Par ailleurs, l'ancien chapitre XXIII sur les donations entre roturiers et l'ancien chapitre XXIV sur les donations entre nobles ont fusionné en un seul titre des donations, avec cinq articles complémentaires. Il en est de même pour l'ancien chapitre XXIX sur le douaire des femmes nobles et l'ancien chapitre XXX sur le douaire entre roturières qui sont réunis sous le seul titre XXX de douaires. Des règles générales vont s'appliquer aux deux espèces de douaires. Ce qui explique que, malgré deux nouveaux titres, on se retrouve avec le même nombre de rubriques. L'écrit coutumier imprimé construit sa propre logique juridique.

L'ordre des articles est fortement bousculé pour un certain nombre de titres, en général pour donner plus de précision, de clarté et également plus de concision et de méthode à l'ensemble de la rubrique (au titre IX, les articles 10 et 12 du chapitre des loyaux aides passent avant l'article 9 ; au titre XIII des articles du chapitre de depié de fief sont inscrits dans le titre consacré aux hommages au seigneur ; de même au titre XXIV des donations). Les dispositions relatives à la garde du mineur noble et de ses biens féodaux subissent de nombreuses modifications proposées par la commission préparatoire à l'assemblée des trois états. À commencer par le changement de l'ordre des articles (titre XXXI de bail).

Au titre premier, le mot semi-droit a été rayé, car il avait le même sens que droit de basse justice et il n'était plus en usage. L'introduction du titre VII sur les droits des Comtes a entraîné l'apparition des mots comté et vicomté aux titres IV, V et XXVI, les droits dont bénéficient les autres seigneurs s'appliquant aux fiefs supérieurs. L'assemblée des trois états a redéfini les droits du seigneur châtelain qui est au-dessus du seigneur justicier. Il peut bannir de sa terre et il a des droits élargis. L'article 62 de 1559 apporte d'importantes corrections. L'importance des mots ajoutés aux différents articles, qui fixent les privilèges et les pouvoirs, explique les oppositions rencontrées. Au titre XII d'indemnité, le mot injonction a été supprimé, car il s'agissait de l'ordonnance faite par le seigneur justicier aux communautés religieuses de payer pour les biens acquis dans le ressort de la justice du seigneur depuis moins de quarante ans, et que la coutume ne traite plus. Au titre XIX des prescriptions, les mots en coutume ont été supprimés du titre, or la prescription traitée est bien coutumière, puisqu'elle se prescrit par cinq ans, à la différence des prescriptions de droit écrit (dix, vingt, trente ans) ou de droit canonique (quarante ou cent ans). Le titre XXV des successions souligne l'effort particulier de l'assemblée des trois ordres pour clarifier une matière qui donne lieu à de nombreux litiges.

Les simples ajouts, inversions, substitutions ou radiations de mots apportent en général une meilleure compréhension ou rendent compte d'une évidence. Ainsi le remplacement, dans le titre XX des vues et égouts de maisons, et autres servitudes, des termes autres 
servitudes, par ceux de latrines, mentionnés au chapitre 19 de l'ancien cahier ou encore dans les articles 3/1507-5/1559, la suppression de par la coutume du pays suggère que, rédigée sous l'autorité du roi, la loi n'est autre que la coutume de la Touraine.

\section{Conclusion}

Sur la procédure : les trois coutumes étudiées dans leur rédaction et leur réformation montrent la modernisation de la formulation du droit en un demi-siècle. Les coutumes étaient à l'origine manuscrites sur un cahier en parchemin, comme en 1460 pour la coutume de Touraine. La volonté royale impose de mettre par écrit les textes coutumiers tant généraux que locaux. L'usage de l'imprimerie se développant à la même époque, les coutumes sont désormais imprimées, publiées, enregistrées et diffusées ; selon les termes des ordonnances, elles doivent être observées pour loi. Elles sont rédigées en français et non en latin, il s'agit bien d'un droit français, ainsi qu'il est désigné.

[Louis XI] désiroit fort qu'en son royaume on usast d'une coustume, d'un poids,

d'une mesure et que toutes ces coustumes fusent mises en françois en un beau livre 48 .

Les rois qui se sont succédé ont autorisé les publications des coutumes, le roi ainsi prend l'initiative et la prérogative d'ordonner la mise en ordre du droit privé. Il est présent à travers ses commissaires auxquels il délègue le pouvoir d'officialiser les coutumes. Il n'impose pas le contenu du droit, mais sa mise en forme.

Le rôle essentiel appartient à l'assemblée des trois ordres des bailliages, provinces ou sénéchaussées, les membres des états donnent leur avis (à Auxerre et Sens) ou opinion et avis (en Touraine) en principe sur chaque article, cependant le procès-verbal ne reprend que les articles controversés, des titres entiers ont été accordés, de nombreux articles en sont pas mentionnés. Les commissaires, qu'ils soient des officiers du bailliage ou des parlementaires, prennent

[...] un soin méticuleux à respecter les formes et les procédures, à faire prêter serment et à recueillir loyalement toutes les opinions ${ }^{49}$.

Dans les procès-verbaux de rédaction, ils utilisent le vocable avons qui révèle leur intervention, pour régler un différend, en particulier dans le cas d'un article discordé, puis croisé et renvoyé à la cour du Parlement, ou pour donner acte à un opposant. Il faut également souligner la place importante occupée par les officiers royaux et les praticiens $\mathrm{du}$ droit, le procureur du roi et l'avocat du roi du bailliage interviennent fréquemment, appuyant les oppositions ou propositions d'un ordre, ou de membres de l'un d'eux. Ainsi à Auxerre, lors de la rédaction de 1507, les officiers du roi s'expriment au nom de la noblesse et du clergé sur un article qui fixe les droits d'usages dans les bois et forêts et au nom des communautés sur un article du titre fiefs.

Les grands personnages du clergé et de la noblesse, ainsi que les communautés religieuses ou laïques sont représentés par des mandataires ou procureurs, qui sont aussi des praticiens du droit donnant des avis. Ainsi dans la coutume de Touraine de 1559, à l'article 156 du titre XVI de retraits, les officiers et les praticiens ont tous rapporté concordablement sur les pratiques, jugements et arrêts qui tenaient cet article pour notoire.

Les contestations, qu'elles génèrent un article de coutume accordé ou discordé ou renvoyé à la cour, désignent les parties en conflit et témoignent du poids des oppositions dans le champ d'application de la coutume. Les protestations des comparants relatives aux 
exemptions, qui les feraient relever d'une autre coutume, protestations toujours rejetées, les défaillants sont réassignés et contraints, les membres du clergé, dont les biens temporels sont soumis aux coutumes du lieu, permettent de déterminer, à quelques paroisses près, le ressort de chaque coutume. Le bailliage est l'espace juridique qui concerne tous les habitants ainsi que leurs biens.

Sur la mise en forme : le travail de rédaction, suivi de la réformation, apparentée à une glose, s'effectue à partir d'un ancien cayer et met en route un processus de construction du droit.

Le livre imprimé, support de l'écrit coutumier, apporte ses propres catégories formelles; il n'a pas le caractère intouchable du cahier de coutume, il définit son propre espace, possède sa logique et montre rassemblés dans l'organisation et le temps d'une page les éléments épars d'un processus historique pourtant tâtonnant 50.

La réformation insère des titres nouveaux et/ou réorganise l'ordre des titres présents dans la coutume rédigée, révélant une logique temporelle absente lors de la rédaction. En repérant les deux titres testaments et successions dans d'autres coutumes rédigées puis réformées, nous retrouvons cette logique chronologique.

- À Amiens, testaments ne figure pas en 1507, successions est au titre III/12 articles ; en 1567 testaments est au titre III/11 art. et successions au titre IV/32 art. ${ }^{51}$.

- À Auxerre, en 1507 testaments titre X/17 art., successions titre VIII/18 art., en 1561 testaments titre XII/14 art., successions titre XIII/15 art.

- En Bourbonnais, en 1500 testaments pas de titre, successions titre XII / 14 art., en 1520 testaments titre XXIV / 10 art., successions titre XXV / 32 art.

- À Paris en 1510 testaments titre VII / 7 art., successions titre XI /15 art., en 1580 testaments titre XIV /10 art., successions titre XV /46 art.

- En Poitou, en 1514 testaments titre III / 6 art., successions titre IV /16 art., en 1559 testaments titre V / 9 art., successions titre VI / 20 art.

- À Sens, ainsi que nous l'avons noté, en 1507 testaments titre X /14 art., successions titre VIII /17 art., en 1555 testaments titre VIII /14 art., successions titre IX /16 art.

- Seulement en Poitou, la logique temporelle existe dès la rédaction. Par contre, la Touraine ignore cette rigueur de classement, en 1507 testaments pas de titre, successions titre XXV /23 art., en 1559 testaments titre XXIX / 4 art., successions titre XXV /36 art.

$\mathrm{Au}$ point de vue du nombre d'articles par titre, testaments entre rédaction et réformation, ces nombres varient peu en plus ou en moins ; le titre successions par contre est très développé à Amiens de 12 art. à 32 art., en Bourbonnais de 14 à 32 art., à Paris de 15 à 46 art., en Touraine de 23 à 36 art. En Poitou, il ne passe que de 16 à 20 art. À Sens et à Auxerre, deux bailliages voisins, les nombres passent respectivement de 17 à 16 art. et de 18 à 15 art. Ces comparaisons sont moins concluantes que pour le reclassement des titres, mais intéressantes pour les quatre régions dans lesquelles l'augmentation du nombre d'articles est très forte.

L'examen de ces trois coutumes permet de dégager deux grandes catégories et un ensemble plus diversifié

- Le droit féodal et les droits seigneuriaux, c'est-à-dire la justice, les droits fiscaux et le ban, dominent dans les textes étudiés. Leurs contenus et leurs limites sont fixés dans les articles qui concernent les censives, le retrait lignager, les bois et forêts, les usages et pâturages, les moulins et les fours, les rivières et les étangs...

À Auxerre en 1507, 9 chapitres sur 24 et 113 articles sur 240, en 1561, 4 titres sur 15 et 
131 articles sur 272; à Sens en 1507, 8 chapitres sur 24 et 133 articles sur 283, en 1555, 8 titres sur 24 et 134 articles sur 286 ; en Touraine en 1507,15 chapitres sur 36 et 170 articles sur 334, en 1559,16 titres sur 36 et 197 articles sur 379 concernent le droit féodal.

- Le droit civil, qui couvre les personnes, les familles et les biens, vient en seconde position par son importance. Il concerne les titres sur les communautés de biens, les rentes et hypothèques, les prescriptions, les acquisitions et les contrats, les douaires, les donations, les testaments et successions, les tutelles, les bâtards.

- En Touraine, des éléments juridiques en matière d'urbanisme sont inclus, comme le droit des vues et égouts des maisons, des gouttières, des latrines. Par contre le titre servitudes se trouve dans les trois coutumes, ainsi que dans celles de Blois, du Berry et du Nivernais. S'y trouvent également des dispositions de droit criminel sur les crimes et amendes de procédure; hormis la Touraine, ces mentions ne sont repérées que dans les coutumes de Bretagne et de la Marche.

Sur le fond du droit, les changements ne sont pas déterminants, mais ils sont plus pertinents sur la méthode, l'exposition ou la division des matières traitées. À Sens, il y a peu de changements entre rédaction et réformation, quant au nombre d'articles et de titres, nous avons signalé la permutation importante des titres testaments et successions. À Auxerre par contre, la coutume de 1507 est profondément remaniée après le retrait d'articles (ceux qui expliquent les renvois, un article supprimé, ceux qui énoncent les coutumes locales). Les six premiers titres sont regroupés dans le premier : justice ; et trois chapitres anciens sont rayés : assurements et sauvegardes, acquérir et bourgeoisies. Un titre reprend deux chapitres sur les successions et rapports. Donc neuf titres en moins, mais un ajout de 32 articles pour précision du droit. En Touraine, le classement des rubriques est peu modifié et le nombre des titres reste le même. Les droits des comtes sont expressément reconnus, tant seigneuriaux que civils. Les donations et les douaires ne forment respectivement qu'un seul titre mieux ordonnancé, ainsi les droits des nobles et des roturiers ne sont plus inscrits dans deux titres différents. Lors de la réformation, les titres deviennent plus courts et plus explicites, la ponctuation est allégée.

Le vocabulaire commun dans les trois coutumes,

[...] comme avoir lieu à l'avenir sans préjudice du passé, droits acquis aux parties et procès intentés, ajout pour précision ou meilleure explication ou interprétation, prend en compte la volonté des rois, de Charles VII à Henri III, de rendre la coutume clere et evidente, de mettre fin aux abus, afin que la justice soit mieux rendue, ainsi qu'il est spécifié dans les ordonnances royales. Les coutumes créent donc des droits certains et stables, et comme elles fixent exclusivement des usages, qui répondent à des besoins sociaux précis et datés, elles tirent ainsi leur force juridique inscrite dans le territoire du bailliage. De là le caractère évolutif des coutumes, qui se plient à la pratique, et qui lorsqu'elles deviennent archaïques, exigent une seconde procédure semblable à la première dans sa forme, pour affirmer le consentement, l'accord des états assemblés, ce qui les oblige à en respecter les règles. 


\section{Annexe : reprise des détails des procès-verbaux (article par article)}

\section{Auxerre, coutume rédigée de 1507}

Le premier chapitre, haut justicier et les 5 autres chapitres (jusqu'à VI) des bâtards ont été accordés par tous les présents des états, exceptés par les habitants de la ville de Varzy, qui ont des coutumes locales écrites au même coutumier et accordées par l'évêque d'Auxerre et les habitants du lieu.

Donc: chapitre premier, haute justice, moyenne et basse 14 art. (1-14); II moyenne justice , 2 art. (15-16) ; III basse justice, 2 art. (17-18) ; IV justice censière, 9 art. (19-27) ; $\underline{\mathrm{V}}$ forfaiture et confiscation, 4 art. (28-31) et 2 art. de la coutume de Varzy (32-33); VI bâtards, 5 art. (34-38) sont tous accordés sans discussion lors de l'assemblée.

À partir du chapitre VII, nous constatons une anomalie dans la numérotation des articles, en effet, chaque article discuté est suivi d'un autre article portant le numéro suivant. Pour la compréhension de ce fait, nous reprenons ces différents cas.

Chapitre VII des retraits, 23 art. (39-61).

- Article 42-l'article est discuté puis après le texte de l'article dans le corps de la coutume et repris au P. V., un article numéroté donne l'explication :

- Article 43 explication: demeure en difficulté et non accordé. Opposition dit: les rentes volages ne gisent en retrait, seulement les rentes foncières, les autres affirment le contraire. L'article n'a pu être accordé et est donc renvoyé.

Le chapitre VII comprend donc effectivement 22 articles et 1 article d'explication de renvoi.

Chapitre VIII de successions, partages, divisions, 18 art. (62-79);

- Article 66 - si aucun ne va de vie à trépas avant oncles et tantes, neveux ou nièces...

- Article 67 explication du désaccord : les neveux et nièces précèdent les oncles et tantes pour l'héritage, sauf absence des premiers, excluant les cousins germains; les autres disent que les oncles et tantes sont plus prochains pour venir à la succession. L'opposition persiste, chacun restant sur ses positions, l'article est renvoyé.

- Article 78 et dernier : Un estranger demeurant outre les monts ne succède pas aux biens de ses parents mortels dans le royaume, les autres parents succèdent sinon au roi. L'article suivant donne la raison du renvoi :

- Article 79 explication: l'article est demeuré discordé parce que les seigneurs chastellains et barons seigneurs hauts-justiciers disent la succession leur competer et appartenir, les avocats et procureur du roi disant le contraire.

Le chapitre VIII comprend donc effectivement 16 articles et 2 d'explications de renvois.

À la fin de ce chapitre successions, sont insérées les coutumes locales de plusieurs châtellenies du dit bailliage articulées au dit coutumier. Soit 4 art. (80-83). Le P. V. ne spécifie pas qu'il s'agit de Varzy.

Chapitre IX de servitudes, 7 art. (84-89) demeure accordé et au dit chapitre inséré certaines coutumes locales entre les habitants de Varzy seulement 1 art. (90).

À signaler que deux articles de ce chapitre portent le numéro 85 . 
Chapitre X de testaments, institution d'héritiers, legs, donations et exécuteurs de testaments 17 art. (91-107) lequel chapitre est accordé le 8 septembre.

Cependant, dans le texte de la coutume au dit chapitre X de testaments :

- Article 106 : femme conjointe par mariage ne pourra tester sans l'autorité de son mary.

- Article 107 et dernier explication : et depuis le 14 octobre, les prélats et gens d'Église se sont opposés à l'accord du dit article, qu'ils jugent non raisonnable, les seigneurs, avocats et procureurs disent que l'article a été accordé le 8 septembre, l'opposition est reprise à la fin du P. V. mentionnant la discussion sur les coutumes locales, l'article est renvoyé à la cour du Parlement.

Donc le chapitre $\mathrm{X}$ testaments contient finalement 16 articles et 1 d'explication.

- Article 121 commençant par: les lods et ventes, amendes des héritages chargés de censives vendus doivent poursuivre par action et s'il n'y a arrêt n'y a point de main garnie s'il n'est ainsi appointé par le juge, parties ouyes.

- Article 122 explication: article demeuré discordé car les prélats et les seigneurs châtelains ont maintenu que l'article ainsi qu'il est posé n'être à la raison. La main doit être garnie sans appointement par justice disant que c'est l'usage dans leur seigneurie. Les avocats et procureurs ayant charge de communautés déclarent que l'article posé a déjà été accordé aux coutumes et cet article pratiqué. Article renvoyé pour être accordé.

- Article 125 pose problème :

- Article 126 explication : les religieux de Vézelay refusent l'article donc non accordé par eux et accordé entre les seigneurs.

Cet article contesté n'est pas mentionné au P. V., seulement dans le texte de la coutume.

- Article 129 (mentionné $7^{\mathrm{e}}$ article du chapitre dans le P. V., donc ne tenant pas compte des deux articles d'explication) : qui transporte et baille héritage à rente ou à rachat... lods avant le rachat, ventes lors du rachat.

- Article 130 explication : discordé par les prélats, gens d'Église et nobles disant que lods et ventes être dues sans attendre le temps du rachat, avocats et praticiens et communautés que de temps immémorial le dit article a été observé. Renvoyé pour être accordé.

- Article 135 (P. V. article $12^{\mathrm{e}}$ du chapitre, article $15^{\mathrm{e}}$ dans la coutume) Si aucun propriétaire veut laisser l'héritage pour le cens et renoncer à celuy faire le peut pourvu qu'il ne soit chargé que de cens.

- Article 136 explication : article discordé, prélats et nobles veulent insérer, pourvu qu'il n'y eu charge autres que le cens d'iceluy héritage et qu'en héritages baillés à cens n'y ait aucune dissimulation. Article ne doit être accordé vu l'opposition des avocats, praticiens et autres ayant charge des communautés voulant le conserver vu qu'il a été gardé et déjà accordé en ces termes, donc renvoi.

- Articles 141 et 142 discordés :

article 141 : s'il advient qu'un héritage chargé de censive soit vendu à rachat jusques à certain temps, le seigneur censier dans ce temps fera payer les lods et ventes, mais si le vendeur le rachète dans le même temps, il n'y aura pas de payement sur le dernier rachat. 
- Article 142 : si aucun vend son héritage étant en censive, si le vendeur baille de l'argent dans un certain temps, lods et ventes payés, si le vendeur rachète l'héritage dans le même temps, pas de payement pour le dit rachat.

- Article 143 explication: les avocats, procureurs, praticiens et autres ayant charge de villes opposent leur jurisprudence, qui confirme les articles, notamment une sentence rendue au châtelet de Paris contre un seigneur; les prélats et nobles objectent que ces sentences ne peuvent leur être opposées et qu'ils ont obtenu d'autres jugements pour leur part, renvois des deux articles pour être accordés.

- Article 144, tous héritages sont réputés francs sauf contraire, celui qui prétend au cens doit le prouver suffisamment. Discordé.

- Article 145 explication : demeure en difficulté, les avocats, procureurs, praticiens, villes et châtellenies soutiennent l'article en sa forme qui doit être accordé, il en a toujours été ainsi et les coutumes voisines disent de même, il contient vérité. Seigneurs et prélats disent la même chose pour défendre le contraire (ils veulent renverser la proposition, tous héritages portent cens sauf titre contraire) donc renvoi.

- Article 146 supprimé, article 147 : le dit article par l'avis du conseil a été délaissé au droit commun. Ceci n'est pas mentionné dans le P. V.

Donc le chapitre XIII censives contient 21 articles, 6 articles d'explication (pour 7 articles renvoyés) et 1 article supprimé.

Même chapitre XIII censives et droits, coutumes locales de Varzy 7 articles (148-154).

- Article 149 discordé.

- Article 150 explication: pour les habitants du lieu héritage franc vendu ne doit rien, pour l'évêque d'Auxerre, droit lods et ventes est dû. Donc renvoi.

- Article 151 discordé.

- Article 152 explication : demeure en difficulté même problème, l'évêque exige un droit que les habitants possesseurs de franc alleu ne veulent payer.

- Article 153 discordé.

- Article 154 explication: article en difficulté, même problème du droit exigé par l'évêque, contesté par les habitants, aucun droit sur héritage franc.

La coutume de Varzy sur les censives contient 4 articles et 3 d'explication.

Chapitre XIV de compagnie et communautés de biens entre hommes et femmes et autres personnes 14 art. (155-168)

Coutumes locales insérées 2 art. (169-170).

Coutumes générales et locales de ce chapitre sont vérifiées et accordées.

Chapitre XV convenances, marchés, ventes, achats... contrats 10 art. (171-180) sont accordés.

Chapitre XVI prescription et laps de temps 2 art. (181-182) accordés.

Chapitre XVII rentes foncières... hypothèques 13 art. (183-195) accordés.

Chapitre XVIII bourgeoisies et des aveux 7 art. (196-202) accordés.

Chapitre XIX eaux, bois 12 art. (203-214).

- Article 204, les habitants ne peuvent prétendre autre que vaine pâture sauf si ils ont titre ou payent redevance ou en aient joui depuis un temps immémorial.

- Article 205 explication: les habitants des communautés et des villes, les praticiens, procureurs et avocats disent article est vérité et accordé aux dernières coutumes, joui et user de tout temps. Les officiers du roi, prélats et nobles disent qu'on ne peut prescrire 
usage fors vaine pâture sans payer redevance, ils ont toujours vu en user ainsi donc renvoi.

- Article 213, le temps de greiner en bois et forêts commence à la Saint-Remy et finit à la Saint-André. Discordé.

- Article 214 explication : article demeuré discordé, gens d'Église et nobles maintiennent que le temps de greiner commence à la Saint-Remy et finit à la purification de NotreDame (BVM). Les avocats, procureurs, praticiens et autres ayant charge des communautés disent que l'article posé contient vérité, joui et user, le temps de greiner commence à la Saint-André. Article croisé et renvoyé.

Le 8 septembre, date du P. V., la discussion sur l'article est renvoyée au 14 octobre date de la discussion sur les coutumes locales.

La Saint-Remy: 1er octobre. La Saint-André : 30 novembre. Purification de la BVM: 2 février.

Le chapitre XIX contient donc 10 articles et 2 d'explication.

149 Les chapitres XX tutelle et curatelle 5 art. (215-219), XXI douaire 3 art. (220-222), XXII d'assurements et sauvegardes 9 art. (223-231) sont tous accordés.

Chapitre XXIII des fiefs et droits 33 art. (232-264).

- Article 251, le vassal qui fait sciemment faux aveu et reprend d'autre seigneur que son féodal commet en ce son fief, tout ainsi que si sciemment il déniait le dit fief, toutefois quand il l'aurait tenu du roi il n'y aurait point de commise.

- Article 252 explication: demeure discordé, les nobles et prélats disent que l'article ne contient pas vérité et qu'il doit être re-cité sous ces mots : toutefois quand il l'aurait tenu du roi, en ce cas il n'y a point de commise. Les officiers du roi, habitants des villes, châtellenies et seigneuries disent que l'article doit être accordé. À cette cause avons croisé et renvoyé le dit article. Les autres articles du chapitre XXIII ont été accordés. Le chapitre XXIII contient 32 articles et 1 d'explication.

151 Chapitre XXIV rapports qui se doivent faire en succession 6 art. (266-271) sont accordés. 


\section{Auxerre, changements intervenus entre la rédaction de 1507 et la réformation de 1561}

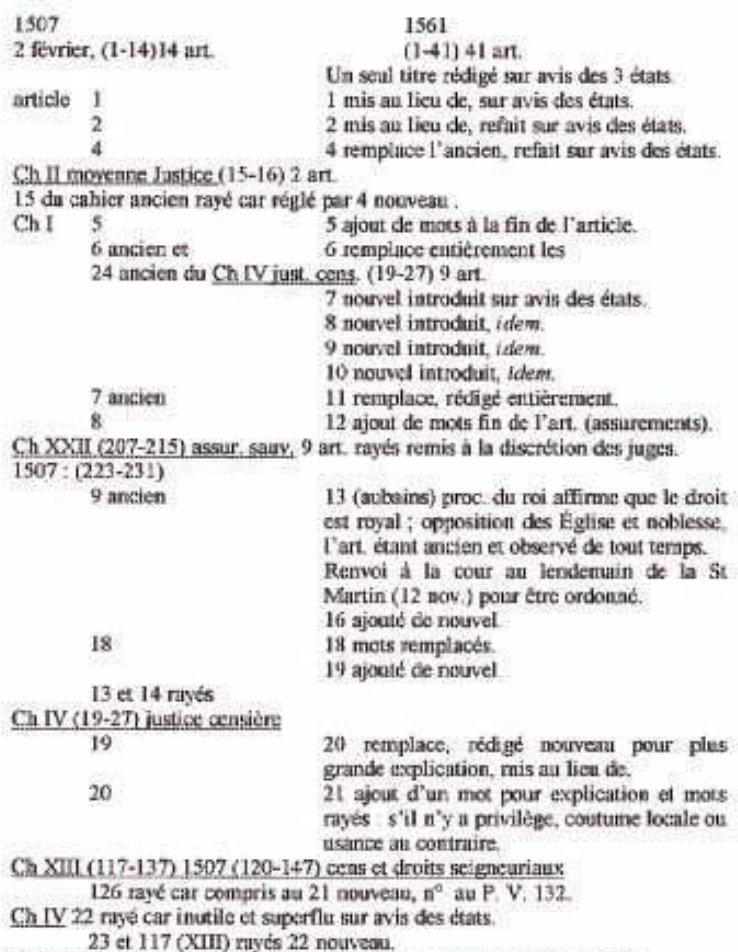

Ch.XIII art. 144 de I507 discordé et renvoyé, remuméroté 135 au P. V.

23 opposition pour le T, E d'un sieur Fernicr : ant. nouveau dressé par Égliso et noblesse contre T. E, : tout héritage doit le cens sauf contraire. Art. ancien discorde en 1507 par $\mathrm{E}$, et $\mathrm{N}$ mais gard et observe car conforme au droil naturch ct comman. Le T, E. demande et $\mathrm{N}$ les jugements et article ancien atiestent que le droit de cens ess dî́ saif

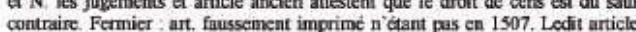
nouveas se refere a la coutume de Vara, les alleux sont nombreax Auxerrois, ne portant pas de cens, d'oû la naurvelle rédaction qui oblige be tenancier à le prouver L a article est renvogé à la fin de la shance. Nouvellement rédigé par les praticiens, l'opposition T. E. persiste : article 23 maintenu malgné cette opposition. 24 nouvel introduit.
25 nouvel introduit. 28 (ch V), sur le P, V. 27
accordé en 1507

26, le procurcur du roi proteste ant. réforme gatrde sans peéjudice au roi et renvoi à tis

Selon le texte c'est I'ant. $28 \mathrm{Ch}$ V. forfaiture et confiscation.

30 sur le P. V. 29 du Ch V, (28-31) forfai

$31 \quad 29$ mots ajoutes à la fin

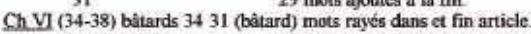

35 P. V. $34 \quad 32$ (batard) rédigé de nowvean, acconde.

36 P. V. 35 rayé sur avis des étals

$38 \quad 32$ et 33 , ajout de mots ef mots rayés

Le ch VI hätards de 1507 est integré au Titre 1

$\frac{\text { Ch XXIII fiefs, droits et profits }}{\text { (216-247) } 32 \text { art. }} \frac{\text { T. II des fiefs }}{(42-82) 41 \text { art. }}$

(216-247) 32 ant

232 P. V. 219

42 mots rayes a la fin car supernlus ef compris aux autres articles

236 P. V. 223 abrogé 46 de nouvel inoutc, sur avis des États

$\begin{array}{ll}236 \text { P. V. } 223 \text { abrogé } & 46 \text { de nouvel introcuil, mis aul lieu de. } \\ 239 \text { P. V. } 226 & 49 \text { ajout de mots pour préfixion du temps }\end{array}$

omis i l'ancien article.

254 P. V. $239 \quad 54$ de nouvel introduit, mais reprise de mots

th substance contens dans l'ancien 239 .

55 de nouvel intruduit sur avis des étots.

56 de nouvel introduit 


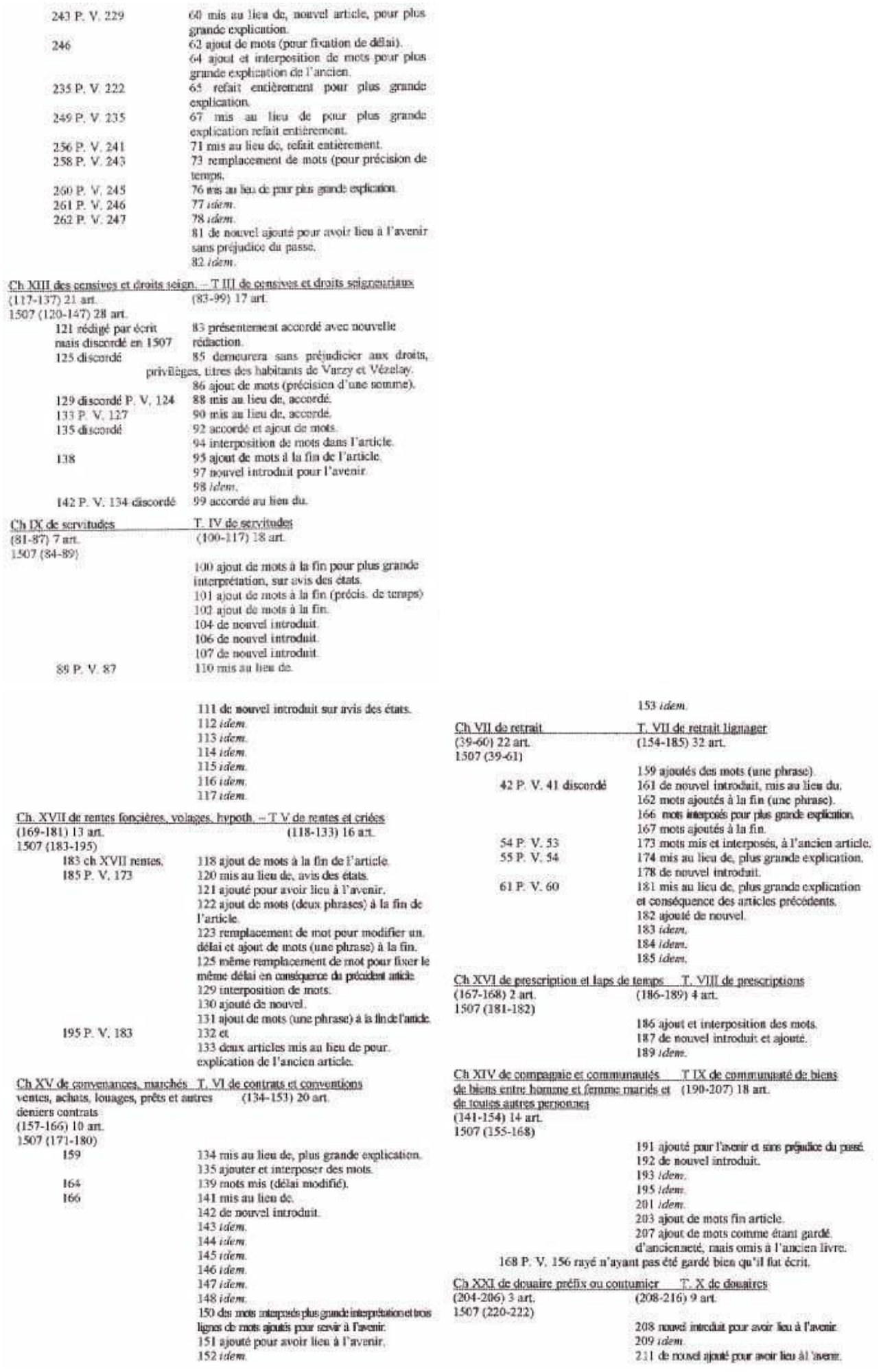




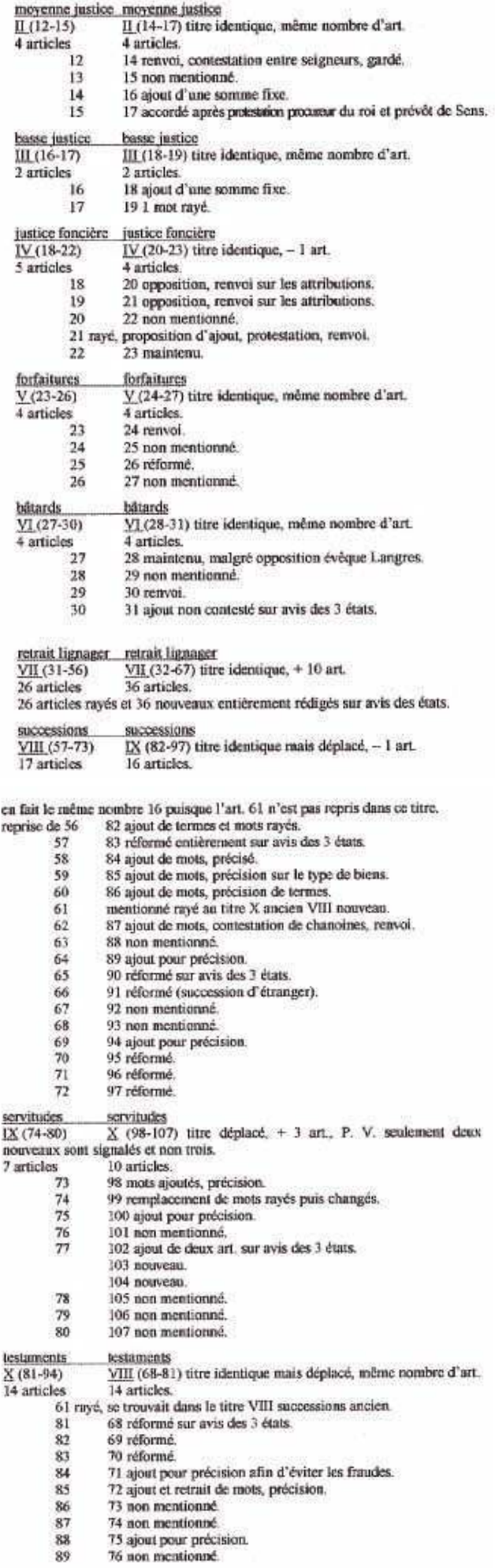




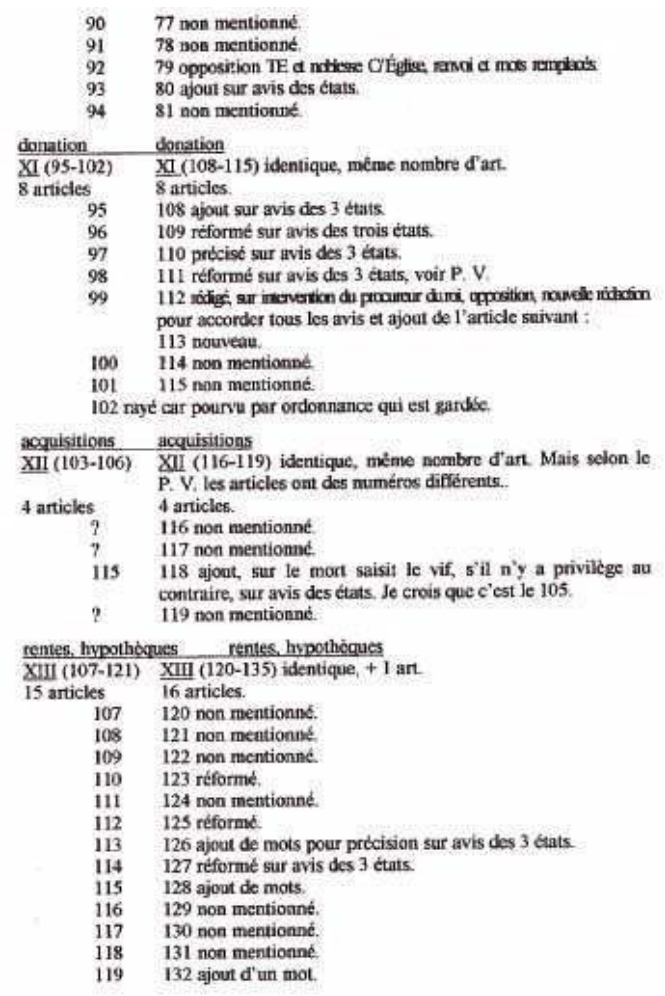

120133 maintenu malgré protestation des archeveques et des chapitres de Sens et de Langres, sur avis des mêmes, ajout de l'article suivant.

$121 \quad 135$ ajd

de mots pour precision.

bourgcoisic bourgeoisic

XIV (122-131) XIV (136-145) identique, même nombre d'an.

10 articles 10 articles.
122.136 droit de bourgeoisje dont le roi est fondé, paicment d' une redevance au roi, ceci concerne tous les articles, opposition des étasts, les 10 articles soat reavoyés au Pariement.

$\begin{array}{ll}123 & 137 \text { renvoi. } \\ 124 & 138 \text { renvoi. } \\ 125 & 139 \text { renvoi. } \\ 126 & 140 \text { renvoi. } \\ 127 & 141 \text { renvoi. } \\ 128 & 142 \text { renvoi. } \\ 129 & 143 \text { reanoi. } \\ 130 & 144 \text { reavoi. } \\ 131 & 145 \text { renvoi. }\end{array}$ bois

XV (132-140) XV $\quad$ XVis $(1455)$ identique, +1 ant

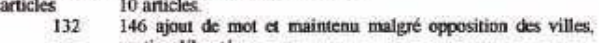
partics didboutices

133147 méme ajout que le présdent.

134148 réforme

135
136
130 non mentionne.

$137 \quad 151$ non mentionne.

138.152 ajout de plusicurs mots pour procision.

$139 \quad 153$ non mentionne

$140 \quad 154$

gards et tutelle garde et tatell

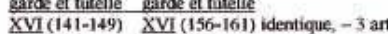

9 articles 6 articless

$141 \quad 156$ réformé et maintenu ainsi mulgré protestation du grand

142. prieur de France. 157 non mentionn

143 rayé

145 158 changement de $\mathrm{l}$ 'àge et ajout de mots pour precision

146.159 non mentionnt. 
$147 \quad 160$ ajout de nots sur avis des teats

148161 non mentionnct

XVII (150-158) XVII (162-169) identique, 2 art antiens sont remplasés par

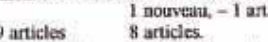

149162 ajout de mots poer prócision sur avis des états

163 ajout de mots pout petcision.

165 non mentionne.

153166 nog mentionne

154 es $155 \quad 167$ ptorme aur avis des états en 1 art.

1561168 nou mentiouné.

137) 169 nom mentionne

XVTII. (159-168) XVIII (170)-179), identique, méme nombre d'ar. mais les

XVIIIL. (159-168) XVIII (170-179), identique, mémé nombre

10 articles 10 articles.

$158 \quad 170$ réformé sur avis des thats.

159.171 non mentiona

161 173idem.

162174 idem

$163 \quad 175$ idem

164
165 177 idem.

$163 \quad 177$ idem

$167 \quad 179$ iderm.

fiefs th nowitis fiefs es profits

XIX (169-220) XIX (180-224) identique, -7 art selon les chiffres.

52 articles 45 articles.

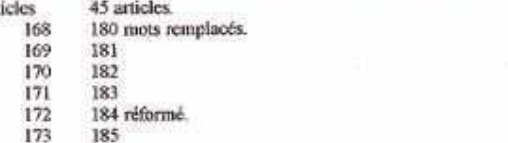

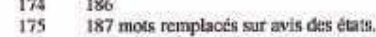

$176 \quad 188$ refforme sur avis des trats

$\begin{array}{ll}177 & 189 \\ 178 & 190\end{array}$

179 191 a jout pour prócision.

181 192

182194 ajcat pour précision.

1831951 mot enlevé

$184 \quad 196$

$185 \quad 197$

$\begin{array}{ll}186 & 198 \\ 187 & 199 \text { mats rives }\end{array}$

\begin{tabular}{ll}
187 & 199 \\
188 & 200 \\
\hline
\end{tabular}

$\begin{array}{ll}188 & 200 \\ 189 & \text { rayd }\end{array}$

190 ruye

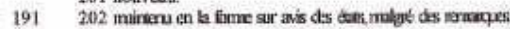

1912202

$\begin{array}{ll}192 & 203 \\ 191 & 204 \\ 194 & 005\end{array}$

$\begin{array}{ll}194 & 205 \\ 195 & 206\end{array}$

$196 \quad 207$ ajout de mots et recruit d'autres mots

1993 zas réformé

200 ragé sur avis des thats.

$201 \quad 209$

2022101 mot nye

$203 \quad 2.11$

204 raye sur avis des ituts

$\begin{array}{ll}205 & 212 \\ 206 & 213\end{array}$

207 raye sur avis des stats.

$208 \quad 214$ rélarmé sarr avis des tatas.

$20 \% 215$

$210 \quad 216$ rélormet sar avis des ctats.

$212 \quad 218$

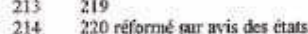

$215 \quad 221$

$236 \quad 222$

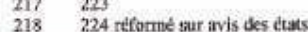

Seuleatent 3 articles signales tryys, les deux autres $21 \%$ et 220 soet zepris an titer suivant.

censives ensives

$\mathrm{XX}(2.21-244) \quad 8 X(2.25-245)$ identique, en fait 22 articles antiens sons repris dont 2 du tiue précédent, et 20 sont mentionanés daus la coutume rédigher. 24 articles 20 articles.

reprise de 219225 ajout pour préeisien et retrait d sutres mots,

remarques filites, opposidion da procureur dia roi, ranvoi 


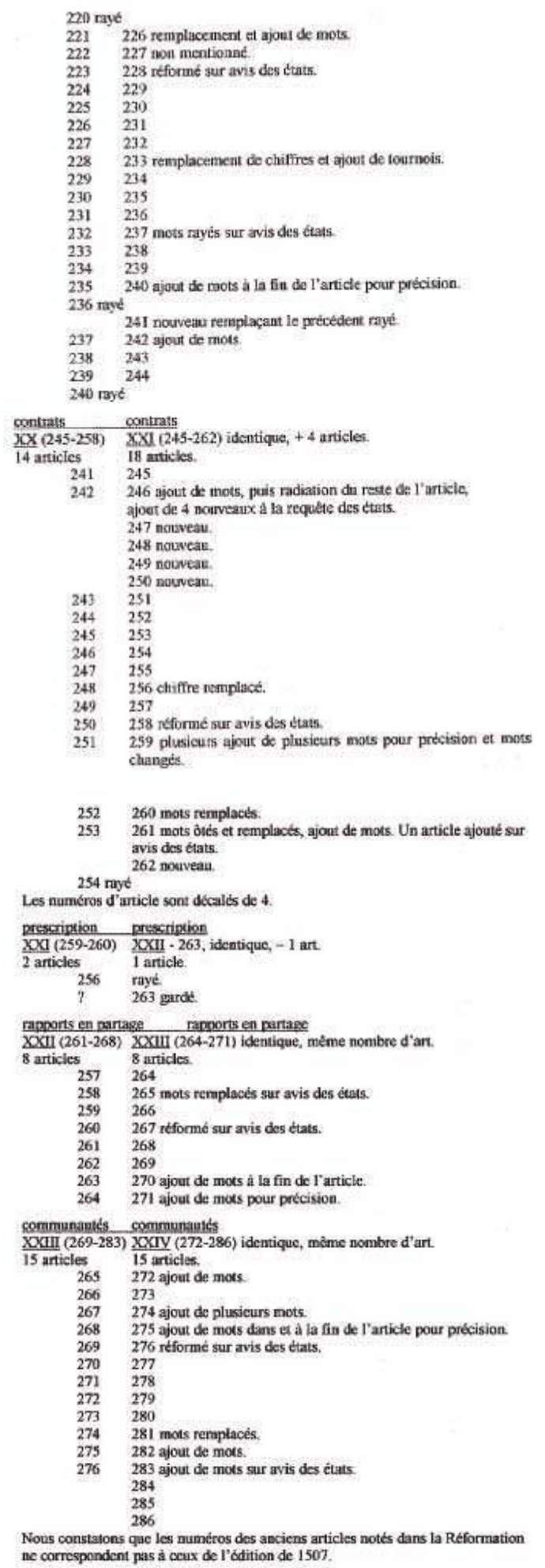

Touraine, changements intervenus entre la rédaction de 1507 et la réformation de 1559

Titre premier de basse justice, autrement dite basse voirie (art. 1 à 38), 38 art. 
Le titre est changé et semi droit retranché, qui bien que synonyme de basse voirie, mettait plus en relief la justice foncière, inséparable de la féodalité.

art. 1 : (1/1507) remplacement (mis au lieu de) et ajout de mots en fin d'article.

art. 3 et $4:$ ajoutés (nouveaux articles).

art. 5 : (3/1507) mots rayés et remplacés pour avoir lieu sans préjudice du passé.

art. $6:$ nouvel introduit.

art. $8:(5 / 07)$ interposition de mots.

art. $10:(7 / 07)$ ajout de mots.

art. $14:(11 / 07)$ interposition de mots.

art. 18 : (15/07) ajout de mots en plusieurs endroits pour plus d'explication.

art. 20 : (17/07) ajout de mots.

art. $21:(18 / 07)$ mis au lieu de.

art. 22 : (19/07) mis au lieu de.

art. 24 : nouvel article.

art. 26 : (22/07) ajout de mots.

art. 27 : (23/07) interposition de nouveaux mots, pour plus d'explication.

art. $28:(24 / 07)$ interposition de nouveaux mots.

art. $30:(26 / 07)$ ajout de mots.

art. $31:(27 / 07)$ ajout de mots et mots rayés.

art. 32 : (28/07) ajout de mots.

art. $33:(29 / 07)$ ajout de mots.

art. 34 : (30/07) mis à la place de pour avoir lieu pour l'avenir, sans préjudice du passé ; importante correction.

art. $36:(32 / 07)$ ajout de mots

art. $37:(33 / 07)$ ajout de mots.

art. 38 : nouvel ajouté, à la demande du substitut du procureur général du roi et sur avis des gens d'Église et de la noblesse.

II de moyenne justice, appelée grande voirie (art. 39 à 51), 13 art.

art. $39:(1 / 07)$ ajout de mots.

art. $41:(3 / 07)$ protestation du procureur général du roi qui est retenue.

art. $42:(4 / 07)$ ajout d'une phrase en fin d'article.

art. 43 : (5/07) mis au lieu de l'ancien article.

art. 44 : (6/07) ajout de mots, pour se conformer à l'article 32 ci-dessus.

art. $45:(7 / 07)$ ajout de mots.

art. $46:(8 / 07)$ mis au lieu de.

art. 49 : (11/07) ajout de mots.

art. 50 : (12/07) ajout de mots pour plus grande explication.

art. $51:(30 / 07)$ mots rayés.

IV de haute justice, où il n'y a droit de comté, vicomté baronnie ou châtellenie (art. 55 à 58), 4 art.

art. 56 : nouvel introduit.

art. $57:(2 / 07)$ ajout de mots.

$\mathrm{V}$ des droits du seigneur châtelain non ayant droit de comté, vicomté ou baronnie (art. 59 à 69), 11 art.

art. $59:(1 / 07)$ mis et ajout de mots.

art. $61:(3 / 07)$ ajout de mots. 
art. 62 : (4/07) mis au lieu de, importante correction.

art. 63 : (5/07) ajout de mots.

156 VI des droits de baronnie (art 70 à 73), 4 art.

art. $70:(1 / 07)$ mots rayés.

art. $72:(3 / 07)$ ajout de mots.

art. $73:(4 / 07)$ mis et correction.

VII des droits des comtes et de leurs prééminences (art. 74 à 81), 7 art. titre nouveau, " pour avoir lieu à l'avenir ».

VIII des droits de péage, et coutume (art. 81 à 87 ), 7 art.

art. $81:(1 / 07)$ ajout de mots.

art. 82 : (2/07) interposition et ajout de mots.

art. 85 : (5/07) interposition et ajout de mots en fin d'article.

art. 86 : (6/07) ajout de mots en fin d'article.

IX des loyaux aides et roucins de service, et des gardes dues aux châteaux des seigneurs (art. 88 à 99), 12 art.

art. 89 : (3/07) ajout.

art. $90:(4 / 07)$ ajout.

art. $92:(10 / 07)$ ajout.

art. $93:(12 / 07)$ ajout.

art. 97 : (9/07 en partie) ajout pour pallier les difficultés soulevées par l'ancien article.

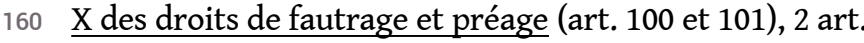

art. $100:(1 / 07)$ ajout.

art. $101:$ (2/07) ajout.

XI du droit de ban à vin (art. 102) 1 art.

art. $102:(1 / 07)$ interposition de mots.

XII du droit d'indemnité (art. 103 à 108), 6 art.

art. 104 : nouvel article ajouté pour clarification de l'art. 103.

art. $108:(5 / 07)$ ajout.

XIII des hommages et offres qui se doivent faire par le vassal à son seigneur (art. 109 à

117), 9 art.

art. 110 : (2/07) interposition de mots pour explication.

art. 111 : (3/07) deux mots mis au lieu de.

art. 113 : (13/07) ajout pour avoir lieu à l'avenir, sans préjudice du passé.

art. $114:(14 / 07)$ interposition de mots.

art. $115:(15 / 07)$ ajout.

art. $116:(16 / 07)$ ajout.

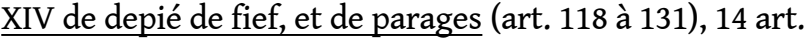

art. 118 : (1/07) ajout pour explication du contenu de l'article.

art. $122:(5 / 07)$ ajout.

art. 123 et $124:$ nouvellement introduits.

art. 127 : (11/07) ajout d'un mot.

art. 128 : (12/07) mis au lieu de pour explication.

art. $131:(9 / 07)$ ajout.

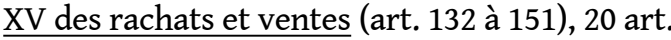


art. $132:(1 / 07):$ ajout.

art. $133:(2 / 07)$ ajout pour explication des mots.

art. $134:(3 / 07)$ ajout.

art. $135:(4 / 07)$ ajout.

art. 136 : (5/07) mis des mots pour, correction pour éviter les difficultés rencontrées.

art. $138:(7 / 07)$ un mot mis au lieu de.

art. 139 : (8/07) ajout de mots dans et à la fin de l'art. pour lever les difficultés.

art. $145:(13 / 07)$ ajout.

art. $146:(14 / 07)$ important ajout.

art. $147:(15 / 07)$ interposition de mots pour éviter des fraudes.

art. 149 : (17/07) correction de mots et ajout.

art. $150:(18 / 07)$ ajout.

art. $151:(19 / 07)$ ajout.

XVI de retraits : (art. 152 à 197), 46 art.

art. 152, $153:(1 / 07)$ ajout.

art. 154,155 : nouveaux pour une grande explication.

art. 156: nouveau, les officiers et praticiens des sièges ayant tous rapporté d'après les jugements et arrêts intervenus qu'il s'agissait d'une coutume notoire.

art. 158 : (3/07) ajout.

art. 159 : (4/07) ajout.

art. 160 : nouveau pour avoir lieu à l'avenir, sans préjudice du passé, droits acquis aux parties et procès intentés.

art. $161:(5 / 07)$ ajout.

art. $166:(10 / 07)$ ajout.

art. $167:(11 / 07)$ ajout.

art. $168:(12 / 07)$ ajout.

art. 169 : (13/07) mis au lieu de.

art. $170:(14 / 07)$ ajout.

art. $171:(15 / 07)$ mis au lieu de.

art. $172:(16 / 07)$ ajout.

art. $173:(17 / 07)$ ajout.

art. $174:(18 / 07)$ ajout.

art. $175:(19 / 07)$ ajout.

art. $180:(24 / 07)$ ajout.

art. $181:(25 / 07)$ ajout.

art. 183 : (27/07) mis au lieu de et ajout en fin d'article.

art. $184:(28 / 07)$ ajout.

art. 186 : (30/07) correction et réformation sur avis des états.

art. $188:(32 / 07)$ ajout.

art. 189 : (33/07) mis au lieu de.

art. 190 : (34/07) ajout.

art. 192 : nouveau.

art. 193 : (37/07) mis au lieu de pour avoir lieu à l'avenir sans préjudice du passé.

art. 194 : (38/07) interposition de mots.

art. 195 : (39/07) ajout pour avoir lieu à l'avenir sans préjudice du passé.

art. 196 : nouveau.

art. 197 : nouveau (art. 40/07 rayé). 
art. 258 : (1/07) ajout pour explication.

art. 259 : (2/07) ajout et mis au lieu de, correction.

art. 260 : (3/07) ajout pour pallier les difficultés.

art. $261:(4 / 07):$ ajout.

art. 262, $263:(4,5 / 07)$ mis au lieu de et correction, et 7/07 corrigé et abrogé.

art. 264 : (8/07) ajout, pour avoir lieu à l'avenir sans préjudice du passé. 
art. $265:(9 / 07)$ mots rayés.

art. $267:(11 / 07)$ ajout.

art. 268, 269, $270:(12 / 07)$ mis au lieu de.

art. 272 : nouveau, ajouté pour éviter les difficultés qui apparaissaient.

art. $274:(20 / 07)$ : ajout.

art. $275:(15 / 07)$ conséquence de la correction des articles précédents.

art. 276 : (16/07) mots rayés, en conséquence des corrections des articles précédents.

art. 279 : (21/07) mots rayés et ajoutés pour avoir lieu dans l'avenir, sans préjudice des droits acquis et des procès intentés.

art. 283 : (25/07) ajout pour avoir lieu dans l'avenir sans préjudice du passé.

art. $284:(26 / 07)$ mis au lieu de.

art. 287 : (30/07) mis au lieu de.

art. 288, 289 : nouveaux, ajoutés pour explication des précédents articles.

art. 290, $291:(31,32$, partie 33/07) mis au lieu de.

art. 292 : (partie 33/07) ajout.

art. 293 : nouvel introduit et interprétatif.

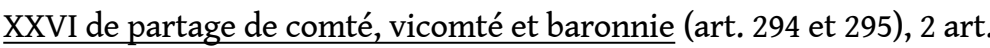

art. 294, $295:(1,2,3 / 07)$ mis au lieu de.

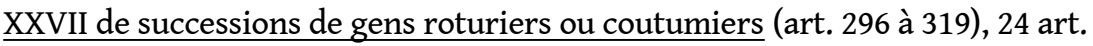

art. $296:(1 / 07)$ ajout pour explication du contenu.

art. 297 : (2/07) mots interposés pour interprétation seulement et ajout en fin d'article.

art. $298:(3 / 07)$ ajout pour explication.

art. 300 : (6/07) ajout pour avoir lieu à l'avenir sans préjudice du passé.

art. $302:(8 / 07)$ mis au lieu de.

art. $304:(10 / 07)$ ajout.

art. $305:(11 / 07)$ ajout.

art. 307 : (13/07) interposition de mots pour avoir lieu à l'avenir sans préjudice du passé.

art. $308:(14 / 07)$ mis au lieu de.

art. 310, 311, 312: 16, (17/07) mis au lieu de, accordés pour l'avenir sans préjudice du passé.

art. 313 : (18/07) interposition de mots pour avoir lieu à l'avenir.

art. $314:(19 / 07)$ ajout pour plus grande explication.

art. $316:(20 / 07)$ ajout d'un mot.

art. 319 : (24/07) mis au lieu de.

XXVIII de succession de bâtard (art. 320 et 321), 2 art.

art. 321 : nouvel introduit.

XXIX de testament (art. 322 à 325), 4 art.

art. 322, 323, 324, 325 : nouvelle rubrique pour avoir lieu à l'avenir.

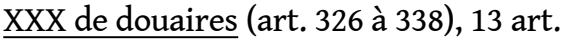

art. 326, 327, $328:(1 / 07)$ mis au lieu de et accordés pour l'avenir.

art. $329:(2$, partir $4 / 07)$ : ajout.

art. $334:$ (7/07) interposition de mots et ajout.

art. 335 : nouveau, ajouté pour l'avenir et éviter les difficultés sur son contenu.

art. 336 : ajout de mots.

art. $337:(1 / 07)$ mis au lieu de.

art. $338:(2 / 07)$ ajout. 
(11/07) : abrogé.

181 XXXI de bail (art. 339 à 345), 7 art.

art. $341:(2 / 07)$ ajout.

art. 342 : (3/07) mis au lieu de.

art. 344 : nouvel ajouté.

XXXII de tuteurs ou curateurs (art. 346 à 350), 5 art.

art. $346,347: 1 / 07)$ ajout pour plus grande explication.

art. $348:(2 / 07)$ ajout.

art. 349 : nouvel ajouté.

XXXIII de émancipation (art. 351), 1 art.

art. 351 : mis au lieu de l'article unique de l'ancien cahier.

XXXV d'amende (art. 364 à 377), 14 art.

art. $366:(3 / 07)$ ajout.

art. $375:(22 / 07)$ mis au lieu de.

art. 376 : (23/07) deux mots mis au lieu de.

art. 377 : nouvel ajouté.

art. $8,9,12,13,15,16,19,20(23 / 07)$, rayés.

XXXVI de crimes (art. 378), 1 art.

art. $378:(1 / 07)$ correction.

art. 2, 3, 4,5 en partie, $6,7,(8 / 07)$ rayés.

coutumes locales (art. 379).

\section{NOTES}

1. Bourdot de Richebourg (B. d. R.) chez Claude Robustel, Paris, 1724, 4 vol., in-folio.

2. Ordonnances du Louvre. Ordonnances des anciens Roys de France, de la troisième race, recueillies par ordre chronologique, Paris, 1790, vol. XIV, p. 312-313.

3. B. d. R., op. cit., t. II, p. 1169 et 1193.

4. B. d. R., op. cit., t. IV, p. 639.

5. B. d. R., ibid., p. 640-641 et Anciennes loys de France (A. L. F.), Paris, 1822-1833, t. IX, p. 457-460.

6. Jean Yver, «Le Président Thibault Baillet et la rédaction des coutumes (1496-1514) ", Revue d'histoire de droit français et étranger, t. LXIV, 1986, p. 19-42.

7. René Filhol, Le Premier Président Christofle de Thou et la réformation des coutumes, Paris, Sirey, 1937.

8. A. L. F., op. cit., t. XIV, p. 611.

9. B. d. R., op. cit., t. IV, p. 631.

10. Robert Descimon, infra, p. 93-106.

11. B. d. R., op. cit., t. IV, p. 631.

12. B. d. R., op. cit., t. IV, p. 708.

13. B. d. R., op. cit., t. III, coutumes, p. 569-584, procès-verbal, p. 584-591. 
14. À l'origine, ce terme désigne les grands feudataires, qui constituaient une cour, puis ce titre devient une dignité conférée par le roi qui distingue ainsi certains nobles, les élevant au-dessus des autres barons et évêques et leur attribuant des privilèges judiciaires et honorifiques.

*. Retrait : du latin retrahere : tirer en arrière, ramener. En droit, il signifie l'action de retirer un bien, de se substituer à un acquéreur en lui remboursant le prix.

15. Martine Grinberg, «La rédaction des coutumes et les droits seigneuriaux, Annales HSS, septembre-octobre 1997, $\mathrm{n}^{\circ}$ 5, p. 1017-1038, particulièrement p. 1019-1021.

16. B. d. R., op. cit., t. III, coutumes, p. 483-504, publication, p. 504.

17. B. d. R., op. cit., t. IV, coutumes, p. 599-627, procès-verbal, p. 628-642.

18. Gabriel d'Espinay, La Coutume de Touraine au XV siècle, Tours, Deslis Frères, 1888.

19. Jacques Dufrémentel, Conférence de la rédaction de la coutume de Touraine en 1460 et de ses deux réformations en 1507 et 1559, Tours, Letourmy, 1786, p. 437.

20. Fille de François baron de Maillé, vicomte de Tours, et de Marguerite de Rohan, épouse de Gilles de Laval, seigneur de Loué.

21. Jean, fils de Jean, bâtard de Louis d'Orléans, comte de Dunois, et de Marie d'Harcourt.

22. Charles VI d'Alençon, mort en 1525, fils de René duc d'Alençon et de Marguerite de Lorraine, il épousera en 1509 Marguerite d'Angoulême, sœur de François I ${ }^{\mathrm{er}}$.

23. B. d. R., op. cit., t. IV, p. 638.

24. B. d. R., op. cit., t. IV, p. 631.

25. François Olivier-Martin, Les Lois du roi, Paris, Loysel, 1988.

26. Dans les chapitres $23(1,4,5,7)$ et $24(2,5,7)$ le mari noble ou roturier ne peut donner sans le consentement de sa femme que sa part à vie des acquêts et les échanger sans son aveu, de même les articles relatifs aux donations entre époux. L'addition des mots à vie est contestée par le maire de Beaune et par le maire et les échevins de Tours. À noter que ces dispositions ne figurent dans aucun article du chapitre sur la communauté de biens, mais dans celui des donations.

27. B. d. R., op. cit., t. III, coutumes, p. 593-610, procès-verbal, p. 610-631.

28. Louis de Lorraine (1527-1578) dit cardinal de Guise, fils de Claude de Lorraine, duc de Guise (1496-1555), et d'Antoinette de Bourbon, frère de François, duc de Guise.

29. Hippolyte II, cardinal d'Este, dit cardinal de Ferrare (1509-1572), fils d'Alphonse I ${ }^{\text {er }} d^{\text {d'Este, }}$ duc de Ferrare et de Modène (1476-1534). Le cardinal de Ferrare vit à la cour de France sous les rois Valois. Il est archevêque de Milan, puis de Lyon, enfin de Narbonne ; il participe au colloque de Poissy en 1561.

30. Odet de Châtillon (1517-1571), fils de Gaspard seigneur de Coligny (1522), maréchal de France, et de Louise de Montmorency (1489-1547), sœur du connétable Anne de Montmorency. Odet est frère de Gaspard II de Coligny, amiral de France en 1552 ; passé à la Réforme en 1560, il mourra en exil en Angleterre.

31. François de Clèves (1516-1562), duc de Nevers, et pair de France en 1538 ; il combat pour les rois de France, François $\mathrm{I}^{\mathrm{er}}$ et Henri II. Il épouse Marguerite de Bourbon-Vendôme, sœur du cardinal de Bourbon.

32. B. d. R., op. cit., t. III, coutumes, p. 505-529, procès-verbal, p. 530-568.

33. Charles de Bourbon (1523-1590), fils de Charles de Bourbon, duc de Vendôme (1489-1537), et frère d'Antoine de Bourbon, roi de Navarre, et de Louis, prince de Condé, futurs chefs des protestants, alors que le cardinal de Bourbon deviendra le « roi de la Ligue opposé à son neveu Henri de Navarre.

34. Jean Du Bellay (1492-1560), cardinal, archevêque de Bordeaux; il est ambassadeur en Angleterre puis à Rome auprès du pape Paul III. Disgracié en 1547, il se réfugie à Rome.

35. Charles III (1543-1608), duc de Lorraine en 1545, fils de François I ${ }^{\text {er }}$, duc de Lorraine, et de Christine de Danemark ; il épouse Claude de France, fille de Henri II et de Catherine de Médicis ; il vit à la cour de France. 
36. Antoinette de Bourbon, fille de François de Bourbon, duc de Vendôme, veuve de Claude de Guise, et mère de François, duc de Guise, qui suit.

37. François de Lorraine, duc de Guise (1519-1563), fils de Claude, frère du cardinal Charles de Lorraine. Il épouse Anne d'Este en 1549, fille d'Hercule II, duc de Ferrare.

38. Anne de Montmorency (1493-1567), gouverneur de Languedoc, grand maître de France, connétable en 1538 , très proche de Henri II.

39. Jacques de Savoie (1531-1585), duc de Nemours, chef d'armées au service de Henri II, colonel général de la cavalerie en 1558 .

40. Anne de Pisseleu (1508-1580), maîtresse de François ${ }^{\mathrm{er}}$, ennemie de Diane de Poitiers, maîtresse de Henri II, elle est reléguée sur ses terres à la mort du roi en 1547.

41. B. d. R., op. cit., t. IV, p. 643-709.

42. René Filhol, op. cit., et Jean Gilisssen (dir.), «La rédaction des coutumes en France aux $x^{e}$ et $\mathrm{XVI}^{\mathrm{e}}$ siècles, La rédaction des coutumes dans le passé et le présent, Bruxelles, Institut de sociologie, 1962, p. 63-68.

43. Charles de Lorraine (1524-1574), fils de Claude de Lorraine, duc de Guise, et d'Antoinette de Bourbon. Frère de François de Guise. Archevêque de Reims en 1545, il est ambassadeur auprès du pape.

44. Fille de Gilbert de Bourbon, comte de Montpensier, et de Claire de Gonzague ; épouse en 1504 Louis de Bourbon, prince de La Roche-sur-Yon; son fils Louis de Bourbon (1513-1582) est duc de Montpensier.

45. Diane de Poitiers (1499-1566), fille de Jean de Poitiers, seigneur de Saint-Vallier, veuve de Louis de Brézé, elle a été la maîtresse de Henri II décédé en juillet 1559. Elle est désormais en disgrâce. Elle devra céder Chenonceau à Catherine de Médicis en échange de Chaumont.

46. Son père, Thomas Bohier, receveur des finances, acquit Chenonceau en 1499 et fit construire le château entre 1513 et 1521. En raison de ses dettes à l'égard du trésor royal, son fils Antoine dut le céder à François $\mathrm{I}^{\mathrm{er}}$.

47. B. d. R., op. cit., t. IV, p. 701.

48. Mémoires de Philippe de Commynes, livre VI, t. I, ch. VI, Bruxelles, Godefroy, 1706, p. 475.

49. Jacques Poumarède, «Droit romain et rédaction des coutumes dans le ressort et parlement de Bordeaux , Études d'histoire du droit et des idées politiques. Droit romain, jus civile et droit français, sous la dir. de J. Krynen, Presses de l'Université des sciences sociales de Toulouse, nº 3/1999, p. 345.

50. Martine Grinberg, op. cit., p. 1032.

51. Martine Grinberg, infra, p. 107-132. 